\title{
Marie Delcourt
}

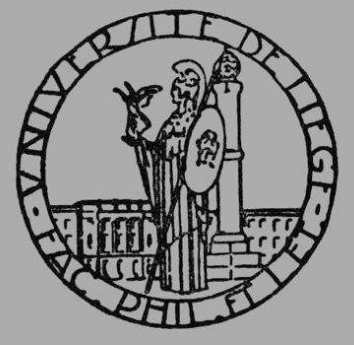

Stérilités

mystérieuses et

naissances

maléfiques dans

l'Antiquité

classique

Bibliothèque de la Faculté de Philosophie

et Lettres de I'université de Liège 


\title{
Stérilités mystérieuses et naissances maléfiques dans l'Antiquité classique
}

\author{
Marie Delcourt
}

DOI : $10.4000 /$ books.pulg. 647

Éditeur : Presses universitaires de Liège,

Édition imprimée

Les Belles Lettres

Année d'édition : 1986

Date de mise en ligne : 22 mai 2013

ISBN : 9782251660837

Collection : Bibliothèque de la faculté de

philosophie et lettres de l'université de

Liège

ISBN électronique : 9782821828704

Nombre de pages : 113

\section{Qbooks}

Ce document vous est offert par Université de Liège

http://books.openedition.org

\section{Référence électronique}

DELCOURT, Marie. Stérilités mystérieuses et naissances maléfiques dans l'Antiquité classique. Nouvelle édition [en ligne]. Liége : Presses universitaires de Liège, 1986 (généré le 21 novembre 2017).

Disponible sur Internet : <http://books.openedition.org/pulg/647>. ISBN : 9782821828704 . DOI :

10.4000/books.pulg.647.

Ce document a été généré automatiquement le 21 novembre 2017. Il est issu d'une numérisation par reconnaissance optique de caractères.

(C) Presses universitaires de Liège, 1986

Conditions d'utilisation:

http://www.openedition.org/6540 
SOMMAIRE

Chapitre premier. Les Fléaux

§1. LE FLÉAU DE STÉRILITÉ.

§ 2. LE FLÉAU DANS ๔DIPE-ROI.

§ 3. LE FLÉAU DU PREMIER LIVRE DE L'ILIADE

§ 4. LA STÉRILITÉ MYSTÉRIEUSE.

\section{Chapitre II. Les enfants maléfiques}

$\S 1$. LES ENFANTS ABANDONNÉS DANS EDIPE-ROI.

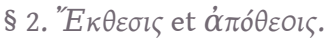

§ 3. L'á $\pi o ́ \theta \varepsilon \sigma l \varsigma$ à Sparte.

§ 4. L'A $\pi$ ó $\theta \varepsilon \sigma \iota \varsigma$ A ATHÈNES.

$\S$ 5. LES ANORMAUX, « SIGNES » DES DIEUX.

§ 6. L'EXPOSITION DES ANORMAUX DANS L'ANCIENNE ROME

§ 7. L'ÉVICTION DES ANORMAUX PENDANT LES GUERRES DE LA RÉPUBLIQUE.

$\S$ 8. LA CROYANCE AUX ANORMAUX MALÉFIQUES SOUS L'EMPIRE.

§ 9. LE TRAITEMENT DES ANORMAUX ET LES CROYANCES ANTIQUES.

Chapitre III. Les remèdes aux Fléaux

Chapitre IV. L'origine des Fléaux

Chapitre V. Les Fléaux en Sicile au temps d'Empédocle

Conclusion

Appendice 


\section{Chapitre premier. Les Fléaux}

Les Anciens ont vu dans la fécondité de la terre et des espèces vivantes un seul phénomène régi par la même volonté divine. Les mots dont ils se servent pour désigner la génération et ses organes sont les mêmes lorsqu'il s'agit de la terre labourée, ensemencée, et du couple humain. Cette croyance est toujours restée parfaitement explicite et bien des rites en ont gardé la trace. Déméter est invoquée dans les fêtes du mariage. Les Thesmophories sont celles de la fécondité. Au cours des Arrhétophories, pour agir à la fois sur la génération des semences et sur celle des hommes, - car, dit le scholiaste qui nous conserva ce règlement, elles obéissent à la même loi - on jetait dans des trous les "offrandes mystérieuses ", des porcs vivants et des gâteaux en forme de phallus et de serpents; on apportait des rameaux avec des pommes de pin; les pommes de pin et les porcs figuraient dans la cérémonie à cause de leur caractère prolifique, comme symbole de la multiplication des fruits et des hommes. Les historiens donnent aujourd'hui une autre explication de la présence des porcs sacrifiés, mais celle du scholiaste rend compte de ce qu'on pensait de son temps et c'est ce qui nous intéresse ici ; acceptons-la donc avec le sens dont elle est chargée et constatons que les Athéniens pensaient jeter dans les trous des emblèmes de la fécondité sous ses trois aspects. Les gâteaux et les porcs étaient en partie mangés par des reptiles. Ce qui en restait, les Puiseuses le relevaient et le mettaient sur l'autel. Les gens venaient chercher un peu de cette matière et la mêlaient aux semences pour avoir de belles récoltes. En 17 avant notre ère, quand Auguste fera célébrer les Fêtes séculaires, bien des rites de celles-ci rappelleront les cérémonies et l'esprit des Thesmophories athéniennes ${ }^{1}$.

2 La fécondité éternelle de la terre et des espèces vivantes a été, pour les anciens, la grande espérance. Leur crainte a été de voir cette fécondité s'arrêter ou dévier. Aussi, lorsqu'ils sentent les dieux en colère, le châtiment le plus terrible qu'ils puissent redouter, c'est la stérilité sous ses trois aspects: stérilité végétale, animale, humaine. Et, lorsqu'ils envisagent un arrêt de la vie, ils ne le voient pas seulement dans l'image d'une femme qui n'a pas d'enfants, ou dont l'enfant meurt, mais aussi d'une femme dont l'enfant est anormal. Une stérilité s'accompagne d'apparitions étranges, où les espèces refusent de se reconnaître.

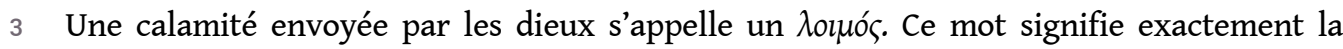
même chose que le français Fléau et on le traduira ainsi dans les pages qui suivent. Il ne désigne pas une peste quoique, parfois, une maladie puisse accompagner une calamité. 
Lorsqu'on trouve un Fléau décrit avec une certaine précision, on constate aussitôt que ce mot si vague fait presque toujours allusion à une stérilité.

4 On n'essaiera pas de tirer de l'étymologie plus qu'elle ne peut donner : ce que l'on cherche à atteindre, ce n'est pas une origine inaccessible, mais simplement le sentiment des

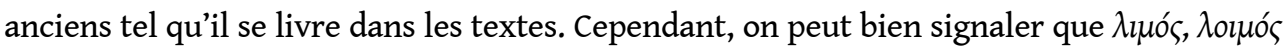

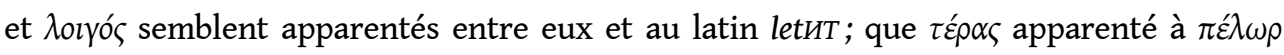
signifie d'abord apparition miraculeuse et significative, puis monstre ${ }^{2}$. Le Fléau par excellence, c'est la faim et l'extinction de la vie ; le Signe par excellence, c'est l'enfant anormal.

\section{§ 1. LE FLÉAU DE STÉRILITÉ.}

Zeus, dit Hésiode, punit l'injustice et récompense l'équité. Et le vieux poète nous donne une précieuse description du châtiment et de sa contre-partie :

6 "Ceux qui sont justes envers étrangers et nationaux, ceux qui jamais ne transgressent la justice, leur ville est florissante, le peuple y est prospère ; la paix, nourricière de jeunes gens, règne dans le pays; Zeus ne leur envoie point la guerre funeste. Ces hommes aux sentences droites, la faim ne les suit pas, ni le désastre : ils jouissent des fruits qu'ils ont récoltés. Pour eux, la terre porte des vivres abondants. Sur leurs montagnes, le chêne est chargé de glands à son sommet et d'abeilles en son milieu ; leurs brebis laineuses traînent de lourdes toisons; leurs femmes mettent au monde des enfants semblables à leurs parents ${ }^{3}$; ils s'épanouissent dans la prospérité ; ils n'ont pas besoin de prendre la mer : la terre fertile porte du fruit » (Travaux, 227-237).

7 Au contraire, « souvent une ville entière souffre à cause d'un seul homme qui va vers le mal et le prépare. Sur eux tous, du haut du ciel, Zeus fait tomber une grande calamité, Faim et Fléau tout ensemble. Les peuples dépérissent, les femmes n'enfantent plus, les maisons s'épuisent par le conseil de Zeus Olympien $»^{4}$ (Trav., 240-245). Justice immédiate, avec la prospérité ou la ruine matérielle pour sanction ; récompense et châtiment collectifs, tout le groupe étant puni avec un seul coupable. Platon ne se satisfera pas d'une telle morale ; mais elle restera populaire pendant toute l'antiquité. Ce qui nous intéresse ici, c'est de savoir ce qu'est exactement le Fléau dont Zeus menace le coupable.

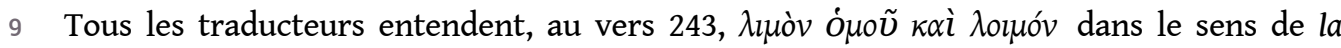
Famine et la Peste. Comme Hésiode, dans sa description du bonheur des justes, y inclut la paix, on veut trouver ici la plus ancienne mention des trois maux qui menacent l'humanité, la Guerre, la Famine et la Peste ; un moderne prend forcément ce dernier mot comme équivalent de maladie. Or, qu'on veuille bien regarder le texte de plus près, on verra que le poète ne mentionne aucun mal qui atteigne le corps humain, excepté lorsqu'il dit: «les femmes n'ont plus d'enfants ", ce qui peut signifier, ou bien qu'elles sont stériles, ou bien qu'elles n'accouchent pas heureusement. La comparaison avec d'autres textes nous amènera à préférer la seconde interprétation. De plus, elles mettent au monde des enfants qui ne sont pas semblables à leurs parents ${ }^{5}$, litote dont le sens devient clair lorsqu'on rapproche la vieille malédiction rapportée par Eschine dans son discours contre Ctésiphon. Il parle de la première guerre sacrée, à l'époque de Solon: les gens de Cirrha ont commis des sacrilèges envers le temple de Delphes; le dieu, consulté, répond qu'il faut faire la guerre aux Cirrhéens et ravager leur pays ; les Amphictyons promettent d'exécuter l'ordre et vouent ceux qui désobéiraient à la malédiction d'Apollon, Artémis, 
Léto et Athéna ; l'exécration est formulée en ces termes : «Que la terre ne porte plus de fruits, que les femmes ne mettent plus au monde d'enfants semblables à leurs parents, mais des monstres, que, même dans les troupeaux, les nouveau-nés ne soient pas conformes à la nature de leur genre $\aleph^{6}$. Dans cette formule, l'anomalie est représentée comme un châtiment plus terrible que la simple stérilité.

Au contraire, c'est de stérilité qu'il est question dans deux passages d'Hérodote. Cambyse mourant confie à ceux de son entourage le soin de reprendre l'empire des mains des mages; s'ils obéissent, "que la terre porte du fruit, que les femmes et les femelles accouchent $»^{7}$.

Les Pélasgiens de Lemnos tuent leurs concubines athéniennes et les enfants de celles-ci parce que les bâtards l'emportaient sur les enfants légitimes. Il en résulte une stérilité générale : la terre ne porte plus de fruit, ni les femmes ni les femelles n'ont plus la même postérité qu'auparavant. Épuisés par la faim et par le manque d'enfants, ils consultent l'oracle de Delphes 8

On voit que, dans aucun de ces passages, il n'est question de maladies qui frappent les adultes. Cette idée ne figure pas davantage dans le couplet imité d'Hésiode où Callimaque loue la puissance d'Artémis lorsqu'elle punit les hommes injustes : "La famine dévore leurs troupeaux ${ }^{9}$ et la gelée leurs travaux ; les vieux rasent leur tête à cause de la mort de leurs enfants; les femmes, ou bien sont blessées et meurent en couches, ou bien, échappant à la mort, mettent au monde des créatures dont aucune ne pourra se tenir debout sur des chevilles droites ».

Les enfants dont les vieillards portent le deuil, ce sont les jeunes gens morts à la guerre, et, cette guerre, c'est la guerre civile: Callimaque, en louant les justes, dit que la

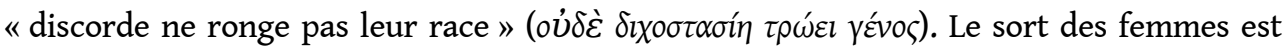
décrit ici plus explicitement que chez Hésiode : ou bien elles meurent en couches, ou bien elles mettent au monde des êtres qu'il aurait mieux valu ne pas voir naître ${ }^{10}$. Les enfants qui ne pourront pas se tenir debout sur leurs chevilles, ce ne sont pas seulement des enfants débiles, comme le veulent les commentateurs, ce sont des enfants anormaux: la station droite est le propre de l'humanité ${ }^{11}$. Callimaque, comme Hésiode, désigne par une litote ceux que la malédiction conservée par Eschine appelle crûment des monstres.

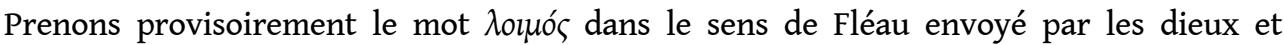
continuons à demander au contexte de nous éclairer sur la nature de ce châtiment. Dans les Perses, lorsque Darius demande à Atossa qui lui annonce la ruine de la puissance perse :

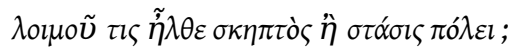

15 M. Mazon entend: "Est-ce la famine ou la guerre civile qui s'est abattue sur l'État?",

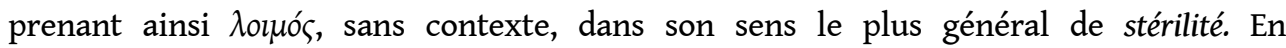
profondeur, l'antithèse signifie : «Souffrons-nous d'un Fléau envoyé par les dieux ou d'un mal né de la volonté des hommes?»

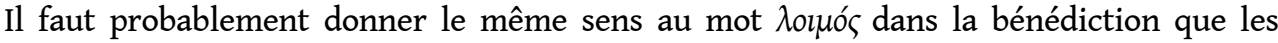
Danaïdes prononcent sur Argos lorsque la ville consent à les accueillir. "Que jamais, disent-elles, un Fléau ne vide d'hommes la cité, que la guerre ne souille pas le sol du sang des jeunes gens $»^{12}$, «que les vieillards emplissent la salle» (666), "que de nouvelles naissances viennent sans cesse donner des chefs à ce pays et qu'Artémis veille sur les 
couches des femmes " (674-678), «que l'essaim douloureux des maladies aille se poser loin du front des Argiens » (684-685). «Que Zeus rende la terre fertile en toute saison et que les brebis des champs soient fécondes » (689-691).

On retrouve ici les trois thèmes qui figurent dans les passages d'Eschine et d'Hérodote : fécondité de la terre, des troupeaux et des femmes. La guerre fait partie du Fléau décrit par Hésiode et par Callimaque. Eschyle insiste particulièrement sur le thème de la dépopulation humaine. Ce chœur des Suppliantes est le seul de tous les textes de ce genre qui mentionne formellement les maladies parmi les maux qu'on prie les dieux d'épargner

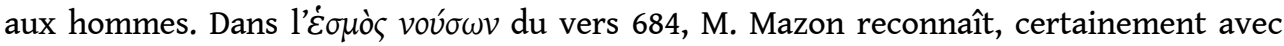
raison, les maladies qui frappent les enfants, spécialement confiés à Apollon Lycien ${ }^{13}$. L'idée dominante est toujours celle de la persistance de la race.

Dans les Euménides, les Erinyes menacent Athènes d'une «lèpre mortelle à la feuille, mortelle à l'enfant $»^{14}$. Athéna les prie de retourner leur imprécation en bénédiction et de donner en Attique la fécondité au sol, aux troupeaux, et à la semence humaine (904-909). Réconciliées avec la ville, elles développent ces trois thèmes dans le chœur qui termine la pièce.

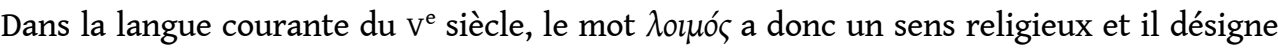
une calamité envoyée par les dieux. Hérodote prend le mot avec ce sens, une fois dans la

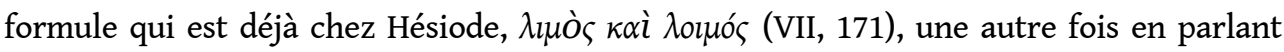

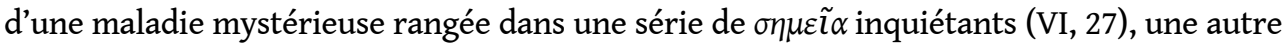
fois encore pour désigner la dysenterie qui s'empare des Perses affamés lorsque, pendant leur retraite de Thessalie, ils mangent des herbes et des écorces ${ }^{15}$. A ne lire que ce dernier

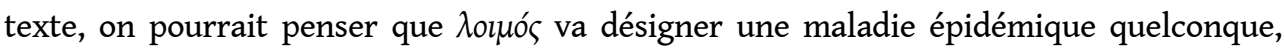
même dénuée de caractère mystérieux. Mais Thucydide ne se sert jamais de ce terme

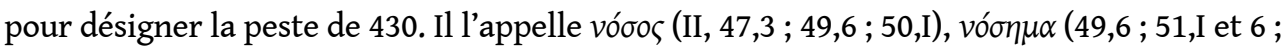

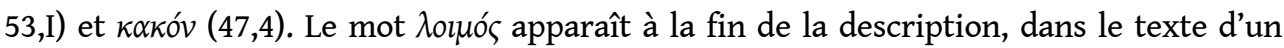
oracle (54,2 et 3) et dans la phrase solennelle qui introduit la description en rappelant que jamais on n'a gardé le souvenir d'une telle calamité : o

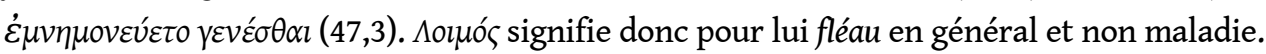

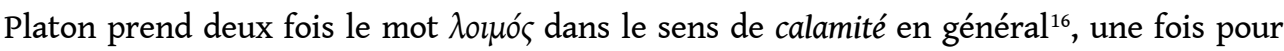
désigner la peste d'Athènes, mais dans un passage qui a une couleur religieuse très marquée, puisqu'il s'agit du rôle thaumaturgique de Diotime qui fléchit les dieux et obtient que le fléau soit retardé de dix ans ${ }^{17}$. On n'a donc nullement le droit de conclure

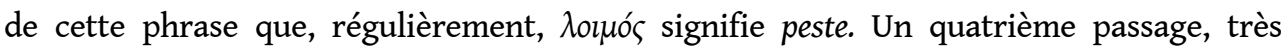

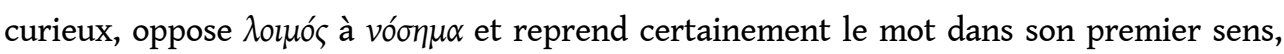
celui des textes ci-dessus, où il désigne une calamité frappant la terre, les animaux et la postérité des hommes. C'est ce passage des Lois qui dit qu'une seule réalité, l'avidité, peut se présenter sous trois aspects différents; « elle est maladie lorsqu'elle frappe les corps,

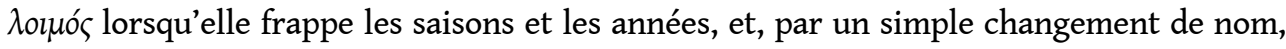
injustice lorsqu'elle atteint les États et les constitutions ${ }^{18}$.

21 Plus tard, le mot garde cette valeur religieuse. Plutarque mentionne un גoıpós dans une série de calamités mystérieuses (Coriolan, 13) mais, parlant de la peste d'Athènes, il

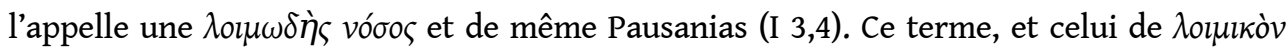


$\pi \alpha ́ \theta 0 \varsigma$, est celui dont se servent également les physiciens, - Aristote dans ses écrits d'histoire naturelle - lorsqu'ils veulent parler d'une véritable maladie épidémique. Est-il

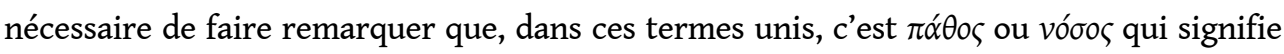

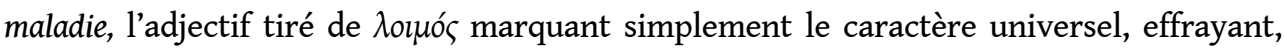
d'un mal présenté comme un châtiment divin? Encore Hippocrate n'emploie-t-il ni le substantif ni l'adjectif. Le traité des épidémies est intitulé $\pi \varepsilon \rho \grave{\imath} \tau \tilde{\omega} v \dot{\varepsilon} \pi \imath \delta \eta \mu \imath \tilde{\omega} v$ et l'auteur les appelle $v o v \sigma \eta ́ \eta \alpha \tau \alpha \dot{\varepsilon} \pi \imath x \omega ́ p l \alpha$.

Un גoluós est donc exactement ce que nous appelons un Fléau, un châtiment envoyé par les dieux et frappant une collectivité19. La forme classique du Fléau, dans l'antiquité, c'est une stérilité de la terre, des femelles et des femmes, stérilité aggravée par la naissance d'êtres anormaux, contraires à la nature. La description la plus complète d'un Fléau de ce genre a été donnée par Sophocle dans đEdipe-Roi. Mais l'importance du début de cette tragédie comme document religieux a été si totalement méconnue qu'il n'est pas inutile d'en faire ici une étude un peu approfondie.

\section{§ 2. LE FLÉAU DANS đEDIPE-ROI.}

On a voulu voir dans la calamité thébaine une allusion à l'épidémie qui ravagea Athènes en 430 et, dans $\Subset$ đipe lui-même, une sorte de figure de Périclès ${ }^{20}$. Disons tout de suite que le rapprochement n'aurait pu être suggéré que par le pire ennemi de Périclès. En effet, si l'on fait appel à đedipe pour guérir le fléau, c'est lui uniquement qui en est responsable et la confiance des Thébains repose sur le plus tragique des malentendus. On ne voit pas très bien non plus le fils de Xanthippe invitant un de ses conseillers, comme đEdipe le fait dans une minute de démagogie, à faire devant tout le peuple rapport sur sa mission ${ }^{21}$. Vouloir à tout prix trouver des allusions historiques dans l'un des poèmes les plus inactuels qu'on ait jamais écrits, c'est s'exposer à en fausser le sens pour y introduire de force ce qu'on est décidé à y découvrir ensuite ${ }^{22}$.

Lorsqu'on lit la tragédie sans idée préconçue, on s'aperçoit que Sophocle n'a entendu décrire ni une maladie, ni une épidémie au sens moderne du mot. Le Fléau qui éprouve Thèbes est une stérilité. Les seuls êtres menacés sont les femmes en couches et leurs fruits.

Le malheur qui pèse sur Thèbes est deux fois décrit, une première fois dans le prologue par le grand-prêtre, une seconde fois par le chœur dans le commentaire lyrique de la parodos. C'est la technique tragique employée par Eschyle dans les Perses, dans les Sept, dans Promethée, par Sophocle lui-même dans les Trachiniennes, et, d'une façon plus mouvementée, dans Philoctète et dans Ajax. Quelques mentions rapides, dans le premier épisode, rappellent le Fléau. La dernière allusion est dans la bouche de Jocaste qui entre en disant à đdipe et Créon (v. 635-636) : « N'avez-vous pas honte, quand l'État souffre tant, d'agiter des querelles personnelles? » Puis, c'est tout. Déjà à l'apparition de Jocaste, les spectateurs, pris tout entiers par la question: «qui a tué Laïos?", ne devaient plus guère penser au Fléau. Personne n'en reparlera plus à la fin de la pièce.

La ville, dit le grand-prêtre, est accablée par l'orage :

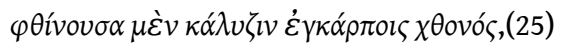

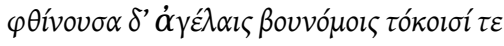

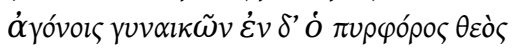

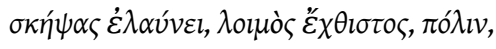




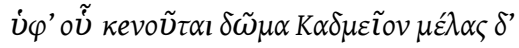

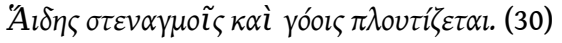

"La ville périt dans les germes fructifêres de la terre, dans les troupeaux des boeufs en pâture, dans les accouchements des femmes, qui, tous, se terminent sans naissances. Le dieu porte-feu, le haïsable Loimos, s'étant élancé, malmène la cité et, par lui, se vide la maison cadméenne tandis que le noir Hadès s'enrichit de larmes et de déplorations. $»^{23}$

Le chœur décrit ensuite le fléau dans la deuxième strophe et la deuxième antistrophe de la parodos:

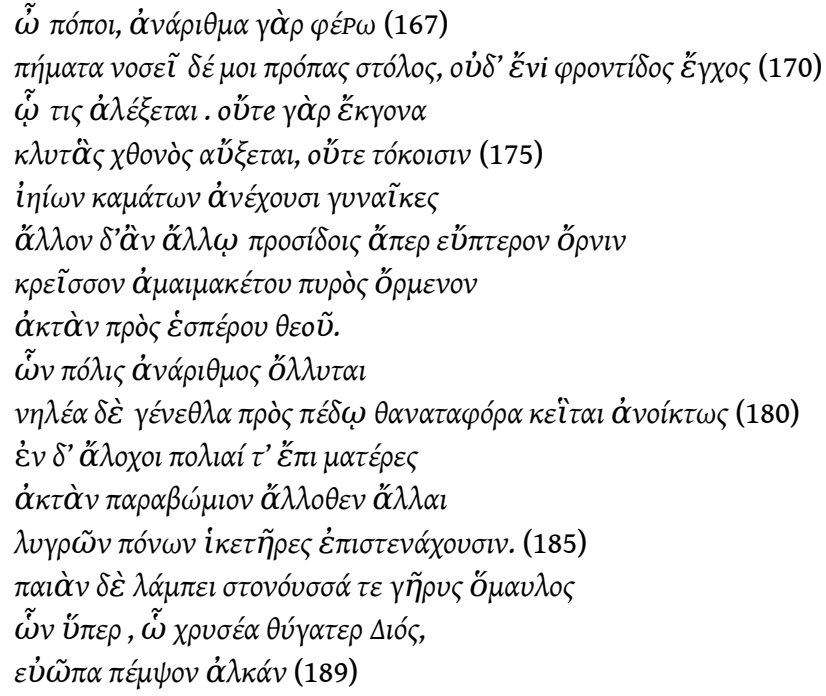

"Hélas! innombrables sont les maux que j'endure. Tout le peuple souffre et l'esprit ne trouve aucune arme pour écarter le mal. En effet, les fruits de cette terre illustre ${ }^{24}$ ne poussent plus et les femmes ne se relèvent plus, dans leurs accouchements, des souffrances qui les font crier. Vie après vie, sous tes yeux, comme l'oiseau aux ailes vigoureuses, plus vite que le feu irrésistible, s'élance vers la rive du dieu occidental.

Comblée de morts, la ville périt. Abandonnés de tous, les nouveau-nés porteurs de mort gisent par terre, sans que nul les pleure. Et les jeunes femmes avec les mères aux cheveux gris, le long de la rive de l'autel, l'une ici, l'autre là, implorant la fin du terrible malheur, gémissent. Et le péan éclate, mêlé aux lamentations. Pour tout cela, fille rayonnante de Zeus, envoie le secours au beau visage ».

Ici encore, je ne vois que la description d'une stérilité. Les femmes mettent au monde des enfants morts ou des enfants anormaux qu'on expose ${ }^{25}$ et elles meurent elles-mêmes. C'est pour cela qu'on voit, dans les temples, des épouses (ö'loxol) prier avec leurs mères pour que ce sort affreux leur soit épargné. Le scholiaste commente ce vers en disant : غ́k

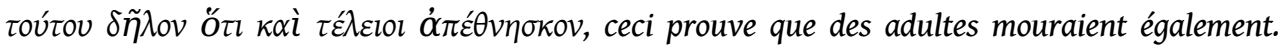
Cette remarque montre que, pour lui, le Fléau comporte essentiellement la mort des germes et des nouveau-nés.

En effet, pas un instant personne ne parle d'une contagion qui menacerait, soit đEdipe, soit les hommes qui composent le chœur. Le seul endroit où đEdipe paraît craindre pour lui-même, c'est celui où il dit à Créon, pour justifier son ordre de parler devant tout le peuple:

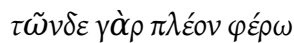

$\tau \grave{o} \pi \dot{\varepsilon} v \theta 0 \varsigma \grave{\eta} \kappa \alpha \grave{l} \tau \tilde{\eta} \varsigma \dot{\varepsilon} \mu \tilde{\eta} \varsigma \psi v x \tilde{\eta} \varsigma \pi \varepsilon \dot{\varepsilon} \rho l(93-4)$,

mais on s'aperçoit bientôt que ces mots ont une valeur toute générale: "J'ai plus de soucis pour eux que pour ma propre vie. » Cela ne veut pas dire qu'il craigne rien pour sa 
vie, mais ignifie simplement que, en sa qualité de roi, il porte le tourment de tout son peuple, idée déjà exprimée aux vers 59-61.

Toutes ses autres paroles définissent une stérilité, non une maladie. Au moment de maudire le meurtrier inconnu, il résume le mal auquel il veut porter remède et dit qu'il travaille au bénéfice du pays qui périt, privé de fruits, privé des dieux.

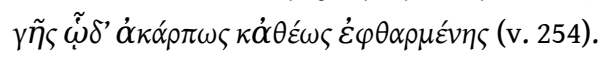

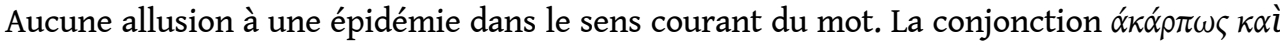
$\dot{\alpha} \theta \varepsilon ́ \omega \varsigma$ s'explique parfaitement. Les dieux manifestent leur faveur par la fécondité, leur colère par la stérilité. Celle-ci, à cause de son caractère destructeur, est ensuite (190-202) identifiée à un Arès qui n'aurait besoin d'aucun appareil guerrier pour accomplir son

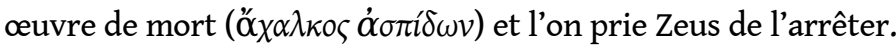

Plus loin, lorsqu'ÆEdipe ordonne aux Thébains d'exécuter l'ordre d'Apollon tel qu'il a été rapporté de Delphes par Créon, il prie les dieux de punir les désobéissants en leur refusant tout fruit né de la terre, tout enfant né d'une femme, et de les atteindre personnellement par le fléau actuel ou par un autre plus affreux encore :

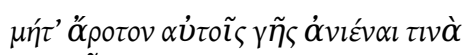

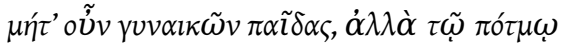

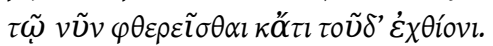

Ces vers sont d'une logique parfaite. Si quelqu'un désobéit à l'ordre du dieu et accueille le meurtrier de Laïos, le Fléau continuera ses ravages. Mais il est possible que le contrevenant n'ait pas encore été touché personnellement. Dans ce cas, Æđdipe appelle sur lui le Fléau collectif transformé en punition individuelle, mais il ne demande pas aux dieux d'en modifier le caractère. Ce qui frappera le coupable, c'est une stérilité sous ses trois aspects classiques, stérilité de la terre et des troupeaux, stérilité des femmes.

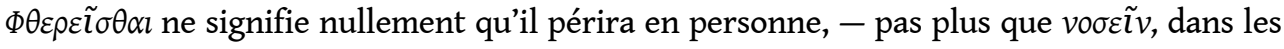
passages cités plus haut, ne signifiait qu'il dût tomber malade, - mais qu'il sera atteint par des forces destructrices, acharnées après sa maison.

On le voit, il n'y a rien de commun entre la maladie contagieuse admirablement décrite par Thucydide et la stérilité mystérieuse dont Sophocle ne montre qu'un effet indirect: l'effroi des hommes devant le mal qui menace d'anéantir les récoltes et les familles.

Une dernière remarque : la tragédie grecque ignore ce que nous appelons les maladies et les morts naturelles. Sophocle dans Philoctète a peint la souffrance physique, étonnante hardiesse que Wagner renouvellera dans Parzival. Sophocle, comme Wagner, relève la souffrance sur le plan poétique en lui donnant une origine mystérieuse, divine. đipe vieux ne pourra mourir naturellement: les dieux devront s'en mêler et le faire disparaître. La légende même ne connaît guère que des morts violentes. Ariane meurt en couches, mais la mort d'une jeune femme avec son fruit est précisément un signe de la colère divine. Et, au surplus, la curieuse légende d'Ariane demanderait à être étudiée de plus près.

Dans Mutter Erde, A. Dieterich, colligeant les superstitions anciennes relatives à la TerreMère, a allégué tous les passages qui sont relevés ci-dessus, excepté le début d'ÆEdipe-Roi. Dans ce livre charmant, le philologue poète regrette que Sophocle, «influencé par sa formation sacerdotale, ait été inattentif aux croyances populaires ${ }^{26}$. Les commentaires 
ont masqué le texte aux yeux de Dieterich. La description du Fléau de Thèbes est inspirée par les mêmes croyances que la prière des Suppliantes ${ }^{27}$ : pour Sophocle, comme pour Eschyle, la fécondité du monde est une idée simple, identique sous plusieurs manifestations, qu'il s'agisse de la Terre, des troupeaux, des familles humaines.

Il est vrai que Sophocle n'invoque nulle part la déesse Gê, qui joue un grand rôle chez les autres tragiques. Ici, on demande à Artémis, à Apollon, surtout à Athéna, de faire cesser le Fléau. Or, ce sont précisément ces divinités qui sont invoquées par les amphictyons contre Cirrha, dans la prière de même contenu, mais de signe contraire, qui nous est conservée par Eschine. Toute la description de Sophocle paraît donc empruntée à une tradition religieuse singulièrement homogène, parfaitement pure de tout enjolivement littéraire.

\section{§ 3. LE FLÉAU DU PREMIER LIVRE DE L'ILIADE}

Plusieurs commentateurs de Sophocle ont pensé que sa description du malheur de Thèbes est une réplique à celle qu'Homère fait du camp grec au début de l'Iliade $e^{28}$. A vrai dire, un autre passage d'Homère aurait pu être allégué, parallèlement à đEdipe-Roi, mais personne ne semble avoir pensé à le faire. Dans l'Odyssée (XIX, 109 sqq.), Ulysse salue Pénélope et lui dit que sa renommée est celle du bon roi qui, craignant les dieux, gouvernant sur des peuples nombreux et forts, tient ferme les sentences justes, et la terre noire porte froment et orge; les arbres plient sous les fruits, les brebis mettent bas régulièrement; la mer donne du poisson; tout cela vient de son bon gouvernement et les peuples prospèrent sous son règne. Le tableau traditionnel des fécondités envoyées par les dieux est traité ici avec une certaine fantaisie : le détail de la mer qui donne du poisson en abondance est bien homérique et ne se retrouve pas ailleurs. Du même fond, Eschyle fait promettre par les Euménides (937) la richesse des mines du Laurium. Les descriptions classiques parlent uniquement de la terre, des femelles et des femmes. Encore cette description de l'odyssée est-elle bien plus conforme à la tradition que le fléau du début de l'lliade. Ce texte curieux mérite quelques mots d'explication. Il offre un exemple parfait de ce qu'on trouve si souvent chez Homère : une superstition populaire utilisée dans un récit après avoir été vidée de son sens religieux et ne gardant plus qu'une valeur pittoresque ${ }^{29}$.

Agamemnon ayant outragé le prêtre d'Apollon, une punition frappe collectivement tous

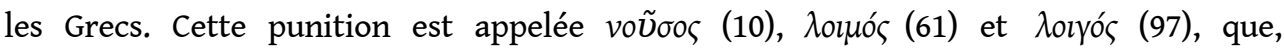
malheureusement, les modernes ont pris dans le sens de maladie et de peste. Avec certains scholiastes anciens du reste, ils ont donc cru que les flèches d'Apollon blessaient d'abord et amenaient une maladie ensuite. Or, nulle part dans le texte, il n'est dit que quelqu'un soit malade. Les flèches partent, les bûchers s'allument aussitôt ${ }^{30}$. Les flèches d'Apollon tuent immédiatement et inévitablement, comme celles qu'il a remises à Hercule et celuici à Philoctète ${ }^{31}$. De plus, la notion même de maladie est rigoureusement exclue de la poétique épique. Les héros d'Homère peuvent être blessés, mais leurs organes ne se dérangent pas. Nóoos doit donc signifier mal (sens qu'il a gardé dans le grec de toutes les

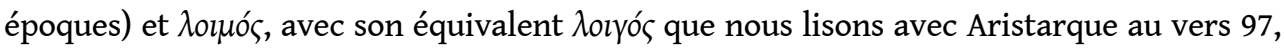
signifie, comme partout ailleurs, mal collectif d'origine mystérieuse.

Si les modernes ont cru que le Fléau déchaîné par la colère d'Apollon comportait des blessures mortelles et une maladie, c'est la faute de quelques scholiastes qui le disent explicitement. Et ceux-ci ont été amenés à le penser à propos des vers 50-52, où l'on voit 
les mulets et les chiens frappés les premiers. Ce détail leur parut bizarre et ils cherchèrent à l'expliquer vaille que vaille. Les uns disaient que la divinité procédait miséricordieusement, frappant d'abord les animaux afin d'éclairer les hommes et de leur donner le temps de se repentir ${ }^{32}$. La plupart, cherchant une explication naturelle, prirent

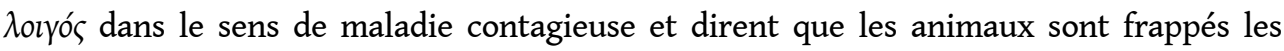
premiers parce qu'ils sont plus près de la terre d'où vient le « mauvais air »"33. Les chiens la flairent et s'exposent ainsi à la contagion; les mulets sont particulièrement frappés parce qu'ils sont des hybrides. Des explications de ce genre ont dû se former assez tôt. Zoïle reprochait déjà à Homère d'avoir prêté à Apollon une colère absurde et insinuait qu'il est indigne d'un dieu de massacrer des animaux innocents. Du moins comprenait-il encore qu'ils sont tués à coups de flèches. Héraclide Pontique répond qu'il y a là chez Homère un trait d'observation exacte, que tous ceux qui ont observé les épidémies savent qu'elles commencent par les quadrupèdes ${ }^{34}$.

Explication inventée pour le passage, car il n'y a pas d'épizooties qui frappent aussi les

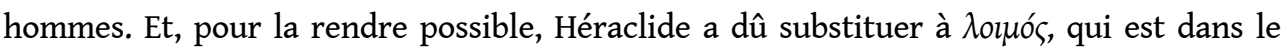

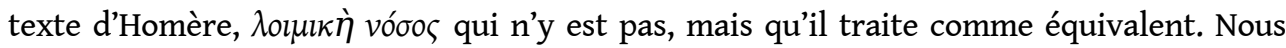
avons montré plus haut qu'aucun écrivain grec, aucun physicien, aucun médecin, ne paraît avoir admis cette équivalence, - sauf peut-être Hérodote. En dehors des deux

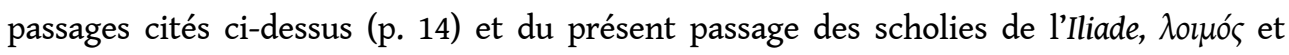

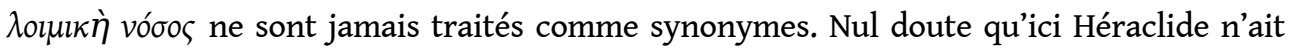

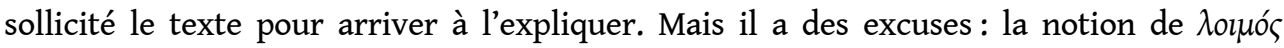
pouvait, à la rigueur, inclure des maladies (cf. supra, p. 14); et le Fléau homérique, qui diffère de la «triple stérilité » traditionnelle, a dû beaucoup l'embarrasser.

L'erreur qui consiste à voir une maladie au début de l'Iliade remonte, disons-nous, à des explications inventées pour rendre raison du détail gênant des animaux massacrés. Or, ce détail, Homère l'a certainement pris dans des descriptions de Fléaux analogues à celle qui est chez Hésiode. On y voit toujours mentionnées, dans un ordre à peu près invariable, la terre, les femelles des animaux et, pour finir, les femmes. Les femelles sont souvent

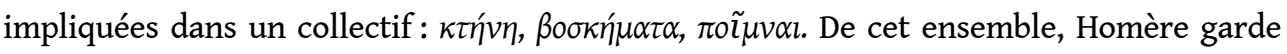
uniquement les détails qui cadrent avec la description d'un camp d'envahisseurs. Dans toute l'Iliade, il n'est pas question une seule fois de rien récolter sur cette terre qui cependant a dû nourrir les Grecs pendant les dix années du siège. Le thème de la stérilité du sol disparaît donc, comme celui de la stérilité des femmes. Le poète aurait pu garder ce qui est relatif aux femelles, mais les Grecs, pas plus qu'ils ne font de culture, ne font d'élevage : le poète parle donc simplement d'animaux exterminés. Le détail, isolé de son contexte naturel, puis altéré (la stérilité des femelles remplacée par la destruction des mâles) est devenu une simple disparate. Chose curieuse, il est resté à sa place, précédant

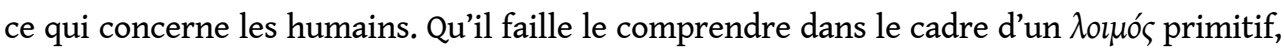
cela ne fait pas de doute. Le fait qu'une fécondité miraculeuse est présentée dans l'Odyssée comme une récompense du bon gouvernement indique que le thème était familier aux poètes homériques; il est aisé de comprendre pourquoi on pouvait l'utiliser dans le cadre d'Ithaque et de la vie patriarcale, tandis qu'on n'a pu l'intégrer à l'épisode troyen qu'en lui infligeant une torsion qui le rend méconnaissable.

Dans l'Hymne à Artémis (122 sqq), Callimaque, qui imite à la fois le passage des Travaux relatif aux châtiments collectifs et le début de l'Iliade, montre la déesse frappant, comme Apollon, à coups de flèches. Celles-ci atteignent d'abord des arbres, puis un animal, puis une ville coupable : on reconnaît là encore l'ordre traditionnel, dont le sens toutefois est 
obscurci par les enjolivements dont le poète surcharge le vieux thème religieux. Cette introduction est du reste suivie de l'excellente description analysée plus haut.

Les Chants Cypriens racontaient une curieuse histoire d'après laquelle la Terre, accablée par le poids des hommes et par leur injustice, demande à Zeus de lui donner un allègement ${ }^{35}$. La guerre thébaine d'abord, puis la guerre de Troie tuent beaucoup d'hommes et diminuent le fardeau. Il est certain que, dans ce contexte, le détail de l'impiété des hommes est étranger au récit primitif. La conclusion indique que la cause primitive du mal dont souffre la Terre, c'est le poids matériel dont les hommes pèsent sur elle. Ici encore, la disparate doit provenir de la description d'une stérilité. Les deux ordres d'idées se seront contaminés parce que le thème de la guerre apparaît dans l'un et dans l'autre. Dans un Fléau, elle est une sanction; dans le récit des Chants Cypriens, elle est un remède. C'est probablement pour cela qu'on aura introduit une cause morale dans un ensemble qui, à l'origine, ne devait rien comporter de semblable.

\section{§ 4. LA STÉRILITÉ MYSTÉRIEUSE.}

Les Anciens n'ont jamais cessé de redouter le châtiment des dieux tel qu'il se manifestait par la stérilité de la terre et des espèces vivantes. Le serment de fidélité imposé par l'empereur Auguste aux Paphlagoniens comporte une formule de malédiction pour les contrevenants et pour leur descendance : la terre et la mer refuseront de les porter et elle (entendons: la terre) ne portera plus de fruits ${ }^{36}$; deux formules d'exécration ont été contaminées, mais elles étaient bien connues l'une et l'autre et tout le monde les attendait dans un semblable contexte.

La stérilité ne figure pas dans les malédictions des defixionum tabellae. Cela se comprend assez bien : ces formules concernent une population plus urbaine que paysanne; de plus, celui qui les lance est préoccupé d'atteindre un ennemi bien déterminé, de l'atteindre

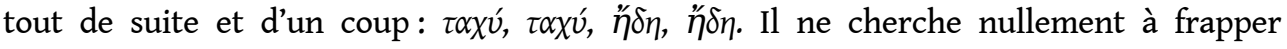
l'entourage. La stérilité était un mal collectif qui se développait lentement ${ }^{37}$.

51 Les mythographes nous ont conservé de nombreuses mentions relatives à des périodes de

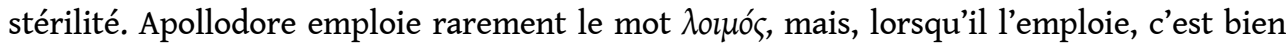
dans le sens archaïque d'ók $\alpha \rho \pi i ́ \alpha$, comme le prouve la double narration relative au sacrilège d'Augé (II, 7, 4 et III, 9,1) où la même calamité est désignée une fois comme un

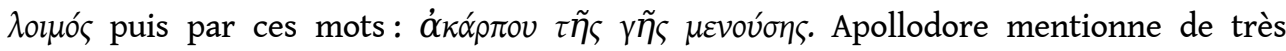
nombreux cas de stérilité ${ }^{38}$; il ne donne aucune description, mais raconte généralement comment on y a porté remède, ce qui nous amènera à revenir plus tard sur ces récits. Il rapporte même ce qu'on pourrait appeler une stérilité truquée (II, 9,I) : Ino, la méchante belle-mère, fait dessécher les semences, de telle sorte que la terre ne produit plus rien. Son mari Athamas envoie à Delphes pour demander la fin du mal, et les serviteurs d'Ino rapportent une réponse mensongère aux termes de laquelle l'ók $\alpha \rho \pi i ́ \alpha$ cessera si Phrixos est sacrifié à Zeus.

52 La littérature latine ne nous rapporte, sur la croyance à la stérilité, que des renseignements décousus. La prière du paterfamilias, conservée par Caton, demande la fécondité pour les troupeaux et pour la terre ${ }^{39}$. Virgile parle deux fois de calamités, mais 
les deux exposés sont difficiles à interpréter. Dans les Géorgiques (III, $440 \mathrm{sqq}$ ), il s'agit d'abord d'une épizootie des brebis (440-478), puis d'une sorte de contagion frappant tous les animaux y compris les poissons. Ce détail relève de l'amplification poétique, à laquelle Virgile a si souvent sacrifié la simple donnée; il provient peut-être de l'odyssée ${ }^{40}$. Cette maladie semble être une maladie naturelle, pour laquelle les bergers cherchent et trouvent des remèdes. Dans l'Enéide, III, 135, sqq Enée est chassé de Crète par une lues qui frappe les végétaux et les hommes; il n'est pas question des animaux. Le mal semble être d'origine mystérieuse, comme le Fléau sophocléen, mais il est mis en rapport avec l'air (corrupto caeli tractu) et la saison (Sirius). Dans les stérilités classiques, envoyées par les dieux pour punir les hommes, les causes naturelles ne sont pas invoquées; il n'est fait allusion aux vents et à la sécheresse qu'à partir du moment où comme nous le verrons cidessous, on a commencé à chercher des explications naturelles du phénomène. Les deux descriptions virgiliennes, comme celle du début de l'Iliade, relèvent de la critique littéraire, même si elles sont faites d'éléments qui ont une lointaine origine religieuse. Elles se rattachent aussi aux débuts de l'histoire des sciences.

Les historiens nous donnent de nombreux détails relatifs aux enfants monstrueux dont la naissance est l'un des symptômes de la colère des dieux. L'apparition des nouveau-nés anormaux est parfois mise directement en rapport avec la stérilitée ${ }^{41}$, mais cela est en somme assez rare. Paul Orose raconte une stérilité en l'année de Rome 470 (IV, 2) : une épidémie de fausses couches se manifeste parmi les troupeaux et fait mourir de nombreuses femmes. Mais, d'une façon générale, les quatre phénomènes qu'Hésiode, Eschine, Callimaque considèrent comme connexes - à savoir la stérilité de la terre, des femelles et des femmes, ainsi que l'apparition d'êtres anormaux, - ces phénomènes se présentent, dans les croyances romaines, comme isolés ; le dernier prend une importance démesurée, rejetant les autres dans l'ombre. Cependant, un texte important prouve que le monde latin faisait toujours écho à la vieille idée qui voit dans la stérilité du monde une réalité unique aux manifestations multiples, c'est le Chant séculaire, prière aux dieux pour qu'ils écartent de Rome la stérilité. Le Chant séculaire et les rites de purification après l'apparition d'un anormal sont peut-être d'origine grecque. Mais c'est leur mise en pratique sur le sol romain qui nous permet le mieux de dégager l'origine chthonienne des Fléaux, origine que la mythopée grecque a une tendance à obscurcir. Nous reviendrons sur ce sujet à propos de l'éviction des enfants anormaux et des cérémonies qui la suivaient.

\section{NOTES}

1. DIETERICH, Mutter Erde, pp. 44 sqq. - Schol. de Lucien, Dial. des court. 2, I ; éd. Rabe, Leipzig, 1906, pp. 275-6;- PLUT. Conj. praec. 138 B.

2. BOISACQ, Dict. étym. s.v. ; - osTHOFF, Arch. f. Relig. VIII, 51 sqq. (1905).

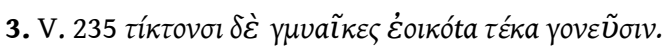

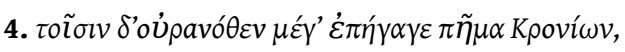

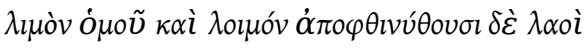




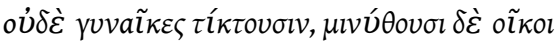

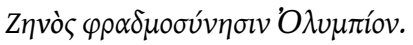

5. Bien entendu, il ne faut pas rapprocher ce vers d'Hésiode de celui où THÉOCRITE (Ptol. 43) parle des femmes infidèles dont les enfants ne ressemblent pas à leur père. Les mss. d'Hésiode hésitent

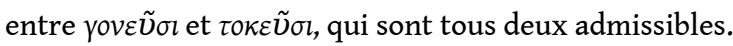

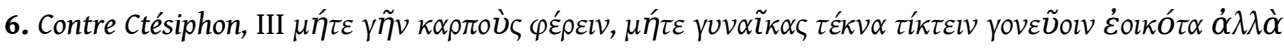

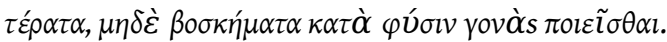

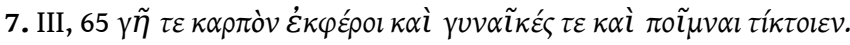

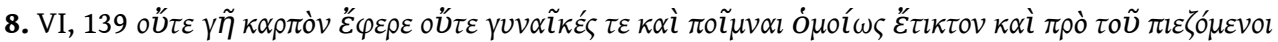

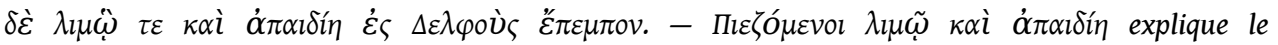

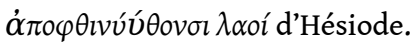

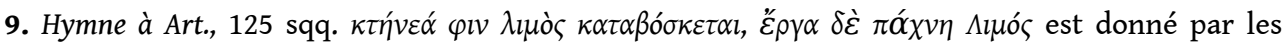
meilleurs mss; il est tout à fait inutile d'accepter la lectio facilior $\lambda_{\text {luó }}$ des recentiores. La fin du vers indique que le poète a voulu introduire des métaphores inattendues.

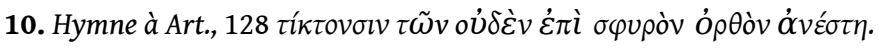

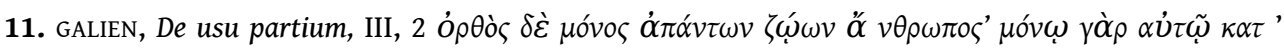

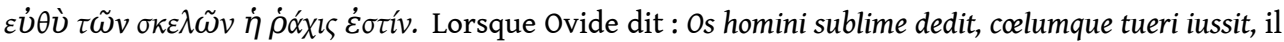
met l'accent sur l'aspect intellectuel du privilège humain, lequel, certainement, avait été remarqué dès une époque très ancienne.

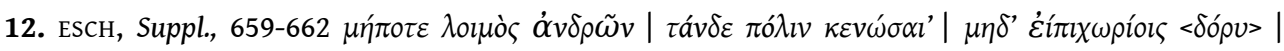

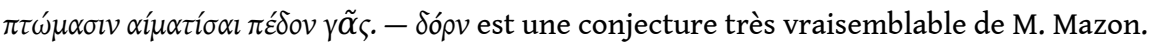

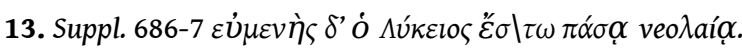

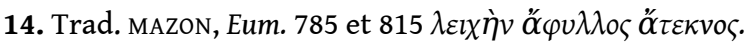

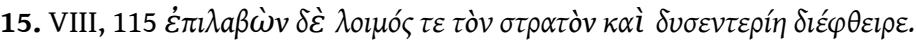

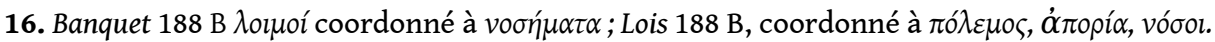

17. Banquet $201 \mathrm{D}$.

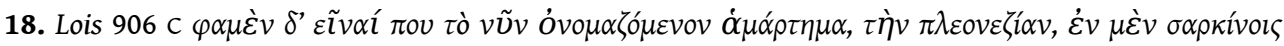

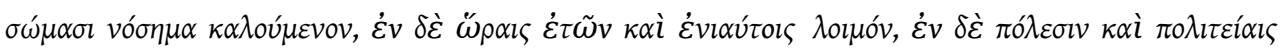

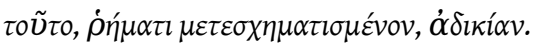

19. C'est peut-être par cette croyance qu'il faut expliquer le vers 348 des Travaux: ov่ $\delta$ ' $\hat{v} v \beta o \tilde{} \varsigma$

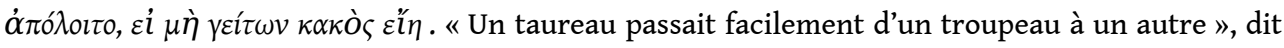
Wilamowitz dans son commentaire. C'est exact, mais un homme méchant porte malheur puisque la faute d'un seul peut faire punir toute la communauté. Un mauvais voisin est maléfique du seul fait de sa méchanceté.

20. Musgrave semble avoir été le premier à proposer le rapprochement. Malheureusement, il fut suivi par Hermann. On s'est ensuite servi de la prétendue allusion pour dater la pièce. Cf. sudHAUs , König EEdipus' Schuld, Rektoratsrede de Kiel, 1912, pp. 9 sqq.

21. CEd.-R. 93.

22. Un médecin humaniste ne s'y trompera pas. Le Dr. BÉTEAU, auteur d'une excellente étude sur la maladie dépeinte par Thucydide, nous écrit : « Dans ce prologue d'Æđdipe-Roi, rien de naturel, rien d'humainement possible, mais un phénomène mythique à l'échelle des personnages. Pas d'assimilation possible du fléau à une épidémie ».

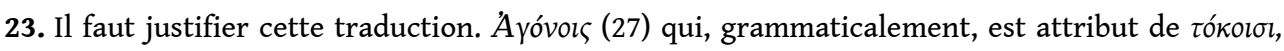

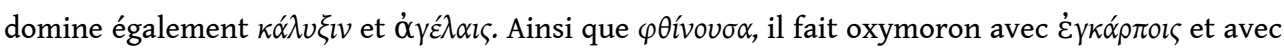

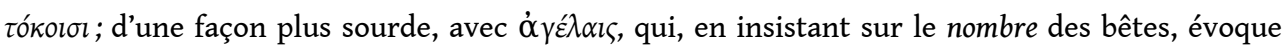
leur multiplication. Il devrait y avoir prolifération; on ne voit qu'avortement. - 'Ev $\delta$ '... $\sigma \kappa \eta ́ \psi \alpha \varsigma$ (27-28) : la plupart des commentateurs font remarquer que Sophocle emploie $180 \theta \alpha v \alpha \tau \alpha \varphi o ́ p \alpha$ ou $\theta \alpha v \alpha \tau \alpha \dot{\varphi} \varphi \rho \rho \alpha \mathrm{L}^{2} \theta \alpha v \alpha \tau \alpha \varphi \rho^{\prime} \omega \mathrm{L}^{1} \theta \alpha v \alpha \tau \alpha \varphi o^{\prime} \omega$ recc.

$\dot{\varepsilon} v$... $\delta \dot{\varepsilon}$ avec la valeur homérique de ensuite; ils en tirent argument pour dire que les vers 25-27 
décrivent une stérilité à laquelle s'ajoute une peste, une maladie définie par les vers suivants. Il est exact que Sophocle emploie $\dot{\varepsilon} v$... $\delta \dot{\varepsilon}$ avec le sens de ensuite ; c'est le cas infra 181, Trach., 206, probablement aussi dans $\Subset$ d. Col. 55. Mais, en dehors de ces trois cas, je n'en vois aucun où $\dot{\varepsilon} v$ ne puisse s'expliquer comme faisant partie du verbe. C'est le cas pour é $\mu \mu \varepsilon \sigma \tau o \tilde{v} \mu \alpha l$ (Ant. 420, El. 713). Quant à Ajax 675, le texte paraît gâté. Ajax énumérant les vicissitudes de la vie, parle des souffles

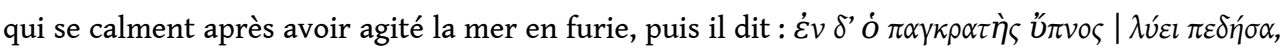

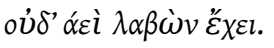

Impossible d'expliquer ici un item (avec Wunder) ou un simul (avec Ellendt). Les détails, visiblement, ne sont pas coordonnés entre eux, mais simplement subordonnés à l'idée dominante. La correction $\grave{\eta} \delta$, adoptée par Schneidewin Nauck, ne vaut pas mieux que le texte traditionnel. On pourrait peut-être proposer $\dot{\varepsilon}^{\prime} \delta^{\prime}$... $\lambda v^{\prime} \varepsilon l$, tous les éléments de ce passage étant simplement reliés par $\delta \dot{\varepsilon}$ après le $\mu \dot{\varepsilon} v$ du vers 670 . - $\dot{\varepsilon} v \sigma \kappa \eta ́ \psi \alpha \varsigma$ est au surplus le terme courant lorsqu'il s'agit d'un fléau qui s'abat. Le Fléau Porte-Feu n'est donc pas quelque chose qui s'ajoute à la $\varphi \theta i ́ \sigma ı \zeta$ c'est elle-même. Inutile de vouloir retrouver la fièvre ( $\pi v \rho \varepsilon \tau o ́ \varsigma)$ dans le terme banal de

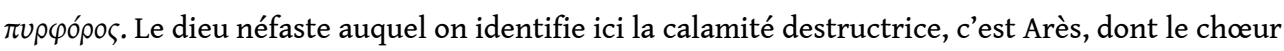

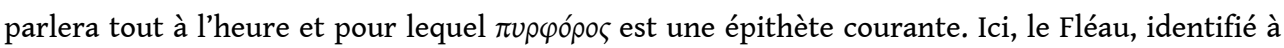
un dieu, traverse la ville en rafale et la dépeuple pour enrichir Hadès. Rien n'indique qu'il s'agisse d'autre chose que des maux décrits par les vers 25-27.

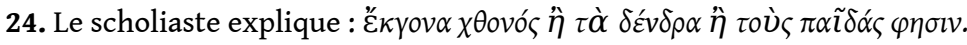

25. La traduction des vers 180-181 sera justifiée dans un chapitre suivant. Pour le reste, voici quelques explications :

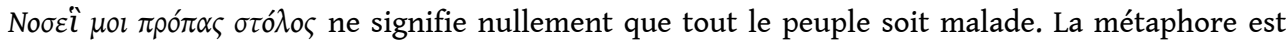
tellement usée en grec que, s'il fallait prendre le mot au pied de la lettre dans tous les passages où on le rencontre, on s'exposerait à d'étranges contre-sens. Aux vers 60-61, đEdipe l'applique à lui-même et au chœur, voulant dire simplement : Nous sommes tous malheureux, et moi, comme roi,

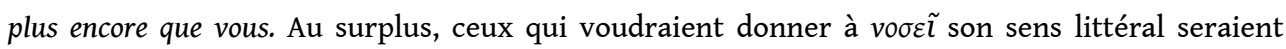
obligés d'entendre : Nous tous qui sommes ici, nous sommes frappés, à quoi, heureusement, personne ne songe.

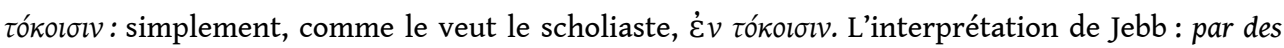
naissances, par la mise au monde d'un enfant vivant, est séduisante à première lecture, mais reprend

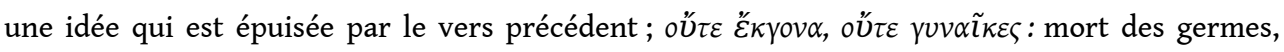
mort des mères.

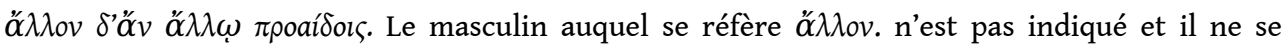
dégage pas aisément du passage. L'image suggère, pour le substantif repris par ce pronom, $\varphi v x \eta ́$. Le sens suggérerait plutôt $\tau$ Ékvov puisque l'idée qui domine le tout est celle de l'appauvrissement de la cité par la mort des germes. Le plus simple est encore de suppléer un mot comme vékpós qui, ne cadrant pas avec l'image de la rafale funèbre, n'est pas exprimé. C'est ainsi qu'entend le

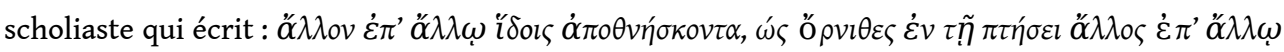
$\pi \dot{\varepsilon} \tau \varepsilon \tau \alpha l$.

26. Mutter Erde, p. 41.

27. Dès qu'on étudie dans le détail le texte d'ÆEdipe-Roi, on est frappé de voir le grand nombre de passages où le rapprochement s'impose avec les Suppliantes d'Eschyle. Cf. MARIE DELCOURT, Antiquité classique, 1937, P. 63 sqq.

28. Notamment BRUHN, dans la préface à sa révision de l'éd. SCHNEIDEWIN-NAUCK et ROBERT, CEdipus, p. 292.

29. Par exemple, cent vers plus bas, Achille jure à Agamemnon que les Grecs le rappelleront un jour en vain. Il jure par son bâton, et un scholiaste rappelle qu'ainsi faisaient les archontes athéniens. Achille ajoute (I, 234 sqq.) que le bâton a été écorcé et poli, qu'il ne refleurira donc jamais. Détails inutiles dans un tel contexte (rudimentaires, dirait Zielinski), mais qui s'expliquent 
parfaitement s'ils ont fait partie d'un serment promissoire du type : " Je ne reviendrai pas avant que ce bâton ait refleuri » (Cf. Il. XXIII, 42 sqq.).

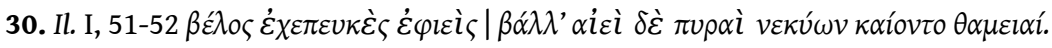

31. Phil. 105.

32. scHOL. ad Il. I, 50 (Didyme et Ven. A).

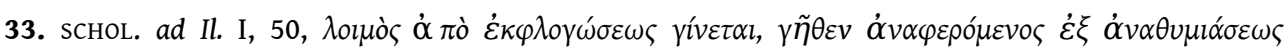
(Didyme et Ven. A).

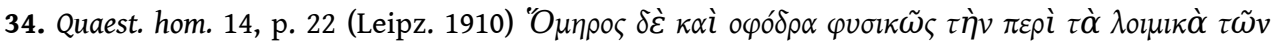

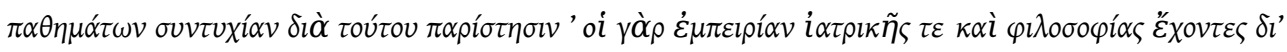

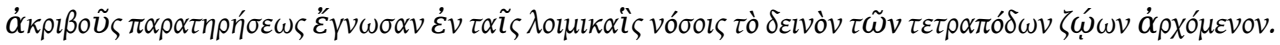

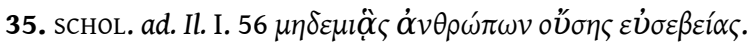

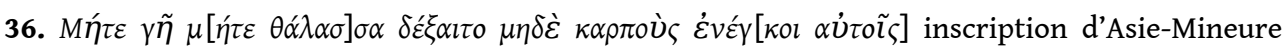
publiée et commentée par F. CUMONT, Rev. Et. Gr. XIV (1901), pp. 26 sqq.

37. Toutefois, dans le papyrus magique de Paris publié par WESSELY (Denkschr. d. kais. -kön. Ak. d.

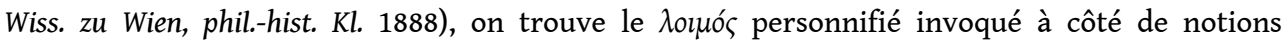

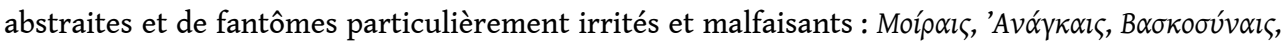

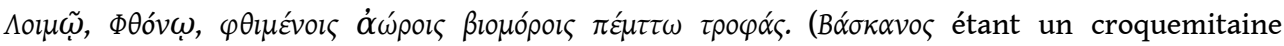

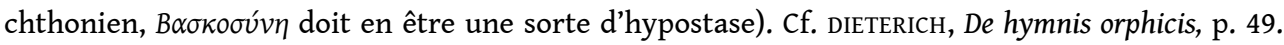

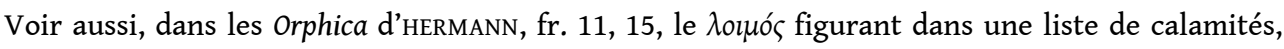
dans un texte orphique probablement surchargé de falsifications juives et chrétiennes.

38. II, 5, 9 ; II, 5, II ; ПI, 7, I ; III, 7, 5 ; III, 12, 6 ; III, 15, 8.

39. De agricultura, 141 : Mars pater te precor quaesoque uti sies uolens propitius mihi domo familiaeque meae quoius rei ergo agrum terram fundumque meum suouetaurilibus circumagi jussi. | Uti tu morbos | uisos inuisosque | uiduertatem / uastitudinemque / calamitates / intemperiasque | prohibessis defendas | auer-runcesque; | ut fruges frumento / uineta uirgultaque | grandire dueneque | euenire siris | pastores pecuaque | salua seruassis / diuque donam salutem / ualetudinemque | mihi domo | familiaeque nostrae, I harumce rerum ergo, fundi terrae agriquemei lustrandi lustrique faciendi ergo, sic uti dixi, macte hisce suouetaurilibus lactentibus immolandis esto, macte hisce suouetaurilibus lactentibus esto. Quel est le sens exact, à cette époque, de uiduertas? Festus (p. 369, 15) dit : Viduertas, calamitas, dicta quod uiduet bonis, explication qui pourrait bien avoir été inventée pour le passage. La uiduertas a peut-être été la stérilité. M. Hubaux qui m'a rendue attentive à ce passage, me fait remarquer que le Dieu invoqué pour donner l'abondance à la ferme, c'est Mars. Dans la parodos d'EEdipe-Roi, le Fléau est identifié à Arès.

40. Od. XIX, 109 sqq. ; vide supra, p. 22.

41. Cf. infra, p. 59 ce qui est dit d'un passage de Julius Obsequens (ch. 50) pour l'année 50 avant J.c. 


\section{Chapitre II. Les enfants maléfiques}

1 Lorsque les dieux étaient irrités contre les hommes, ils faisaient naître d'eux une descendance anormale. Rien d'étonnant si ces nouveau-nés étaient considérés comme maléfiques. Nous distinguons nettement entre cause et effet; bien des superstitions prouvent combien, primitivement, les deux notions sont mêlées l'une à l'autre ${ }^{1}$. Et, souvent, l'évolution même d'une légende nous permet de saisir le moment où la logique est devenue plus exigeante.

2 Ainsi, Sophocle dit que Philoctète a été exposé parce que ses malédictions et ses cris empêchaient l'armée de faire les sacrifices. Homère ignore ce motif. Dans l'Iliade, on ne donne de l'abandon de Philoctète aucune raison et personne ne songeait à en demander². Philoctète est abandonné parce qu'il est atteint d'un mal mystérieux et inquiétant. Ceux de son entourage redoutent, non une contagion au sens moderne du mot, mais que la colère des dieux, qui s'est manifestée sur Philoctète, s'étende également sur eux. Le seul fait que Sophocle allègue une justification supplémentaire montre que son public ne comprenait plus bien la vieille superstition et demandait une explication plus rationnelle. Plutarque raconte que, dans une haute antiquité, on tenait les malades hors des maisons afin que les gens qui passaient, et qui avaient quelque expérience du cas, pussent donner des conseils pour le soigner ${ }^{3}$. Ici encore, on trouve rationalisée après coup la coutume qui consiste - en une époque où toute maladie paraît mystérieuse et liée à la colère des dieux - à écarter le malade simplement pour qu'il ne porte pas malheur.

3 A vrai dire, les historiens des religions n'interprètent pas ainsi la coutume relative aux malades. Dieterich ${ }^{4}$ pense que, lorsqu'on met un mourant sur le sol, c'est qu'on le confie à la Terre avec l'espoir qu'elle le guérira peut-être et, en tous cas, qu'elle recevra son âme. Il cite à l'appui de cette théorie des faits qui, en effet, paraissent clairs. Mais ces cas, recueillis en Allemagne, en Irlande, dans l'Inde, par des folkoristes, ne sont pas analogues à l'exposition telle qu'on en trouve encore des traces en Grèce. Autre chose est de mettre le mourant en contact avec le sol, dans sa propre maison, et de porter un malade dans la rue. S'il s'agissait simplement de lui faire toucher la terre, ce devait généralement être possible sans quitter la maison. Il faut donc distinguer deux coutumes. Celle, d'une part, qui résulte de la croyance à la Terre guérisseuse et réservoir de vie ; c'est à cet usage que se serait conformé saint François d'Assise lorsqu'il se fit déposer mourant par terre. Mais, de cela, il n'y a aucune trace en Grèce. D'autre part, une excommunication des malades hors de la maison, attestée par la légende homérique de Philoctète et par un passage de 
Plutarque. Hérodote $(1,197)$ dit qu'elle était pratiquée par les Babyloniens. Pour Rome, nous savons peu de chose. Un mourant, en latin, se dit parfois depositus. Servius donne du mot le même sens et la même justification que Plutarque ; Nonius, lisant dans Servius " depositi idest desperati » et ne comprenant plus l'idée, dit que deponere signifie desperare. Impossible, d'après nos textes ${ }^{5}$ de savoir si depositus doit se prendre dans le sens de posé par terre ou de mis hors de la maison. S'agit-il d'une restitution à la Terre ou d'une éviction d'un être maléfique, analogue à celle dont souffrirent Philoctète, les Babyloniens d'Hérodote et les «anciens » dont parle Plutarque? Comme Servius dit formellement qu'on mettait les mourants devant la porte, il semble bien qu'on songeait surtout à les écarter. Toute cabane romaine à l'époque ancienne avait un carré de terre battue suffisant pour qu'on pût y déposer un malade sans avoir besoin de le mettre dans la rue.

L'éviction des nouveau-nés anormaux est apparentée à celle des malades. Elle est heureusement mieux connue. En ce qui concerne l'antiquité latine, nous possédons quantité de documents faciles à interpréter. Pour la Grèce, deux témoignages importants ont été méconnus ou mal compris. Le premier, c'est précisément la phrase constituée par les systèmes 179-180 de la parodos d'ÆEdipe-Roi. Ils ont reçu une interprétation si différente de celle que nous proposons qu'il faudra bien justifier celle-ci terme à terme.

\section{§ 1. LES ENFANTS ABANDONNÉS DANS EEDIPE-ROI.}

Nous avons traduit par « Abandonnés de tous, les nouveau-nés porteurs de mort gisent par terre,

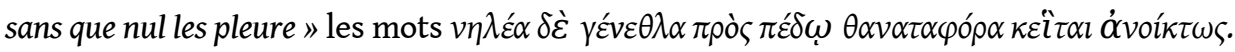

Il nous faut essayer de démontrer que cette traduction est la seule possible.

$7 \quad$ En général, le collectif $\gamma \varepsilon ́ v \varepsilon \theta \lambda \alpha$ a été entendu dans le sens de les enfants de la cité ( $\kappa \lambda v \tau \tilde{\alpha} \varsigma$ $\chi \theta 0 v o ́$ : $:$ v. 172), c.-à-d. les citoyens. Puis, on a considéré comme allant de soi que ces gisants étaient des morts (ce que le texte ne dit pas). Tous les éditeurs entendent donc, à peu de chose près, comme Masqueray : «Sans pitié, sans qu'on les pleure, les cadavres restent étendus sur le sol, semant la contagion. $»^{6}$

8 A l'appui de cette exégèse - car c'est bien plus une exégèse qu'une traduction -, les commentateurs de ce texte le rapprochent de ce que dit Thucydide (II, 50) : $\pi 0 \lambda \lambda \tilde{\omega} v$

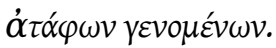

Je voudrais démontrer qu'il s'agit bien, comme Sophocle le dit, d'enfants; que ces enfants sont exposés vivants, et qu'ils sont néfastes par leur existence même et non parce que leur cadavre répand une contagion.

Personne en effet ne paraît avoir été frappé par l'invraisemblance du détail que l'on ajoute au texte sous prétexte de le rendre intelligible : à savoir que l'on aurait abandonné volontairement des cadavres sur la voie publique. Quelques annotateurs expliquent que, si l'on renonçait à enterrer les morts, c'était à cause du danger de contagion que présentaient les cadavres. Il est bien évident que, plus un cadavre est contagieux, plus vite on l'enterrera, parce qu'une raison de simple bon sens agira dans la même direction que les scrupules religieux. Si les gens de la famille craignent le contact du mort, ils chargeront des esclaves de la pénible besogne. A vrai dire, c'était un manque de respect envers les morts que de faire accomplir par des esclaves les cérémonies funéraires ${ }^{7}$. Il est 
probable que cela se faisait néanmoins quand le devoir était particulièrement répugnant ou dangereux. Thucydide ne dit nullement que, pendant la peste d'Athènes, on ait renoncé à enterrer les morts, mais, bien au contraire, qu'on enterrait comme on pouvait ("ع $\theta \alpha \pi \tau o v \delta \grave{\varepsilon}$

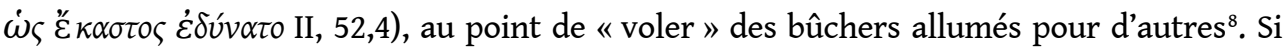
cependant, en 430, de nombreux morts ne furent ni incinérés, ni inhumés, ce fut ou faute de parents vivants, ou faute de bois à brûler, ou faute de terre meuble: toute la population était entassée sur le sol rocheux de la ville forte et les Spartiates tenaient la campagne. A Thèbes, aucune de ces raisons ne peut jouer.

11 Si notre passage avait le sens qu'on veut lui donner, ce serait un témoignage unique et absolument isolé dans toute la littérature grecque où, invariablement, la privation de sépulture est représentée comme le plus terrible châtiment que les vivants puissent infliger aux morts, comme une punition réservée à des traitres, Ajax, Polynice ${ }^{9}$. Dans le cas présent, il s'agirait d'une négligence gratuite et particulièrement révoltante envers des malheureux.

12 Ajoutons qu'elle serait dangereuse. Les morts se vengent du mépris dont ils sont l'objet. Tertullien (De anima, 56) expose, pour la combattre, la conception païenne d'après laquelle trois catégories d'âmes étaient particulièrement malfaisantes : les ó $\tau \alpha \varphi \circ l$, les ö $\omega \rho o l$, les $\beta l \alpha ı 0 \theta \alpha ́ v \alpha \tau o l^{10}$. Pour lui, naturellement, le genre de mort ne saurait avoir aucune influence sur la destinée ultérieure de l'âme : peu importe au salut éternel que le cadavre soit sans sépulture, que l'enfant soit mort prématurément, que l'homme ait péri de mort violente. Mais cette classification de ceux qui ne peuvent être des quiescentes animae est déjà dans la Nekyia virgilienne et son vocabulaire même indique qu'elle existait chez les Grecs.

Les Thébains, devant le Fléau, devaient se sentir coupables d'une üßpis inconnue et inconsciente. Ils n'y auraient pas ajouté délibérément l'ǔßpıৎ supplémentaire et particulièrement grave de ne pas ensevelir les morts. En effet, l'abandon des cadavres aurait amené un redoublement du Fléau, quelle que soit la nature de celui-ci, car, ainsi que le fait remarquer Wundt, chez tous les peuples, c'est sous la forme d'un Krankheitsdaemon que l'âme errante est le plus redoutée ${ }^{11}$. Cette explication est parfaitement applicable au cas présent, puisque le message d'Apollon, rapporté par Créon, est précisément que c'est l'âme malfaisante de Laïos qui, insuffisamment apaisée, a suscité le Krankheitsdaemon. Les Thébains auraient donc été fous en n'enterrant pas au plus tôt des gens qui, frappés de "mauvaise mort», devaient devenir des esprits particulièrement dangereux.

14 Il est donc impossible de prendre $\gamma \varepsilon ́ v \varepsilon \theta \lambda \alpha$ dans le sens des « enfants de Thèbes ». Il reste un autre sens, celui d'enfants, sans plus.

15 S'agit-il d'enfants morts-nés ou morts à peine nés ?

16 A première lecture, cette explication paraît séduisante ; nous connaissons nombre de cas où l'enfant mort avant la dénomination ou avant la circoncision ne reçoit pas les rites funéraires complets. Mais aucun de ces exemples n'est relatif à la Grèce ${ }^{12}$.

17 A Rome, l'enfant mort en bas-âge était enterré, non brûlé, usage à propos duquel Dieterich propose une explication très vraisemblable : l'enfant était rendu à la terre pour qu'elle le fit renaître en un frère plus heureux ${ }^{13}$. En Grèce également, la Terre est коvротрó $\varphi$ os et ce n'est pas là une simple métaphore. Dans ce cas, comment expliquer que le peuple thébain n'ait pas enterré des enfants morts?

18 D'autant plus que, il faut y revenir, les enfants morts en bas âge ne sont pas des quiescentes animae. Leur puissance magique est grande et redoutable. C'est dans leurs 
tombeaux que les magiciens vont souvent déposer les tablettes de plomb des defixiones. On essaie aussi de capter leur force pour opérer des guérisons. Mais tout ce qu'on nous dit d'eux indique qu'on prenait grand soin de les enterrer ${ }^{14}$.

On ne saurait trop le répéter, les Grecs respectent religieusement l'obligation d'enterrer tous les morts. M. Jobbé-Duval a relevé les nombreux cas où la législation romaine prive un mort de sépulture. Ces lois supposent un étrange illogisme: on punit le mort en le privant de son repos; mais s'il est troublé, ne viendra-t-il pas tourmenter son juge? En

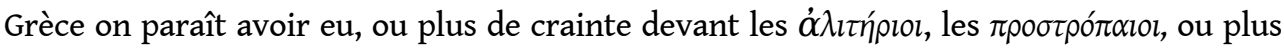
de respect devant les morts. Il est vrai que, contre les suicidés, la privation de sépulture est la seule punition possible. Encore ne semble-t-elle pas avoir été appliquée à Rome, sinon peut-être en ce qui concerne les pendus. On a pu refuser aux suicidés certaines cérémonies, par exemple les honneurs du bûcher. Les autres châtiments post mortem paraissent bien n'avoir jamais existé que dans les législations fictives inventées par les rhéteurs ${ }^{15}$.

M. Jobbé-Duval estime que, dans certains cas, on n'enterrait pas les mutilés ${ }^{16}$. L'exemple qu'il cite, celui de Déiphobe sauvagement mutilé par Ménélas, se retourne contre cette thèse, car Énée rencontre Déiphobe dans les cercles des sepulti. La mutilation, d'après les idées des anciens, devait simplement rendre la sépulture vaine, puisqu'un corps incomplet était restitué à la terre, une partie restant à l'abandon. Déiphobe, conformément à cette conception, continue à souffrir dans les Enfers. «Chez les Indiens de l'Amérique du Nord, dit M. Jobbé-Duval, le cadavre du guerrier scalpé n'est plus qu'une simple charogne et n'est jamais enterré. L'âme est censée être anéantie ». En Grèce, il n'y a rien de semblable: Clytemnestre, chez Eschyle et chez Sophocle, mutile le corps d'Agamemnon et le fait ensuite enterrer rituellement. De la sorte, elle s'est mise en règle avec les coutumes, sans pour cela donner au mort le bénéfice d'une sépulture efficace ${ }^{17}$.

Par conséquent les enfants gisants du début d'ÆEdipe-Roi ne peuvent pas être des morts. Et, du reste, encore une fois, le poète ne dit nulle part que ce sont des morts. Ils ne peuvent

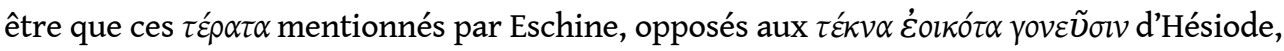
ces enfants anormaux qui figurent dans toutes les descriptions classiques des périodes de stérilité.

Il reste à faire une remarque sur une variante curieuse. Au système 180, la première main de L semble avoir eu $\theta \alpha v \alpha \tau \alpha \varphi o ́ \rho \omega$ corrigé ensuite en $\theta \alpha v \alpha \tau \alpha \alpha \varphi o ́ \rho \alpha$. Plusieurs mss récents ont $\theta \alpha v \alpha \tau \alpha \varphi o^{\prime} \rho \omega$. Avec ce texte, ce ne sont donc pas les enfants qui sont mortifères, mais le sol.

Cette leçon était bien plus facile à justifier que $\theta \alpha v \alpha \tau \alpha \varphi o ́ p \alpha$. On comprend que les copistes l'aient répandue à une époque où plus personne ne connaissait la vieille superstition des anormaux maléfiques, mais où, avec les scholiastes, on savait encore que le Fléau thébain ne comportait aucune épidémie au sens moderne du mot. Comme on ne s'expliquait plus que des enfants puissent être dits funestes, mais comme on savait que la terre était frappée de malédiction, on a trouvé plus simple de référer à $\pi \varepsilon ́ \delta \omega$ l'adjectif incompréhensible et de le mettre au datif. Et il a fallu que les modernes se trompent complètement sur la nature du Fléau pour qu'ils arrivent à expliquer de nouveau $\theta \alpha v \alpha \tau \alpha \varphi o ́ \rho \alpha$ rattaché à $\gamma \varepsilon ́ v \varepsilon \theta \lambda \alpha$. 


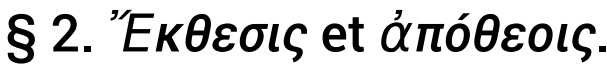

Ces anormaux, nous savons qu'une série de lois grecques et romaines ordonnaient aux parents de les exposer. Malheureusement pour la clarté des idées, les théoriciens anciens et modernes ont confondu fâcheusement, à propos des expositions d'enfants, deux réalités bien différentes, l'exposition par les parents et l'exposition par l'État.

Exposition par les parents. Dans toute l'antiquité, le père, ou la mère si le père fait défaut, ont le droit d'exposer un enfant nouveau-né. Ils le font pour s'en débarrasser, mais, en général, ils souhaitent que l'enfant survive. C'est pourquoi on l'expose souvent à la fin de la nuit, dans un endroit fréquenté, après l'avoir habillé et abrité dans une corbeille ou dans un récipient en terre cuite. Ainsi agissent les filles séduites (Créuse dans Ion), les gens pauvres accablés d'enfants, les bourgeois avares et prétentieux qui, pour garder leur rang, ne veulent qu'un fils unique (Chrémès dans Heautontimoroumenos). Très tôt, les cités ont essayé de réglementer les expositions et de limiter en cette matière le droit des parents. La plus ancienne réglementation est celle de la loi de Gortyne, relative à la mère abandonnée ${ }^{18}$. Cette exposition, qui dérive de causes sociales, se dit ع̌k $\theta \varepsilon \sigma \iota \zeta$.

Exposition par l'État. D'autre part, à Sparte, à Athènes, en Étrurie, à Rome, des lois ont ordonné de sacrifier certains enfants dès leur naissance. Ces enfants étaient mis dans un lieu spécial, non fréquenté, peut-être inconnu, éloigné de la ville, ou encore jetés dans une eau courante. Ils doivent disparaitre. Nulle part on ne dit qu'ils soient ensevelis, et tout donne à penser qu'on ne les enterre pas. Tout se passe comme si ces enfants étaient des êtres maudits et maléfiques dont il faut se débarrasser en toute hâte. Cette coutume a une origine religieuse. Elle se dit $\dot{\alpha} \pi o ́ \theta \varepsilon o l \zeta$.

Elle seule nous intéresse ici. Voyons les textes qui la concernent. Il faut les regarder d'autant plus soigneusement qu'ils n'ont jamais été considérés à part.

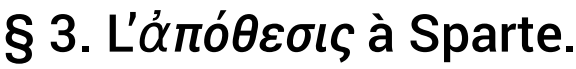

8 Le seul texte est un passage bien connu de la Vie de Lycurgue. Malheureusement, le renseignement de Plutarque, au lieu de passer seul dans les traités modernes, y est entré accompagné des commentaires de l'historien. Celui-ci, ne comprenant plus le rite très ancien qu'il décrivait, en a donné une interprétation rationaliste, acceptée à la légère depuis des siècles.

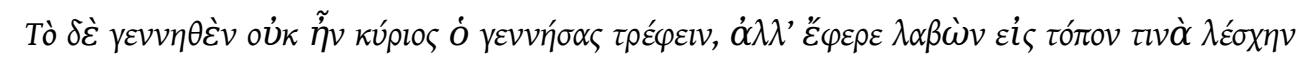

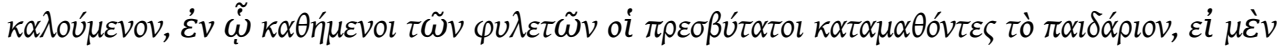

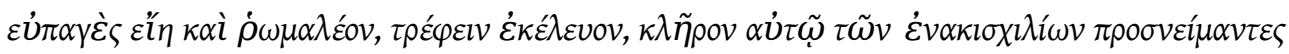

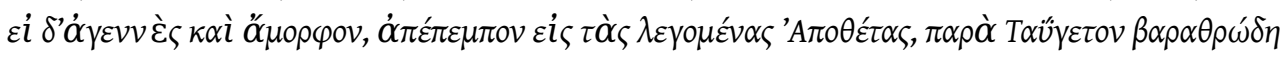

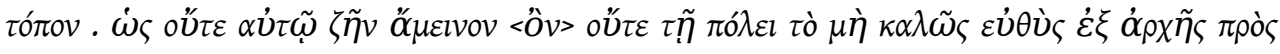

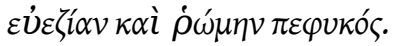

"Le géniteur n'avait pas à décider s'il fallait ou non nourrir le nouveau-né; il l'apportait à la lesché où les plus vieux des phylètes, ayant examiné l'enfant, (A) ordonnaient de le nourrir lorsqu'il était bien fait et robuste et lui attribuaient alors un des 9000 lots de terre; (B) si l'enfant était dégénéré et difforme ${ }^{19}$, ils le reléguaient dans un lieu dit les Dépôts, situé près du Taygète, plein de trous 
profonds. (C) Ils pensaient que ni l'individu ni la ville n'ont intérêt à ce que vive un être qui, dès sa naissance, manque de ce qu'il faut pour être beau et robuste » (Lyc. 16).

Ce texte est présenté par Plutarque comme une unité. Il suffit néanmoins de le Ure pour voir qu'il contient, pour un seul fait, deux explications incompatibles l'une avec l'autre, rapprochées par quelqu'un qui ne les comprenait plus.

En effet, les 9000 lots sont des majorats qui ne peuvent être donnés qu'à des aînés de famille. S'il fallait prendre le texte ci-dessus à la lettre, nous comprendrions qu'on

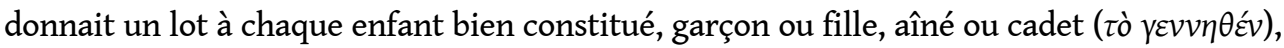
ce qui est impossible.

Alors, de deux choses l'une :

Ou bien l'examen des nouveau-nés avait en effet pour but d'attribuer les majorats à des futurs citoyens capables de porter les armes, et dans ce cas, le père ne soumettait aux phylètes que son fils aîné, et le second si le premier avait été exclu ${ }^{20}$.

Ou bien l'examen avait pour but de débarrasser le pays des enfants mal portants ; dans ce cas, il n'avait pas de rapport avec la distribution des majorats; il devait porter sur tous les enfants, garçons ou filles, car Plutarque lui-même insiste sur le fait que l'eugénique de Lycurgue englobait les femmes.

Je crois qu'on peut rejeter tout de suite la première explication.

7 En effet, si ignorants qu'aient été les Spartiates en fait de médecine, ils savaient certainement qu'un nouveau-né débile peut devenir un adulte vigoureux, et réciproquement. Promettre un majorat à un nouveau-né aurait été une absurdité. Si les lots étaient donnés à la suite d'un "conseil de révision ", celui-ci devait se placer bien plus tard, peut-être au moment du service militaire.

De plus, si l'examen à la naissance avait été simplement préliminaire à la distribution des lots, on ne voit pas pourquoi on aurait ordonné de tuer les éliminés; ils pouvaient parfaitement être élevés dans le gynécée, comme le fut le fils d'Alcibiade à qui furent refusés tous les droits inhérents à la qualité de prince royal ${ }^{21}$.

Il semble donc évident qu'il faut dissocier les éléments de la notice de Plutarque. A se rapporte à une docimasie pour l'attribution d'un majorat, erronément référée au moment de la naissance ; $B$ seul consigne une loi relative à l'exposition des nouveau-nés.

Ici, chaque mot est intéressant. L'enfant, garçon ou fille ( $\tau$ ò $ү \varepsilon v v \eta \theta \dot{v}$ ), est exclu de la communauté s'il est $\dot{\alpha} \gamma \varepsilon v v \eta ́ \zeta$ ou ŏ́$\mu о \rho \varphi \circ \varsigma$, c'est-à-dire s'il ne porte pas la marque, la forme

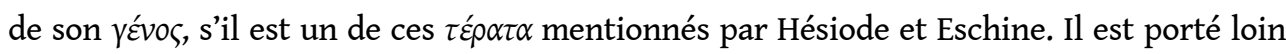
de la ville. On ne le tue pas, pour ne pas assumer le miasma du meurtre, mais on le jette dans un trou pour qu'il disparaisse. Il porte malheur, il est néfaste, comme les nouveaunés thébains dans $\Subset$ dipe-Roi.

1 Remarquons ici que les adjectifs de $\mathbf{A}$ et ceux de $\mathbf{B}$ ne forment pas une antithèse régulière, ce qui se comprend parfaitement s'il s'agit de deux renseignements d'origines différentes.

42 Le titulaire d'un majorat doit être fort ( $\left.\varepsilon \dot{U} \pi \alpha \gamma \varepsilon \dot{\varepsilon}, \dot{\rho} \omega \mu \alpha \lambda \varepsilon \varepsilon^{\prime} v\right)$; l'enfant exposé est, non faible, mais difforme: né pied-bot, ou avec des mains syndactyles, ou avec des doigts en surnombre, il peut très bien être robuste. La débilité et l'anomalie sont deux notions bien distinctes que le vocabulaire de Plutarque n'a heureusement pas confondues.

La phrase $c$ donne l'explication de Plutarque : c'est par souci à la fois d'humanité et d'eugénique que l'on sacrifiait les nouveau-nés. Justification rationaliste proposée par les 
philosophes (nous allons la trouver chez Aristote et chez Platon) pour mettre sur le plan de la sagesse une coutume d'origine purement superstitieuse. Il est étonnant que les commentateurs modernes aient accepté docilement une interprétation qui est absurde si on la compare aux autres institutions de la cité lacédémonienne. "A Sparte, dit Denys d'Halicarnasse (XX, 2, 13), l'État n'a ni cure ni souci de ce qui se passe dans les maisons ; la porte de la cour est pour chacun la limite où commence la liberté de la vie ». Si vraiment

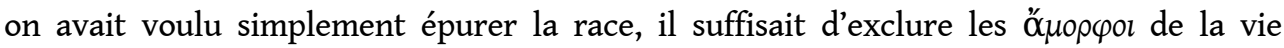
publique et de refuser à leurs enfants la qualité de citoyen. Si on les exposait, c'est parce qu'ils faisaient peur; ils étaient le signe de la colère des dieux et ils en étaient aussi la raison. Le symptôme est une concomitance où un esprit non exercé distingue mal entre cause et effet. « Pour se garantir de ce que le monstre annonce, on le fait disparaître, dit fort bien Lévy-Bruhl. Procédé d'une absurdité enfantine si le monstre ne faisait qu'annoncer le malheur $»^{22}$.

Et, comme la naissance d'un teras menace toute une région (car la stérilité est une punition collective), c'est un collège de vieillards qui décide; des parents pourraient s'attendrir, surtout si l'anomalie est bénigne; la communauté, hautement intéressée, accepte l'enfant, ou le chasse s'il lui paraît néfaste.

Enfin, les expositions d'anormaux devaient être courantes dans toute la Grèce archaïque, car aucun historien avant Plutarque, pas même Xénophon dans ses Institutions lacédêmoniennes, ne signale sur ce point une singularité des Lacédémoniens. Si Plutarque mentionne les expositions obligatoires - en les contaminant du reste avec les formalités pour l'investiture des majorats -, c'est probablement que, de son temps, elles n'existaient plus ailleurs en Grèce. Les Spartiates devaient avoir gardé la coutume plus longtemps que les autres Grecs et ils se vantaient, en l'observant, d'obéir encore à Lycurgue. La notice de la Vie ne doit pas signifier autre chose.

$\mathrm{Au}$ surplus, plusieurs historiens récents ont découvert, dans les institutions Spartiates, d'anciens rites religieux rationalisés après coup. M. A. Thomsen a montré que les flagellations à l'autel d'Orthia sont un rite de fécondité revêtu après coup d'un sens pédagogique ${ }^{23}$. M. Martin Nilsson a étudié les syssities et les syscénies, ainsi que les groupements d'enfants Spartiates d'après leur âge : il ramène toutes ces coutumes aux pratiques des sociétés secrètes masculines, encore en usage dans quantité de civilisations primitives $^{24}$. M. Jeanmaire explique la cryptie lacédémonienne comme un rite d'initiation pour les jeunes gens qui vont devenir des citoyens : ils doivent rester cachés un certain temps afin d'apprendre dans une sorte de retraite les secrets qui feront d'eux des Égaux. Plutarque (ch. 28) rationalise la chose après coup, exactement comme il l'a fait pour les expositions d'enfants, et il transforme cette coutume religieuse en une chasse aux hilotes ${ }^{25}$. Bien entendu, la rationalisation avait commencé bien longtemps avant lui. Et, lorsqu'on réfléchit à ce que devint, pour les philosophes, le modèle spartiate ${ }^{26}$, on se rend compte que la transformation de Sparte en maîtresse politique de la Grèce repose sur une étonnante série de contre-sens et de malentendus. L'explication ci-dessus proposée pour l'exposition des anormaux s'inscrit dans la même ligne que les travaux de MM. Thomsen, Nilsson, Jeanmaire; elle pourra peut-être aider à détecter, sous d'autres institutions Spartiates, des survivances religieuses méconnues depuis une époque très ancienne. 


\section{§ 4. L'A} sommes ici en pleine législation fictive et en plein rationalisme. La justification donnée est empruntée à l'eugénique du temps. Mais qu'on regarde le texte de près ; on verra qu'il s'agit d'une coutume existante que Platon conseille de garder, et non d'une innovation qu'il voudrait instaurer; de plus, l'origine archaïque et superstitieuse de la coutume est

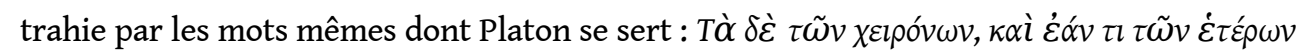

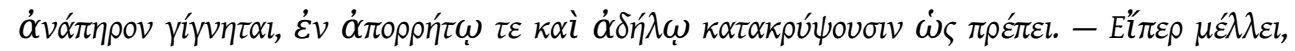

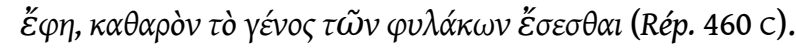

51 "Les enfants des gens mal conformés, ou s'il naît un infirme parmi les autres, on les cachera dans un lieu mystérieux et inconnu, comme il convient. - Oui, vraiment, ainsi restera pure la race des Gardiens. nous autorise à traduire par enterrer.

Les enfants infirmes sont mis à l'écart dans un lieu qui est frappé d'une sorte de malédiction ( $\dot{\alpha} \pi o ́ \rho \rho \eta \tau o v)$. La majorité de la population en ignorera l'emplacement (ö $\delta \eta \lambda o v)$ - Pourquoi cette précaution? Peut-être pour éviter que des parents mécontents ( $\chi \alpha \lambda \varepsilon \pi \alpha i v \varepsilon v v$ dans Théétète) aillent rechercher leurs enfants pour les élever secrètement. 
Peut-être aussi pour éviter que des malveillants n'aillent prendre des corps dans des intentions qui nous échappent. ' $\Omega \varsigma \pi \rho \varepsilon ́ \pi \varepsilon l$ indique que la chose se faisait encore à Athènes au temps de Platon. Mais la réponse de l'interlocuteur semble signifier que l'origine religieuse de la coutume était oubliée. Celle-ci ne se trahit plus que dans les mots $\dot{\varepsilon} v \dot{\alpha}$

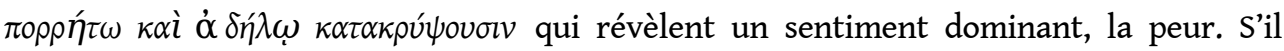
s'agissait simplement de garder pure la race des Gardiens, il suffirait de faire descendre les enfants mal conformés dans une classe inférieure, ou encore de les tuer; il serait inutile d'aller les exposer loin de la ville. Enfin, Platon ne parle pas d'enfants débiles, mais d'enfants nés infirmes. Il s'agit évidemment des $\tau \dot{\varepsilon} \rho \alpha \tau \alpha$ qui sont maléfiques du fait seul de leur existence et qu'on écarte parce qu'on les redoute.

On objectera que, s'il s'agit de raisons d'ordre superstitieux, la prescription devrait exister pour toutes les classes de l'État, cela est évident, mais Platon ne connaît plus d'autre explication que la justification rationnelle qui lui paraît particulièrement opportune à propos de l'aristocratie du pays. La raison religieuse affleure dans son exposé uniquement à son insu.

\section{Aristote dit dans la Politique (IV (VII), 16, 18 = p. 1335 b) :}

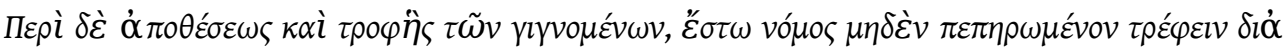

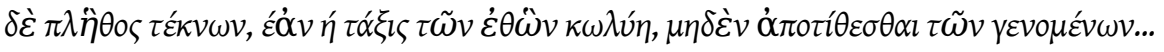

"Quant à l'exposition et à la nourriture des enfants, il faut qu'il y ait une loi interdisant de nourrir un enfant estropié. Quand le nombre des enfants est en cause, si la coutume l'empêche, il ne faut pas exposer les nouveau-nés » (mais procéder par avortements précoces).

Ce texte, qui note une législation fictive, ne peut nous donner que des renseignements indirects sur un état de fait. Mais ces renseignements sont aussi intéressants que ceux que Platon donne, sans le savoir, dans le passage de la République.

Aristote distingue encore les deux formes d'exposition: celle qui concerne les enfants infirmes qu'il est interdit de nourrir, et celle qui concerne les enfants en surnombre qu'il est plus sage de ne pas nourrir. Les enfants infirmes sont exclus de la communauté ; cela lui paraît aller de soi et il ne prévoit sur ce point aucune résistance. Il ne nous donne aucun détail sur la façon dont les anormaux seront écartés. C'est pourquoi il nous est impossible de savoir comment il justifiait leur exclusion. Il est probable que lui-même et les gens cultivés de son temps ne devaient plus savoir pourquoi on avait horreur des enfants maléfiques, et l'on donnait un peu partout les deux justifications consignées par Plutarque : l'anormal n'a aucun avantage à vivre et la cité n'a aucun avantage à ce qu'il vive.

C'est l'État qui imposera aux parents d'abandonner les anormaux : ع̌ $\tau \tau \omega$ vómos. Les choses se passaient ainsi à Sparte certainement, peut-être encore à Athènes. La législation d'Aristote, sur ce point, n'innove pas plus que celle de Platon ; l'une et l'autre reviennent simplement au passé.

Mais Aristote innove en ce qui concerne les abandons de la seconde espèce, ceux qui, en général, étaient livrés à l'arbitraire du père de famille. Celui-ci était juge et décidait combien d'enfants il voulait nourrir. Pour Aristote, le juge, c'est l'État. La notion de surnombre $(\pi \lambda \tilde{\eta} \theta 0 \varsigma)$ est relative, non aux familles, mais à l'État. L'État seul décide de la 
quantité d'enfants qu'on laissera grandir. Seulement, là où une constitution plus ancienne interdit l'exposition, on respectera l'interdiction, à laquelle on suppléera en détruisant le germe avant la naissance. Aristote connaissait donc des cités où les parents n'avaient pas le droit d'abandonner les nouveau-nés : cela donne une valeur au témoignage d'Elien disant qu'à Thèbes il était interdit d'exposer des enfants ${ }^{28}$. Toutefois, l'emphase avec laquelle Elien loue l'humanité de la loi thébaine, laquelle avait prévu une sorte d'assistance collective pour les enfants des indigents, semble indiquer que, de son temps, aucune cité n'avait semblable régime. Aristote au contraire prévoit le cas comme n'ayant rien d'exceptionnel.

Enfin, pour Aristote, les deux formes d'exposition sont de la compétence exclusive de

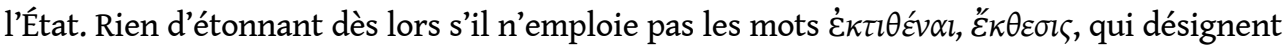

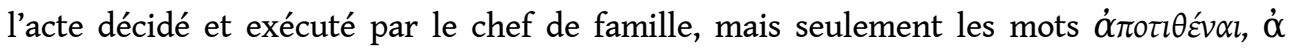
$\pi o ́ \theta \varepsilon \sigma \iota \varsigma$, qui désignent le même acte lorsqu'il est décidé et accompli par la communautée ${ }^{29}$. d'exposer ses enfants, hormis le cas où il aurait les pieds enflés par la faim. On a accepté ce témoignage, du reste parfaitement vraisemblable, d'autant plus volontiers qu'on le rapprochait de la législation thébaine rapportée par Elien, où un père pouvait exposer ses enfants uniquement s'il était pauvre. On ne s'est pas aperçu que Proclus emploie le verbe 


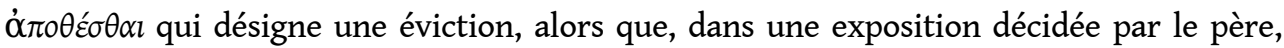
c'est $\dot{\varepsilon} \kappa \theta \dot{\varepsilon} \sigma \theta \alpha_{l}$ qu'il faudrait dire. On pourrait admettre que l'expression banale $\dot{\varepsilon} \kappa \tau \imath \theta \dot{\varepsilon} v \alpha_{l}$

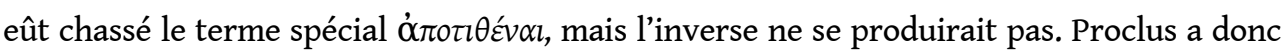

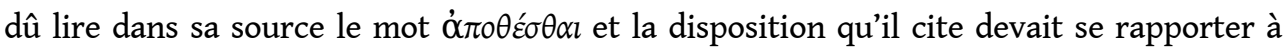
une éviction. Dans ce cas, le détail des pieds enflés devait concerner l'enfant et non le père. La loi disait probablement qu'à Ephèse on exposait uniquement, en fait d'enfants anormaux, ceux qui naissaient pieds-bots. Proclus aura rationalisé un texte dont il ne comprenait plus la portée.

L'altération du document, l'absence de toute date, rendent une conclusion précise impossible. Tout ce qu'on peut en déduire, c'est qu'il y a eu à Ephèse une législation relative aux évictions.

Il n'y aurait rien d'étonnant qu'elle eût porté sur les pieds contrefaits. Un enfant anormal promet une stérilité ; combien plus maléfique encore devait paraître l'enfant qui, en fait d'anomalie, était précisément chargé du signe physiologique de la misère ? Et comment ne pas se rappeler ici qu'ÆEdipe, l'enfant maudit, s'appelle Pieds-Enflés ?32

\section{§ 5. LES ANORMAUX, « SIGNES » DES DIEUX.}

69 Aucun autre texte ne nous parle plus de l'éviction des anormaux dans l'antiquité grecque. Mais le langage lui-même nous révèle toute l'importance qu'on attachait à leur apparition. Chez Homère, $\tau$ ḱp $\alpha \varsigma$ signifie simplement signe et ce signe peut même être favorable ${ }^{33}$. Chez les tragiques, c'est une apparition étonnante, effrayante; pour Platon, c'est un complexe qui présente une contradiction interne. Mais, dans la langue courante de la fin $d u v^{e}$ et du IV siècle, le mot n'a plus d'autre sens que celui qu'il a dans la malédiction conservée par Eschine, celui de malformation humaine ou animale (et même parfois végétale). Le signe par excellence envoyé par les dieux aux hommes coupables, c'est le nouveau-né anormal, - signe toujours inquiétant. Les philosophes, les savants cherchent à expliquer les anomalies ; mais la plupart d'entre eux, tout en faisant enquête sur les causes secondes, restent persuadés que la cause première est la colère des dieux. Le phénomène garde sa valeur comme présage, même après qu'on l'a analysés ${ }^{34}$. Nous reviendrons plus bas sur les tentatives des savants pour trouver une raison à la naissance des monstres ${ }^{35}$.

Avant de quitter le monde grec, signalons deux passages dont le sens devient plus clair si l'on se souvient que l'apparition d'un monstre est un signe de la colère des dieux et une promesse de malheur pour la terre qui le porte.

71 Dans les Choéphores, Clytemnestre rêve qu'elle a mis au monde un $\tau \dot{\varepsilon} p \alpha \varsigma$ - serpent qui l'a mordue au sein. Les interprètes des songes déclarent que les morts sont irrités (Choéph. 38 sqq.) Elle envoie faire des expiations à la Terre et aux morts. Le chœur, qui en est chargé, estime que cet hommage est un outrage à la Terre-Mère, qu'il invoque avec terreur (44).

Oreste, apprenant la chose, prie la Terre d'exécuter le songe :

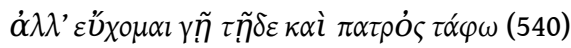

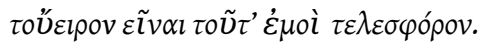


Il s'identifie au $\tau \dot{\varepsilon} p \propto \varsigma$ pour être chargé de la force maléfique dont celui-ci est plein et pour pouvoir rendre cette force efficace :

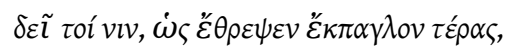

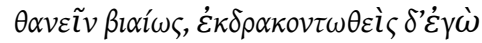

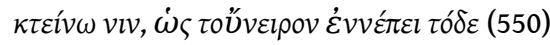

On voit l'importance que la Terre a dans ce passage, auquel il faudra revenir plus bas. Disons tout de suite qu'il est du reste difficile de savoir si elle apparaît ici comme Mère des Songes ou comme Mère des Monstres. Elle était l'un et l'autre.

Le second texte est l'oracle donné par Diopithès au moment où Lysandre soutient la candidature d'Agésilas, prétendant au trône de Sparte contre Agis présumé bâtard :

«Prends garde, Sparte, toute fière que tu sois, que, de toi, si droite sur tes pieds, ne naisse une royauté boiteuse; pendant longtemps, des maux inattendus t'oppresseront, et la vague redoublée de la guerre meurtrière ${ }^{36}$.

Lysandre interpréta l'oracle en disant que la royauté boiteuse serait celle d'un bâtard, intrus dans la série des Héraclides. Explication d'esprit fort. Peu de gens durent l'admettre à Sparte: lorsqu'Agésilas eut été vaincu et l'hégémonie perdue, des traditionalistes rappelèrent certainement qu'il eût encore mieux valu se confier à un bâtard qu'à un boiteux. L'oracle nous est parvenu quatre fois, ce qui montre combien put être ressassée l'idée du caractère maléfique des infirmes. Le fait que Sparte se tient bien droite sur ses pieds accroît le caractère monstrueux de la royauté née d'elle : la fille n'est pas semblable à la mère. Celui qui a composé ce texte se souvenait du passage d'Hésiode au début des Travaux : il s'est borné à en donner une application pour un cas précis.

Rien mieux que les récits relatifs à Agésilas ne montre que les Spartiates faisaient parfaitement la distinction entre la notion de vigueur et celle de normalité. Ceux qui voulaient écarter Agésilas parce que boiteux le faisaient pour des motifs d'ordre purement religieux, et nul doute que Lysandre ait dû vaincre de leur part une résistance d'autant plus forte que leurs superstitions étaient plus tenaces. Par ailleurs, ces conservateurs savaient parfaitement qu'Agésilas était un prince vigoureux, énergique et bien entraîné. Il avait reçu la rude éducation des autres enfants de la noblesse et son infirmité ne l'avait jamais arrêté devant aucune fatigue ni aucune entreprise. Il avait mis toute sa coquetterie à vivre comme s'il n'avait pas été infirme. Ce qui effrayait les Spartiates, c'était le caractère mystérieux de la tare physique et non ses conséquences fonctionnelles ${ }^{37}$.

Il nous est impossible de savoir à quelle époque l'éviction des anormaux a été présentée à Sparte comme une méthode pour assurer la pureté de la race. Mais l'oracle attribué à Diopithès et les hésitations au moment de l'avènement d'Agésilas montrent qu'à la fin du $\mathrm{V}^{\mathrm{e}}$ siècle la distinction était encore parfaitement nette entre la notion de faiblesse physique et la notion de malformation maléfique. 


\section{§ 6. L'EXPOSITION DES ANORMAUX DANS L'ANCIENNE ROME}

79 Nous disposons ici de deux textes anciens. L'un est une loi attribuée par Denys d'Halicarnasse à Romulus. Ce texte est empreint d'un curieux rationalisme; on y voit le premier roi de Rome limitant le droit des parents à exposer les nouveau-nés et subordonnant toute la législation à l'intérêt de l'État. Il est impossible de savoir grand chose concernant l'historicité de ces dispositions. Ce qui est intéressant pour nous, c'est de constater qu'elles trouvent parfaitement place dans le cadre religieux qui se dessine peu à peu sous nos yeux. Le second document est une disposition des XII Tables, conservée par Cicéron.

81 A partir de ce moment, nous ne trouverons plus aucun texte de loi relatif à l'exposition des anormaux, mais un grand nombre d'anecdotes et de petits faits qu'il faudra essayer d'interpréter.

Denys d'Halicarnasse a conservé le renseignement suivant (Ant. R. II, 15) : Romulus obligea les habitants de la ville à nourrir toute la géniture mâle et, quant aux filles, les premières-nées; à ne faire périr nul enfant avant l'âge de trois ans, excepté s'il naissait infirme ou monstrueux, et, dans ce cas, tout de suite après la naissance. Ceux-là, il n'empêchait pas de les exposer pourvu qu'auparavant les géniteurs les eussent montrés à cinq hommes de leurs voisins ${ }^{38}$.

Ce passage contient plusieurs obscurités (s'agit-il des premières-nées des filles ou des premières-nées des enfants ?) mais il nous apporte des détails très intéressants. Il est le seul texte grec, qui, à propos d'une législation sur l'exposition, ait conservé le terme

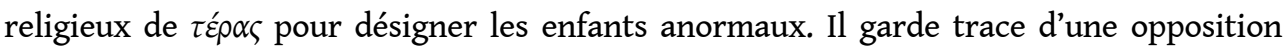
entre les populations superstitieuses, qui veulent se débarrasser des nouveau-nés difformes, et les esprits forts, qui se résignent à ces coutumes, mais prennent leurs précautions pour qu'elles ne conduisent pas à trop d'abus. Romulus institue un conseil de voisins qui décideront si la monstruosité est suffisante pour justifier l'abandon. Weiss, dans son commentaire à ce texte ${ }^{39}$, estime que ce «conseil » doit être une falsification hellénistique, car jamais on ne trouve de voisins dans les tribunaux de famille des Romains. Nous n'avons aucune raison de rejeter sur ce point le précieux témoignage de Denys, bien au contraire : la naissance d'un $\tau \dot{\varepsilon} p \alpha \varsigma$ est un symptôme de stérilité. La stérilité menace toute une terre, par conséquent il est judicieux et équitable de consulter tous ceux qui habitent dans les parages et qui peuvent tomber sous le coup du fléau. Remarquons aussi la différence d'époque entre les deux sortes d'abandon: le père qui veut se débarrasser d'un enfant parce qu'il est trop pauvre pour le nourrir doit attendre jusqu'à ce que le petit ait trois ans; l'idée atteste une étonnante finesse psychologique ; l'auteur de la loi sait que l'infanticide est fréquent sur les nouveau-nés et rare sur les enfants plus âgés. Au contraire, pour les enfants difformes, les parents ne sont pas obligés d'attendre ; il n'est même pas question de savoir si la monstruosité est curable. Le $\tau \dot{p} p \alpha \varsigma$ est dangereux : on l'écarte tout de suite. 
La loi des XII Tables paraît avoir été plus respectueuse que Romulus à l'égard des superstitions populaires qui condamnaient les enfants maléfiques. Romulus permettait de les exposer. Elle semble l'avoir ordonné. Malheureusement nous ne connaissons cette disposition que par un passage certainement altéré des Lois de Cicéron. Parlant (III, 19) de la puissance accordée par la loi aux tribuns du peuple, Quintus dit :

Mihi quidem pestifera uidetur, quippe quae in seditione et ad seditionem nata sit; cuius primum ortum si recordari uolumus inter arma ciuium et occupatis et obsessis urbis locis procreatum uidemus. Deinde cum esset cito † legatus + tamquam ex XII tabulis insignis ad deformitatem puer, breui tempore nescio quo pacto recreatus multoque taetrior et foedior renatus est.

"Quant à moi, je la trouve maléfique, à cause de son origine et de son résultat, la révolution; si nous remontons à sa naissance, nous la voyons apparaître parmi la guerre civile et dans les régions de l'État qui sont occupées, en état de siège. Puis, après avoir été rapidement... comme, aux termes de la loi des XII Tables, l'enfant atteint d'une monstruosité évidente, peu de temps après, je ne sais comment, elle a ressuscité plus laide et plus honteuse ».

Legatus est certainement une faute. Comment la corriger ? Le traitement infligé à l'enfant difforme était sans nul doute la mort, puisque la loi qui lui est comparée renaît alors qu'on ne s'y attendait pas. La correction necatus donne une bonne antithèse avec recreatus, mais ne vaut rien : on ne tue pas un enfant maléfique, on le laisse mourir. Ceux qui ont étudié ce texte n'ont pas pensé à le rapprocher d'autres où sont racontées des évictions authentiques. Julius Obsequens emploie dans ce cas, certainement d'après Tite-Live, le mot delatus, qui donne la correction la meilleure à tous égards et qui correspond aux

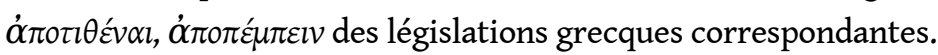

De plus, il est instructif de suivre l'image qui se développe dans l'esprit de Cicéron. La loi monstrueuse est née en temps de guerre et elle apporte la guerre, c'est pourquoi elle est pestifera. Comme les $\lambda$ oluoí des vieilles superstitions, elle apparait avec d'autres signes d'une malédiction divine dont elle est à la fois le résultat et le symptôme. Enfin, l'éviction des anormaux devait, d'après la loi des XII Tables, se faire vite (cito). Peut-être justifiaiton cette hâte en la présentant comme une précaution pour que l'enfant anormal ne renaisse pas (ou, plus exactement, pour que la terre ne le renvoie pas en la personne d'un frère aussi déshérité). Mais, ce qui est sûr, c'est qu'elle s'explique par le fait que l'enfant difforme est une souillure dangereuse, qu'il faut écarter au plus tôt.

\section{§ 7. L'ÉVICTION DES ANORMAUX PENDANT LES GUERRES DE LA RÉPUBLIQUE.}

87 A partir de la période républicaine, nous n'avons plus aucun texte de loi, mais les annales mentionnent quantité de naissances monstrueuses, végétales, animales et surtout humaines. Ces prodiges sont toujours considérés comme intéressant l'État, ce qui montre bien que le mal qu'ils annoncent - ou, plus exactement, le mal dont ils sont un des symptômes - menace toute la communauté. En effet, qu'on veuille bien se souvenir de ce que Tite-Live dit des prodiges privés, ceux auxquels on ne fait pas attention parce qu'ils arrivent in loco privato ou in loco peregrino ${ }^{40}$, on verra qu'à en juger par l'analogie les naissances anormales n'auraient pas dû être tenues pour des prodiges publics. Qu'une pluie de pierres ou une statue qui se met à brandir sa lance annoncent du malheur à toute une communauté, cela se comprend aisément. Mais une mule qui met bas ne devrait inquiéter seulement son propriétaire; un nouveau-né androgyne, uniquement ses 
parents ; exactement comme le palmier poussé en 171 dans la cour de Marcius Figulus fut considéré comme insignifiant pour ses concitoyens. Il n'en est rien. Les naissances anormales sont toujours expiées par ordre de l'État et à ses frais. Cela se comprend parfaitement si l'on se souvient que, depuis une haute antiquité, les $\tau \dot{\varepsilon} \rho \alpha \tau \alpha$ sont liés à la crainte de la stérilité collective. A vrai dire, cette idée était, chez les Romains, fort obscurcie. Le rituel seul en garde nettement la trace. Explicitement, ce que l'apparition d'un monstre fait redouter, c'est une guerre, une invasion, une calamité quelconque. Le terme de pestilentia, qui désigne souvent ces malheurs, ne nous dit rien sur leur nature. A moins qu'il n'ait un contexte descriptif. Il arrive du reste qu'une pestilentia apparaisse dans une liste de prodiges, comme signe de la colère des dieux ${ }^{41}$.

Il arrive assez souvent qu'on découvre des anormaux déjà grandis. L'État, comme nous le verrons, s'en empare et les fait non pas seulement disparaître, mais tuer. Jamais le narrateur ne nous dit que les parents aient été inquiétés pour avoir laissé vivre un enfant mal conformé. Cela semble indiquer que, dans la pratique, on s'inspirait de la vieille loi attribuée à Romulus, qui permettait aux parents d'exposer les $\tau \dot{\varepsilon} \rho \alpha \tau \alpha$, plutôt que de la disposition des XII Tables qui ordonnait de s'en débarrasser.

Les guerres et les invasions, la menace punique, la menace teutonne, s'accompagnent d'un grand nombre de prodiges: la peur fait qu'on remarque des choses qui auraient passé inaperçues en temps normal. Le sommet de la superstition semble avoir été atteint à Rome au moment de la seconde guerre punique. En 216, un Grec et une Grecque, un Gaulois et une Gauloise furent enterrés vifs dans le marché aux bestiaux, à un endroit où, déjà auparavant, on avait sacrifié des victimes humaines ${ }^{42}$. Polybe, avec un profond dégoût pour la superstition romaine, mentionne la grande peur qui s'empara alors de toute l'Italie ${ }^{43}$. Une simple lecture de Tite-Live, et, pour les décades qui nous manquent, du livre où Julius Obsequens a, d'après Tite-Live, inscrit les prodiges, permet de suivre le mouvement des superstitions. A mesure que les événements inquiétants deviennent plus nombreux, les cérémonies se compliquent et se multiplient. Ces rites seront étudiés plus loin. On s'est borné à les signaler ici, au passage, lorsqu'ils concernent uniquement et particulièrement une naissance anormale.

Tite-Live nous offre, pour la période qui va de 215 à 186, un important ensemble de documents explicites et souvent confirmés par ailleurs. Ils concernent principalement deux catégories d'anormaux maléfiques, les parleurs précoces et les androgynes.

De son temps, dit l'historien, on ne croit plus aux présages qui résultent des prodiges et on ne croit plus nécessaire de les consigner dans les annales ${ }^{44}$. Mais celles du passé relataient, parmi les anomalies effrayantes qui avaient nécessité des expiations, la naissance d'enfants monstrueux. Or, dans plusieurs cas, il nous paraît que le présage, en soi, aurait dû, d'après notre logique, être interprêté favorablement, par exemple lorsqu'un enfant dans le sein de sa mère s'écrie: «Io, triomphe!», qu'un enfant de six mois de naissance libre, crie «Triomphe!» en plein marché aux légumes ${ }^{45}$. Ces présages sont considérés avec effroi, en dépit de leur contenu favorable, à cause de leur origine: l'enfant anormal effraie. La parole articulée, apparaissant avant l'âge, est un mauvais signe $^{46}$. Tite-Live ne nous dit pas ce qu'on fit de ces parleurs précoces ni d'une petite fille née à Auxime, en 174, avec des dents (XLI, 21, 12). Mais il nous renseigne très explicitement sur le sort réservé aux hermaphrodites ${ }^{47}$, qui sont «conduits » à la mer. 
Dans un passage du XXVII livre relatif à l'année 207, on retrouve aggravées les vieilles précautions prises en Grèce pour l'éviction des anormaux ${ }^{48}$ : l'enfant, un hermaphrodite qui, à peine né, paraît avoir quatre ans, est placé vivant dans une caisse, écarté du territoire romain, mis à la mer loin des côtes, sans qu'il ait touché le sol. On l'écarte avec de grandes précautions, comme une souillure contagieuse ; une seule différence avec les pratiques grecques: ce sont des aruspices étrusques, et non un collège de vieillards représentant l'État, qui décident que le prodige est maléfique.

On retrouve ailleurs des faits et des prescriptions analogues ${ }^{49}$.

L'hermaphrodite est toujours inquiétant, qu'il soit un humain ou un animal. En 200 apparaissent en plusieurs endroits des bêtes difformes (animalium obscoeni foetus); un androgyne naît dans la Sabine, et on y découvre un autre hermaphrodite âgé de seize ans ; ailleurs naissent des animaux monstrueux : «toutes ces choses affreuses, hideuses, parurent être le fait d'une nature qui aurait confondu et brouillé les germes. On eut surtout horreur des hermaphrodites; ils furent conduits à la mer comme l'avait été précédemment un fotus atteint de la même étrangeté $»^{50}$. Ce passage est particulièrement instructif parce qu'il montre que, ce qu'on a en vue, c'est d'écarter l'enfant ou même simplement, le germe monstrueux. On le conduit à la mer (deportare correspond au grec $\dot{\alpha} \pi 0 \tau i \theta \dot{\varepsilon} v \alpha l)$. Les traducteurs ont tort de traduire par jeter: on usait certainement d'un procédé moins brutal, mais presque aussi sûr.

En 186, on découvre en Ombrie un hermaphrodite de douze ans. Cette fois, on ordonne de le faire porter au plus tôt hors du territoire et de le tuer, injonction que l'on rencontre ici pour la première fois, mais qui se comprend parfaitement bien. Un enfant de douze ans, abandonné dans la campagne, avait toutes les chances de survivre. Il ne s'agit plus ici d'un nouveau-né de qui l'exposition en plein air entraînait automatiquement la mort. Au surplus, le fait que, vers 200 avant J.-C., il y avait de grands enfants de sexe incertain indique peut-être que la croyance au caractère maléfique des androgynes allait s'atténuant. Mais, évidemment, il suffisait d'une guerre, d'une maladie, d'une «grande peur » pour ranimer le vieil effroi.

Bien entendu, des questions de personnes interviennent dans toutes ces histoires. En 193, dit Tite-Live (XXXV, 21), des prodiges apparaissent: une chèvre met bas six petits; à Arretium, il naît un enfant avec une seule main ; il pleut de la terre ; la foudre tombe. Un bœuf appartenant au consul $\mathrm{Cn}$. Domitius dit : « Rome, prends garde à toi » ${ }^{51}$. On expie les autres prodiges par des prières publiques, mais, pour le bœuf, les aruspices ordonnent de le garder et de le nourrir avec soin. Nul doute qu'ici les aruspices n'aient voulu faire leur cour au consul. En effet, les animaux parlants effrayaient les Romains au moins autant que les enfants trop précoces ${ }^{52}$. Le bœuf de $\mathrm{Cn}$. Domitius aurait dû être brûlé vif, comme ceux qui, en 191 (XXXV, 37), montèrent sur le toit d'une maison. C'est certainement aussi le sort qui échut à la chèvre aux six petits: une fécondité anormale effraie, comme une vigueur anormale, une aptitude trop précoce.

Tite-Live nous fait défaut à partir de 167. Mais Julius Obsequens, dans son Liber Prodigiorum, que nous avons pour la période qui va de 190 à 11 avant J.-C. (sauf quelques lacunes), a consigné, d'après Tite-Live, quantité de détails intéressants. Il relate la naissance d'un grand nombre d'animaux et d'enfants monstrueux, chargés de mains, de pieds ou de têtes surnuméraires. En général, il ne dit pas ce qu'on fait d'eux, probablement parce que ces pauvres êtres mouraient à peine nés ${ }^{53}$. Mais, dans certains cas, il précise la façon dont on s'en est débarrassé. 
97 En 136, une servante mit au monde un couple de frères siamois qui « fut brûlé par ordre des aruspisces et la cendre jetée à la mer $»^{54}$. Ce traitement est celui qu'on inflige aux animaux qui se sont trouvés dans les lieux où leur présence est jugée effrayante, comme les bœufs montés sur un toit, les guêpes trouvées en 193 dans le Forum ${ }^{55}$. Qu'on ait brûlé l'anormal de 136, cela semble indiquer qu'on ne reconnaissait pas en lui un être humain et, en tout cas, cela donne une idée de l'épouvante où les gens durent être.

98 En général, le nouveau-né est simplement transporté à la mer (delatus, deportatus, dejectus) . Ce traitement est presque toujours mentionné à propos des androgynes, probablement parce qu'ils naissent viables ${ }^{56}$. En dehors du couple siamois de 136, Obsequens ne dit jamais qu'on ait tué un nouveau-né. Mais on tue les androgynes que leurs parents ont sauvés à leur naissance et dont on dénonce l'existence quand apparaissent d'autres symptômes inquiétants. Et l'on peut s'imaginer ici les commérages villageois, les soupçons, les sournoises vengeances personnelles qui devaient précéder et accompagner ces lamentables exécutions d'enfants déjà grandis et capables de survivre si l'on n'aidait pas la mort.

99 Les enfants d'esclaves paraissent avoir joué, dans ces histoires, le rôle de l'âne de la fable. Obsequens raconte, comme Tite-Live, que l'androgyne de douze ans trouvé en Ombrie en 186 fut tué ${ }^{57}$; un autre, de huit ans, est in mare deportatus ${ }^{58}$; un autre, de dix ans, est mari demersus ${ }^{59}$. Rien n'égale l'esprit d'économie des anciens en matière de meurtre. Dès que la chose est possible, dès qu'on peut espérer que la mort suivra sans qu'on ait besoin d'intervenir davantage, on laisse les événements suivre leur cours.

100 Phlégon de Tralles $^{60}$ raconte qu'un androgyne naquit en 125 . C'étaient des temps troublés; un autre cas identique s'était déjà présenté en 133, lors des entreprises de Tiberius Gracchus. En 125, on recourut aux Livres Sibyllins qui prescrivaient des prières et un cérémonial sur lequel nous reviendrons. Nous avons en effet la bonne fortune d'y trouver un rituel concernant une naissance anormale et ne concernant qu'elle.

On porta à la mer, en 83 , sur l'ordre des aruspices, un serpent né d'une femme à Chiusi. Il se mit aussitôt à nager, et à contre-courant (OBS., ch. 57). L'ordalie était en sa faveur : les hommes avaient fait ce qu'ils pouvaient; ils avaient rejeté le mauvais présage; ils n'avaient plus rien à craindre.

102 Les expiations sont faites par des vierges, qui sont tantôt dix, tantôt vingt-sept, et par des enfants patrimi et matrimi ${ }^{61}$.

103 Trois fois, les naissances anormales sont mises en rapport avec la stérilité et la « pestilentia », exactement comme dans nos textes les plus anciens. Toutefois, il n'est pas facile de savoir ce que fut exactement cette pestilentia qui sévit en 142, en même temps que la famine, et qui amena les decemvirs à faire une supplication. « A Lune, il naquit un androgyne qui, sur le conseil des aruspices, fut conduit à la mer. Si terrible fut la peste de Lune que les cadavres gisaient par terre faute de gens pour les enterrer ${ }^{62}$. En 92, après plusieurs naissances monstrueuses d'enfants et d'animaux, on fait une supplication et l'on porte une offrande à Cérès et à Proserpine. Ce rite est accompli par tout le peuple ; vingtsept vierges purifient de plus la ville par des incantations ${ }^{63}$. La stérilité est une affaire qui intéresse tout le pays.

104 En 50, une mule met bas : «Cela signifiait citoyens en discorde, braves gens en perdition, lois bouleversées, matrones accouchant de rejetons inavouables ${ }^{64}$. On le voit : au moment de la jeunesse de Virgile, une erreur de la nature annonçait exactement les mêmes choses 
qu'au temps d'Hésiode, en vertu de cette solidarité des enfants de la Terre dont le sentiment n'a jamais changé dans le vieux monde.

\section{§ 8. LA CROYANCE AUX ANORMAUX MALÉFIQUES SOUS L'EMPIRE.} telle qu'elle figure chez tous les philosophes depuis Platon. Comme Platon et comme Aristote, comme Plutarque aussi, il laisse affleurer dans son exposé quelque chose qui trahit l'ancienne origine religieuse d'une pratique dont il se refuse à voir autre chose que l'aspect utilitaire: le rite de la noyade. Pour la première fois on trouve ici les enfants faibles et chétifs mis sur le même rang que les anormaux. A partir du jour où tout le monde a cru que l'on condamnait les infirmes, non parce qu'ils étaient difformes, mais parce qu'ils étaient moins robustes, les débiles ont dû être englobés dans le verdict de mort (purement théorique du reste). Quand Tite-Live désigne comme maléfique un hermaphrodite grand, à sa naissance, comme un enfant de quatre ans, il montre qu'en 207 on dissociait encore parfaitement la notion d'anomalie et celle de faiblesse. Senèque les juxtapose. Les historiens modernes s'y tromperont et les confondront.

110 La lecture de Pline ne confirme pas l'affirmation tranchante de Senèque. Les hermaphrodites, dit-il, ne sont plus considérés comme des prodigia, effrayants, mais bien au contraire comme un agréable jeu de la nature ${ }^{66}$. Naturellement, il n'est plus question de les mettre à mort. Les autres portenta sont encore tenus pour des curiosités plus ou moins inquiétantes. "Les membres surnuméraires sont inutiles aux êtres vivants, par exemple un sixième doigt pour l'homme. En Égypte, on s'est amusé à nourrir un monstre qui avait sur chaque face de la tête deux yeux, lesquels du reste n'y voyaient pas ${ }^{67}$. Sont maléfiques les enfants nés par présentation des pieds parce que cela est contraire à la nature qui veut que les hommes arrivent au monde la tête en avant et s'en aillent les pieds en avant. On les appelle Agrippas, «ut aegre partos». Marcus Agrippa est le seul de tous les hommes nés de cette manière qui fut heureux; encore connut-il bien des épreuves, et il apporta le malheur par ses deux filles, les deux Agrippine, mères de Caïus et de Néron. Celui-ci, cet ennemi du genre humain, sa mère écrit qu'il est né par présentation des pieds. Par tout cela, "Agrippa parait bien avoir justifié le mauvais augure qui résulte de sa naissance à rebours $»^{68}$. 
111 Évidemment, il y avait longtemps que personne ne songeait plus à mettre à mort un enfant de grande famille, fût-il même anormal et maléfique, - à supposer que ces mesures aient jamais été prises contre d'autres que de pauvres gens. Mais, dans le peuple, on devait murmurer en voyant les maux apportés à la collectivité par des êtres signalés par les dieux, dès leur naissance, comme calamiteux, et qu'on avait eu le tort de laisser vivre. Le passage de Pline nous donne un écho très exact de ces racontars, de ces sourdes protestations. Même dans les milieux éclairés, on se méfiait encore des anormaux. L'empereur Auguste s'écartait des nains et des gens contrefaits parce qu'il les considérait comme étant de mauvais augure ${ }^{69}$, ce qui ne l'empêche pas d'exhiber le nain Lucius qui ne mesurait que deux pieds, pesait dix-sept livres et avait une voix formidable ${ }^{70}$. La présence de nains et d'enfants contrefaits dans les grandes maisons romaines, la fabrication de monstres par les mangones à l'usage de la haute société ${ }^{11}$, c'est un sujet que nous n'avons pas à traiter ici. Toute l'évolution d'idées que cette coutume atteste est résumée par la phrase de Pline : Hermaphroditi olim in prodigiis habiti, nunc in deliciis (VII, 3).

112 Voilà pour les milieux riches du $\mathrm{I}^{\mathrm{er}}$ siècle de l'Empire, tels qu'ils apparaissent à travers Pline et Suétone. Des récits épars dans les recueils de Mirabilia montrent que la vieille croyance aux anormaux maléfiques subsistait dans le monde ancien. Phlégon de Tralles raconte d'après, dit-il, Hiéron d'Alexandrie ou d'Ephèse, personnage inconnu par ailleurs, l'histoire suivante ${ }^{72}$.

L'Étolien Polycrite, bienfaiteur de sa cité, meurt et sa femme, une Locrienne, met au monde un androgyne. Les proches, effrayés, apportent l'enfant à l'agora et provoquent une délibération, après avoir convoqué les sacrificateurs et les inspecteurs des prodiges ${ }^{73}$. Les uns pensent qu'il faut interpréter la chose comme un présage de guerre entre les Étoliens et les Locriens; les autres, qu'il faut transporter la mère et l'enfant au delà des frontières et les brûler ${ }^{74}$. Le père mort apparaît et demande grâce pour son enfant qu'il ne veut pas voir brûlé à cause de la folie des prêtres ${ }^{75}$. La foule refuse. Le revenant, alors, s'empare de l'enfant, le déchire et, tandis qu'on le lapide, mange le nouveau-né, à l'exception de la tête, puis il disparaît. La tête posée à terre vaticine, conseille au peuple de ne pas aller à Delphes et annonce une guerre entre les Étoliens et les Locriens, qui arrive en réalité. Elle demande aussi qu'on l'expose au levant et qu'on ne l'enfouisse pas dans le sol.

114 Faisons abstraction des additions horribles qui surchargent à plaisir cette anecdote et qui appartiennent à d'autres chapitres du folklore. Le récit de Phlégon prouve qu'à une époque tardive, exactement comme aux temps de Lycurgue et de Romulus, la naissance d'un anormal n'est pas une affaire privée, mais qu'elle intéresse toute la communauté. L'existence de l'enfant monstrueux est néfaste en soi, comme dans les cas rapportés par Tite-Live. Phlégon raconte que les devins étoliens veulent brûler l'enfant. On est tenté de considérer ce détail comme une exagération, le ton de Phlégon n'inspirant jamais qu'une confiance limitée. Mais, après tout, Obsequens, pour l'année 136, nous dit aussi qu'un couple siamois fut brûlé et les cendres jetées à la mer. Il n'est pas impossible qu'on ait voulu infliger à l'androgyne étolien le sort réservé à Rome aux animaux monstrueux ${ }^{76}$.

Relevons ici un fait absolument isolé. Le jour où l'on annonça dans Rome la mort de Germanicus, la foule, dans son désespoir, « lapida des temples, renversa des autels ; des Lares furent jetés dans la rue et des gens mariés exposèrent des enfants ${ }^{77}$. Il faut 
évidemment entendre: des enfants nés ce jour-là. Nous aurions donc ici une sorte de réciproque du théorème démontré plus haut. Normalement, on redoute les enfants anormaux parce qu'ils manifestent la colère des dieux. Ici, cette colère s'est manifestée par la mort de Germanicus. Un enfant né ce jour-là devait être atteint par la contagion du malheur commun. Mieux valait donc ne pas le laisser vivre. Peu importe, bien entendu, que le fait soit ou non historique. Ce qui nous intéresse, c'est l'esprit dans lequel il a été raconté et reçu. Et cet esprit est difficile à saisir parce que Suétone semble avoir groupé des actes qui appartiennent à des séries psychologiques différentes; la mort de Germanicus peut du reste avoir inspiré à certaines gens des actes d'hostilité à l'égard des dieux et, à d'autres, des actes de frayeur à l'égard des volontés divines mystérieusement manifestées.

\section{§ 9. LE TRAITEMENT DES ANORMAUX ET LES CROYANCES ANTIQUES.}

116 Aucun texte ne nous dit qu'on tue les nouveau-nés maléfiques, excepté le renseignement conservé par Denys d'Halicarnasse (Ant. Rom. 1, 84) relativement à la loi de Romulus, où $\dot{\alpha}$

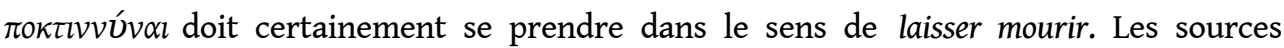
grecques disent toutes que l'enfant est exposé au loin; tel est probablement aussi le sens de la disposition correspondante de la loi des XII Tables. Les textes latins et grecs postérieurs à la loi des XII Tables, lorsqu'ils donnent un détail précis concernant le sort des anormaux, disent qu'on les porte à l'eau, fleuve ou mer. On parle explicitement de les noyer uniquement lorsqu'il s'agit d'enfants déjà grandis. Tout donne donc à penser que les autres, les nouveau-nés, n'étaient pas noyés immédiatement, mais mis sur l'eau dans une caisse (Tive-Live, XXVI, 37), qui, évidemment, ne tardait guère à se retourner. ${ }^{78}$

117 Cette façon de procéder implique un double sentiment.

1. Les anciens détestent donner la mort. Ils préfèrent mettre le condamné dans une situation telle que la mort paraisse résulter, soit de sa volonté personnelle, soit du jeu des lois de la nature. Socrate boit lui-même la ciguë qu'on lui apporte. Antigone est emmurée vive : si elle se pend dans le caveau, c'est qu'elle l'a bien voulu. Il est difficile de savoir jusqu'à quel point les anciens considéraient les nouveau-nés anormaux comme des êtres humains. Mais une

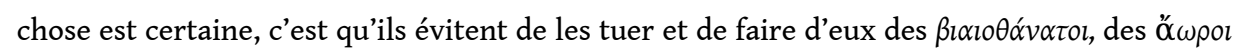
irrités, malfaisants.

2. L'exposition des nouveau-nés implique un recours aux dieux. On remet les enfants à la volonté divine qui agira à son gré. Les hommes préfèrent ne pas s'aventurer plus loin. Ils s'arrangent, du reste, pour que les exposés ne survivent jamais. Ce qui le prouve, c'est que les anormaux grandis étaient exclus du bénéfice de l'ordalie. Ils auraient eu trop de chances d'échapper à la mort : on les tuait tout de suite.

118 Deux textes mentionnent un «monstre » qui a été brûlé et ses cendres jetées à la mer ( supra p. 57 et 62). Le récit de Phlégon est tellement surchargé d'absurdités qu'on le récuserait s'il était isolé. Mais le rapprochement avec le compilateur de Tive-Live donne à penser que, dans quelques cas particulièrement effrayants, on procédait ainsi, traitant les êtres humains comme des animaux redoutables. Dans l'Heracliscos attribué à Théocrite (89 sqq), Tirésias conseille à Alcmène de faire brûler les serpents qui ont menacé Hercule et de jeter la cendre à la mer. Tive-Live, nous l'avons dit, a conservé des récits analogues (XXXV, 9; XXXVI, 37), Macrobe (III, 20,3) parle de plantes funestes et monstrueuses 
qu'on brûle, d'après un règlement attribué à Tarquin l'Ancien; Pline, d'un corbeau parlant brûlé sous Tibère (Hist. N., X, 122).

Tenons-nous en aux coutumes les mieux attestées: l'exposition en un lieu désert, qui paraît bien avoir été la pratique courante en Grèce ; l'exposition sur l'eau qui est de règle à Rome et qui paraît résulter d'une influence étrusque. Dans les deux cas, l'enfant n'est $n i$ enterré, ni enfoui. Le passage d'ÆEdipe-Roi dit très clairement qu'il gît par terre sans être

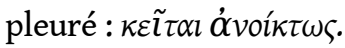

Rapprochons cela d'un vers de Juvénal qui dit que les petits enfants ne sont jamais brûlés, mais enterrés; d'une phrase de Pline qui donne le même renseignement pour les nourrissons n'ayant pas encore de dents, et qui affirme que c'est là une coutume, non seulement romaine, mais universelle ; et relisons l'explication que propose Dieterich ${ }^{79}$.

Dieterich suppose que les parents rendent intact à la terre le corps d'un enfant mort prématurément, afin qu'elle, qui est koupotpó $\varphi$ os, leur renvoie cet enfant en la personne d'un frère plus heureux. Le fait que les monstres ne sont pas enterrés cadre parfaitement avec cette hypothèse : on évite d'inhumer un anormal, parce qu'on ne souhaite nullement le voir ressusciter. On l'expose pour que son corps se disperse le plus vite possible. La famille ne se livre à aucune manifestation, de peur que le ghost-child ne la retrouve et ne renaisse chez elle aussi malencontreusement que la première fois. Peut-être à cette crainte s'ajoute-t-il une autre idée, qui est que la Terre est la mère des monstres et qu'il ne faut pas lui donner, en un cadavre d'enfant anormal, une sorte d'aliment, de semence pour d'autres naissances déplorables.

Ce qui est sûr, c'est qu'à partir des renseignements rapportés par Tite-Live et relatifs aux temps troublés de la seconde guerre punique, le scrupule augmente. Non seulement on n'enterre pas le cadavre, mais on évite que l'enfant vivant touche la terre, et on le porte le plus vite possible à la mer ou au fleuve. Tout donne à penser que cette minutie vient des règlements étrusques auxquels Tive-Live se réfère formellement, la première fois qu'il signale une naissance d'androgyne (XXVII, 37, année 207).

Toutefois, ces règlements ne devaient pas être en contradiction avec les vieilles pratiques romaines. Tout au plus étaient-ils plus stricts, plus scrupuleux, plus minutieux dans l'ordonnance des cérémonies. En effet, lorsque Cicéron parle de l'apport des peuples étrangers pour l'interprétation divinatoire, il parle de la compétence des Chaldéens en matière d'astrologie, des Étrusques en fait de météores ; aucun peuple ne paraît avoir rien ajouté d'essentiel aux pratiques romaines relatives aux anormaux (de Div., 92-121)

On peut se demander pourquoi on portait l'anormal à l'eau. Était-ce uniquement pour empêcher tout contact entre lui et la terre ? C'est possible. Un être débile qu'on préfère ne pas tuer et qu'on ne veut pas mettre en contact avec le sol, que pourrait-on en faire sinon le placer sur l'eau dans un esquif destiné à sombrer? Cependant, un détail rend peu satisfaisante cette explication purement négative. Les androgynes grandis étaient jetés à l'eau. Il semble donc bien qu'il y avait là une intention précise et générale. Voyait-on dans l'eau un véhicule capable d'emporter la souillure le plus loin possible? ou l'élément purificateur capable de la laver? Il est bien difficile de le savoir. ${ }^{80}$ 


\section{NOTES}

1. LÉVY-BRUHL, Fonctions mentales dans les soc. inf., p. $117:$ : Un signe est presque toujours pris pour une cause »; Mentalité primitive, p. 145: «les présages sont des signes infaillibles de ce qui arrivera, car ce qui est présage est en même temps cause ».

2. Phil, 5 sqq. Iliade II, 721 sqq. Cf. Appendice III.

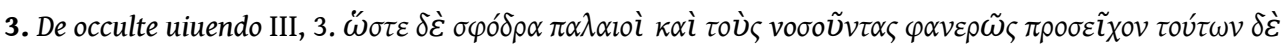

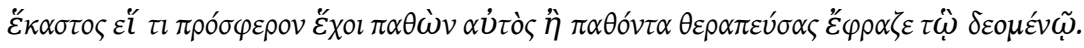

4. Mutter Erde, p. 26 ; il néglige de citer Soph. Phil. 819. - SAMTER, Neue Jahrb. f. Klass. A. 1905, pp. 34 ss.

5. NONIUS MARC. De comp. doctr. p. 279, 24, groupe les exemples. - SERV. ad Æn. XII, 395, apud ueteres consuetudo erat ut desperati ante ianuas suas collocarentur.

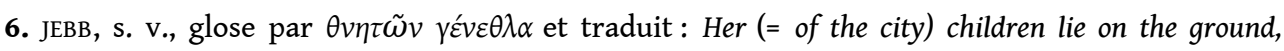
spreading pestilence. CAMPBELL et АВВОТT: Corpses. Hermann annote simplement $\theta \alpha v \alpha \tau \alpha \varphi \rho_{\rho} \alpha$ :

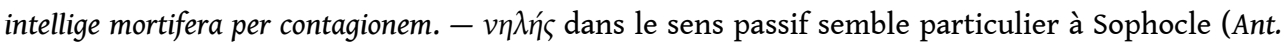

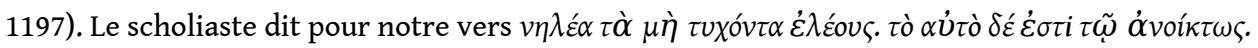

7. EUR. Suppl. 763.

8. Très peu de textes mentionnent des cas où l'on renonça à enterrer les morts. TITE-LIVE le dit à propos de la peste de Syracuse (XXV, 26: 212 avant J.-C), et, là, le fait s'explique par le manque d'esclaves. Cf. aussi, p. 59 et n. 1.

9. GLOTZ, Solidarité familiale, p. 29. «Le genos qui l'avait expulsé ne le recevait pas dans le tombeau commun. La privation de sépulture accompagnait forcément le bannissement ou l'infamie ».

10. JоввÉ-DUVAL, Les morts malfaisants, "laruae, lemures ", d'après le droit et les croyances populaires des Romains. Paris, Recueil Sirey, 1924. - HILD, Daemon dans Daremberg-Saglio-Pottier, p. 17, col 2. - HUBERT, Magia, ibid. p. 1512, col. 1. - JACOBSEN, Les Manes, Paris, 1924.

11. WUNDT, Voelkerpsychologie, II, Myth. И. Rel., 1906, p. 480.

12. VAN GENNEP, Les Rites de passage, p. 218. - LÉVY-BRUHL, Mentalité primitive, pp. 257 sqq., dit que l'enfant mort-né ou mort à peine né ne compte pas, c'est un « ghost-child ». Cf. aussi LÉVY-BRUHL, Fonctions mentales dans les sociétés inférieures, pp. 400, 405.

13. Le texte classique, JUV. XV, 140 : Terra clauditur infans et minor igne rogi est appuyé par d'autres et par des découvertes archéologiques, qu'on trouvera relevés par DIETERICH, Mutter Erde, pp. 21 sqq. Cf. ET. AYMONIER, Rev. hist. des rel. XXIV (1892) p. 267.

14. JOBBÉ-DUVAL, Morts malf. p. 102. - HUBERT, Magia dans Dar.-S.-Pott., p. 1512, col. 1. - RIESS, Aberglaube, dans Pauly-Wiss., col. 92 : «Beides, ein frühes Sterben und gewaltsamer Tod machte die Seele fähig, ein magischer Paredros zu werden ».

15. HIRZEL, Der Selbstmord. Arch. f. Relig. XI (1908), pp. 433 sqq. ; JACOBSEN, Les Manes, III, p. 139, n., pense au contraire que la règle générale était de refuser la sépulture aux suicidés et qu'il ne faut rien conclure des exemples de « suicides glorieux » qui sont tous pris parmi l'aristocratie et dans les derniers temps de l'Empire. Mais Jacobsen est influencé par son désir de démontrer que les croyances chrétiennes, à partir de Constantin, sont toutes pénétrées par les croyances romaines relatives à l'outre-tombe. Son affirmation ne saurait prévaloir sur la solide démonstration de Hirzel.

16. JOBBÉ-DUVAL, Morts malf., pp. 44 sqq.

17. JоввÉ-DUVAL, Morts malf. p. 64 ; Choéph. 439 ; SOPH. El. 445.

18. GLotZ, art. Expositio dans Daremb.-Saglio-Pott., p. 933. Loi de Gortyne, III, 44. 17. 


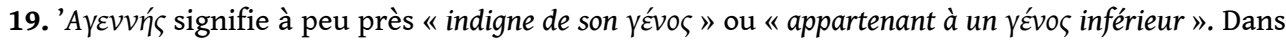

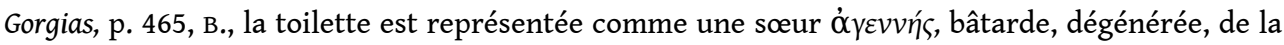

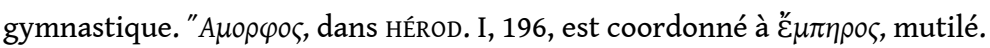

20. Ainsi l'entend GLOTZ, dans Daremb.-Sagl.-Pott. s. v. Expositio.

21. Plut. Alc. 23, Agés. 3 ; XÉN. Hell. III, 2 ; Auguste, tenant pour illégitime l'enfant que sa petitefille Julia mit au monde après avoir été condamnée, interdit de la reconnaître et de l'élever ( cognosci aligue vetuit, SUÉT. Aug. 65). Mais l'enfant ne fut certainement pas exposé.

22. Mentalité primitive, p. 159.

23. Arch. für Religions wiss. IX (1906), pp. 397 sqq. - S. REINACH, Cultes, mythes et religions, I, pp. 173 sqq.

24. Die Grundlagen des spart. Lebens, dans Klio, XII, pp. 308 sqq.

25. La cryptie lacédémonienne, Rev. Et. Gr., 1913, pp. 121 sqq. - Ernst Kessler, qui a fait une étude sur Plutarchs Lebens des Lyk. (dans les Quellen und Forsch. zur alten Gesch. u. Geogr. hgg. v. Sieglin, Berlin, 1910), ne paraît pas avoir soupçonné l'aspect religieux des institutions lacédémoniennes. Au contraire, LÉVY-BRUHL (Mentalité primitive, p. 169) a très bien vu le caractère religieux des évictions Spartiates, mais sans les rattacher à leur véritable contexte de croyances.

26. On connaît le beau livre de F. OLLIER, Le Mirage Spartiate, où il a étudié l'influence de la constitution laconienne, ou de l'image que l'on se faisait d'elle sur les philosophes jusqu'aux cyniques. On espère que $M$. Ollier reprendra ces recherches. Elles seront particulièrement fécondes pour la seconde moitié du IV ${ }^{\mathrm{e}}$ siècle.

27. PLAT. Crat. 393 B, 394 A et D.

28. Hist. Var. II, 7. Elien distingue encore très bien entre l'ह̌ $\kappa \theta \varepsilon \sigma \zeta$ où les parents souhaitent que

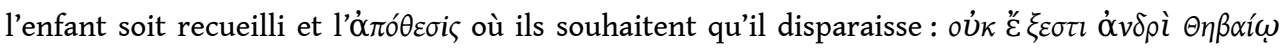

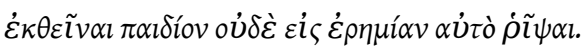

29. Newmann, dans la note à ce passage de son édition de la Politique, se demande si $\dot{\alpha} \pi o ́ \theta \varepsilon \sigma \iota \varsigma$ se rencontre ailleurs dans le sens d'exposition. Denys d'Halicarnasse (Ant. R. I, 84) parle de l'ó $\pi$ ó $\theta \varepsilon \sigma i s$ $\tau \tilde{\omega} v \beta \rho \varepsilon \varphi \tilde{\omega} v$ à propos de Romulus et Rémus, qui étaient probablement des enfants maléfiques, sans qu'on sache exactement pourquoi (vide infra, p. 104). Faut-il rappeler que Platon dit $\dot{\alpha}$

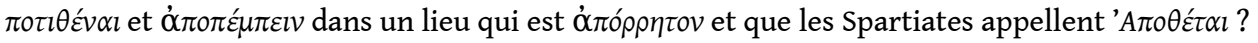

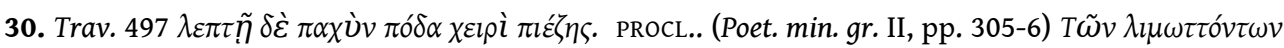

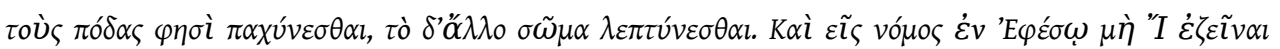

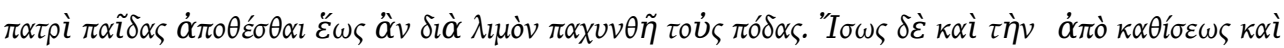

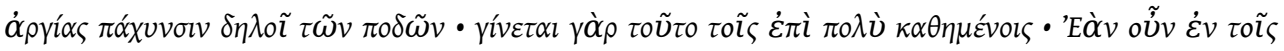

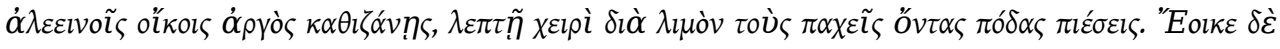

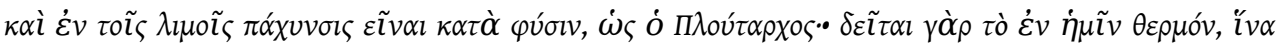

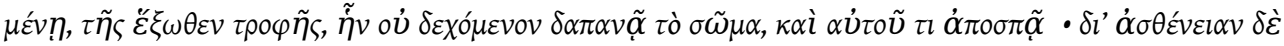

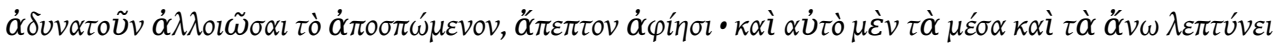

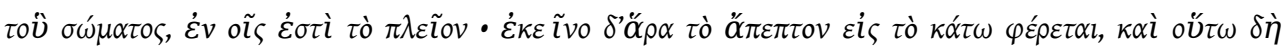

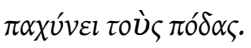

31. M. Hubaux me signale un vers du Catalepton Virgilii (XIII, 40) : pedes inedia turgidos et la description de la Faim aux articulations enflées telle que la donne Ovide (Metam., VIII, 730 sqq) : immodico prodibant tubere tali.

32. Sur CEdipe nouveau-né maléfique, cf. Append. I, p. 94 sqq.

33. Tous les passages ont été réunis par P. STEIN, TÉp $\alpha \zeta$, diss. de Marbourg, 1919, dans un ordre malheureusement absurde. Cf. notamment pp. 32 sqq. et Iliade, II, 308-319, Od., III, 173 ; PLATON, Crat. 393 B, 394 A et D. 
34. C'est, on le sait, la position des stoïciens et aussi celle de Plutarque commentant, par exemple, l'épisode du bélier monstrueux de Péricles (Pér. 6). Cf. к. STEINHAUSER, Der Prodigienglaube u. das Prodigienwesen der Griechen, diss. de Tubingue, 1911, pp. 1 sqq.

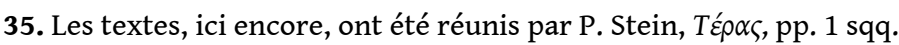

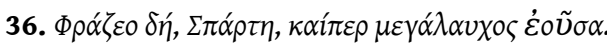

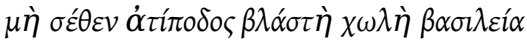

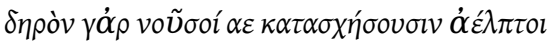

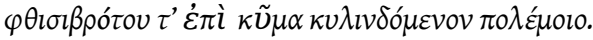

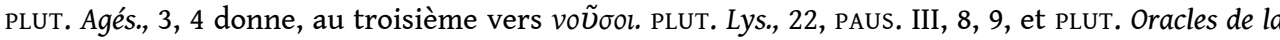
Pythie, XI, donnent $\mu$ ó $\theta 0$. Les quelques variantes sont sans intérêt. Plusieurs mss, suivis par les éditeurs anciens, ne pouvant comprendre comment la seule apparition d'une "royauté boiteuse " nuirait à la ville, corrigeaient $\beta \lambda \alpha ́ \sigma \tau \eta ̣$ donné chaque fois par la bonne tradition en $\beta \lambda \alpha ́ \psi \eta \eta$. Cf. l'excellente note de R. FLACELIÈrE, dans son édition des Oracles de la Pythie, p. 161, n. 32.

37. Rien de semblable n'affleure dans la légende de Tyrtée. Les traditions qui font de lui un infirme sont tardives; elles soulignent simplement l'absurdité qu'il y a à faire d'un boiteux un chef militaire; ce sont les conséquences fonctionnelles de l'infirmité et non ses conséquences religieuses qui rendent le choix dérisoire.

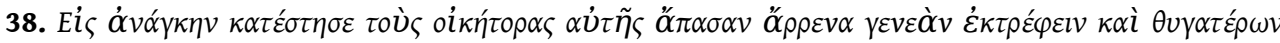

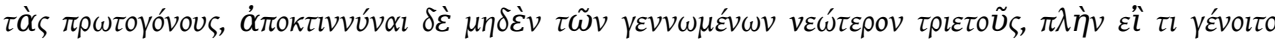

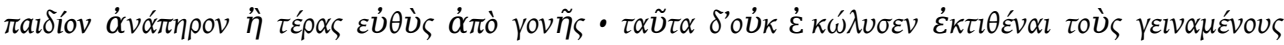

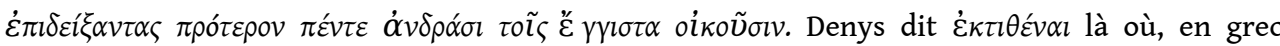

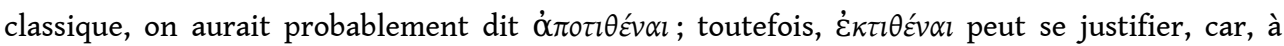

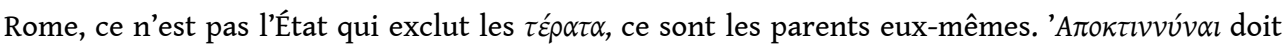
se prendre comme une brachylogie: dans des cas de ce genre, les Anciens laissent simplement

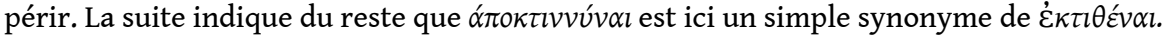

39. S. v. Kinderaussetzung dans Pauly-Wiss., XI, I, p. 466. - Cf. MORITZ VOIGT, Leges Regiae, Abh. d. phil.-hist. Kl.d. Kön. sächs. Ges. der Wiss., 1879.

40. TITE-LIVE, XLIII, 13, 6. Tous les textes ont été réunis, sinon interprétés, par M. WÜLKER, Die geschichtl. Entwicklung des Prodigienwesens bei den Römern, diss. de Leipzig, 1903. Wülker se place au point de vue du droit religieux des Romains et n'interroge pas les coutumes pour y découvrir des croyances profondes.

41. Cf. L. WÜLKER, Prodigienwesen bei den Römern, p. 21 et 22.

42. TITE-LIVE, XXII, 57, 4.

43. III, 112, 6. M. René Henry veut bien me signaler un passage de Diodore conservé par РнотіUs (379, A, 6 sqq), où l'historien blâme également la superstition de ceux qui considèrent soit les changements de sexe, soit l'apparition d'androgynes, comme un signe fâcheux. - On ne s'est pas occupé ici de réunir les cas de changement de sexe : ce sont des prodiges effrayants; ceux qui en sont l'objet sont exilés ou mis à mort (TITE-LIVE, XXIV, 10, 10).

44. XLIII, 15. Non sum nescius ab eadem negligentia qua nihil deos portendere uulgo nunc credant, neque nuntiari admodum nulla prodigio in publicum, neque in annales referri.

45. XXIV, 10, pour l'année 214 ; XXI, 62, pour l'année 218. Peu importe que les faits rapportés soient absurdes et sûrement faux. Ce que Tite-Live nous apporte, c'est la réaction authentique du peuple lorsqu'on lui racontait ces sornettes.

46. CICÉRON (de Div. 121) fait dire à son frère ceci : Scribit Herodotus Croesi filium, cum esset infans, locutum, quo ostento regnum patris et domum funditus concidisse. Or, Hérodote raconte tout autre chose, à savoir qu'un fils de Crésus, muet depuis l'enfance, guérit au moment de la prise de Sardes, le grand malheur annoncé par l'oracle. On conclurait simplement à une erreur de Cicéron si l'on ne trouvait dans PLINE (XI, 112, 4): Semestris locutus est Croesi filius in crepundiis : quo prodigio totum id concidit regnum. A première lecture, les deux versions semblent indépendantes l'une de 
l'autre. M. Jastrow (Religionsg. Vers. u. Vorarb., 14, 1914, p. 57) pense que Cicéron et Pline ont l'un et l'autre eu connaissance d'une bonne tradition relative à cette légende. Dans cette version archaïque conservée par les deux auteurs latins, on voyait un parleur précoce, anormal et maléfique. Hérodote l'aurait rationalisée en lui substituant l'histoire banale d'un muet recouvrant la parole à la faveur d'une secousse psychologique. L'explication est séduisante, mais peu convaincante : en effet, le caractère maléfique des parleurs précoces n'est signalé nulle part dans l'antiquité grecque, alors qu'il est mentionné quantité de fois dans les textes latins. Et la référence erronée de Cicéron montre qu'il n'a pas d'autre source que le récit d'Hérodote qu'il cite de mémoire et inexactement. Reste à savoir si Pline dépend de Cicéron pour ce renseignement. M. A. S. Pease (Class. Phil. XV, 1920, p. 201) répond affirmativement. Il pense que Cicéron prend infans dans son sens étymologique de mutus. Cicéron aurait donc bien lu Hérodote, mais Pline aurait mal compris Cicéron. Cette explication attribue à Cicéron une préciosité dont il est certainement innocent. Il parait plus simple d'expliquer les choses comme ceci : Cicéron cite de mémoire une anecdote rapportée par Hérodote; il modifie l'histoire sous l'influence des superstitions romaines relatives au caractère maléfique des parleurs précoces. Pline, qui veut apporter des preuves de ce caractère, trouve l'anecdote lydienne chez Cicéron. Il se reporte à Hérodote et s'aperçoit qu'elle ne vient pas de cet auteur. Au lieu de conclure que Cicéron s'est trompé sur le fond du récit, il estime qu'il s'est trompé en mentionnant sa source. L'interprétation de Pline se comprend d'autant mieux que l'anecdote lydienne dans la version de Cicéron sert sa thèse à lui, Pline : on renonce difficilement à un bon argument. Semestris est une précision que Pline s'est cru autorisé à emprunter à Tite-Live, qui la donne à propos d'une autre histoire de parleur précoce (XXI, 62).

47. L'hermaphrodisme vrai est rarissime. Un ami médecin me dit que les anciens devaient appeler de ce nom l'hypospadias. Cf. Appendice IV.

48. TITE-LIVE XXVII, 37. Id uero aruspices ex Etruria acciti foedum ac turpe prodigium dicere: extorrem agro romano procul terrae contactu alto mergendum vivum in arcam condidere, prouectumque in mare proiecerunt. Le traducteur de l'édition Garnier, qui ne comprend plus la valeur religieuse de procul terrae contactu, entend: "Il fallait purger de ce monstre le sol du continent et le plonger dans l'abîme des mers ». Rien, mieux que de telles altérations du ton, ne dissimule la substance même d'un texte.

49. TITE-LIVE XXVII, II, 4 (naissance d'un enfant à tête d'éléphant, consignée également dans PLUT. Marc, 28, 2) et XXVIII, II, 3 (années 207-208) : animaux monstrueux.

50. TITE-LIVE XXXI, 12, 8. Foeda omnia et deformia errantisque in alienos foetus naturae uisa. Ante omnia abominati seminares iussique in mare extemplo deportari : sicut proxime C. Claudio M. Livio consulibus deportatus similis prodigii foetus erat (201 avant J.-C).

51. TITE-LIVE XXXIX, 22, 5. Id prodigium abominantes arceri Romano agro necarique quam primum iusserunt.

52. L. WÜLKER, Prodigienwesen bei den Römern, pp. 15 sqq. a réuni tous les textes.

53. Lib. Prodig. 12 (année 166) ; 14 (163) ; 20 (147) ; 21 (143) ; 40 (108) naissance de deux jumeaux, une fille bien conformée et un garçon né sans paroi ventrale, lequel meurt aussitôt ; 41 (année 106) : un parleur précoce, l'enfant d'une servante qui dit ave, à peine les yeux ouverts ; 50 (année 95) ; 52(93) ; 53 (92) : l'enfant d'une servante naît sans orifices naturels; il a évidemment dû mourir de mort naturelle après quelques jours.

54. Lib. Prodig. 25 : puer ex ancilla quattuor pedibus, manibus, ocuiis, auribus, et duplici obscoeno... aruspicum iussu crematus cinisque eius in mare deiectus.

55. TITE-LIVE XXXV, 9,4; XXXVI, 37. 1.

56. Lib. Prodig. 22 (année 142); 27 A (133) ; 32 (122) ; 47 (98); 5 (95) ; 53 (92).

57. Lib. Prodig. 4 In Umbria semimas duodecim ferme annorum + natus + aruspicumque iussu necatus. Barth corrige en inventus; Rossbach (d'après Hase), dans son édition de Julius Obsequens, propose : annos natus aruspicum. La correction de Barth est certainement préférable, car ces listes 
de prodiges mentionnent plus de nouveau-nés que d'enfants grandis : la substitution de natus à inventus s'explique donc parfaitement. Rossbach a tort de renvoyer au ch. 22 où il est question d'un androgyne qui vient de naître ; le nouveau-né et l'enfant déjà grand ne sont pas traités de la même façon.

58. Lib. Prodig. 32 (année 122).

59. Lib. Prodig. 36 (année 117).

60. Scriptores rerum mirabilium Graeci, ed. Westennann, 1839, p. 133, 10 sqq. Julius Obsequens présente une lacune pour l'année 125.

61. JULIUS OBSEQUENS, ch. 1 (année 190) ; 27 A (133) ; 34 (119) ; 36 (117) ; 40 (108); 53 (92) ; Enfants patrimi matrimi mentionnés 1 (190) et 40 (108).

62. Ch. 22 : Fames et pestilentia cumessent, per decemuiros supplicatum. Lunae androgynus natus praecepto aruspicum in mare deportatus. Tanta fuit Lunensibus pestilentia ut iacentibus in publicum cadaueribus qui fumrarent defuerint.

63. Ch. 53.

64. Ch. 65 : Mula pariens discordiam ciuium, bonorum interitum, mutationem legum, turpes matronarum partus significauit.

65. De Ira, 1, 15. Portentosos foetus exstinguimus, liberos quoque, si debiles monstruosique sunt, mer gimus. Non ira, sed ratio est, a sanis inutilia secernere.

66. Hist. Nat. VII, 3.

67. Hist. Nat. XI, 113.

68. Hist. Nat. X, VII, 3 : luisse pratposteri natalis augurium existimatur.

69. Suét. Aug. 83 : pumilos atque distortos et omnes generis eiusdem, ut ludi-bria naturae malique ominis abhorrebat.

70. SUÉT. Aug. 43.

71. LONGIN, De subl. 44, 5 .

72. Scriptores rerum mirabilium graeci ed Westermann, Brunswick, 1839, pp. 121 sqq.

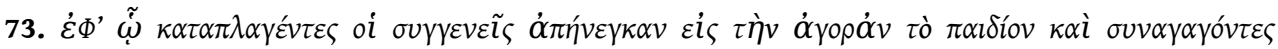

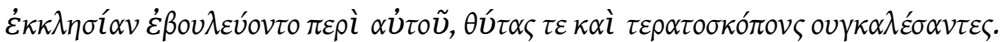

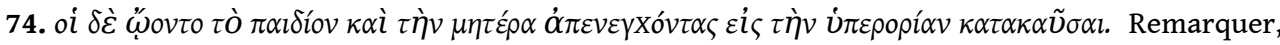

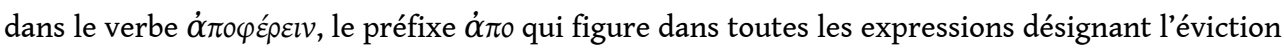
des êtres maléfiques. 'Y $Y \varepsilon \rho \rho \rho i ́ \alpha v$ rend exactement la même idée que le extorrem de Tite-Live (supra ,p. 55, n. 2).

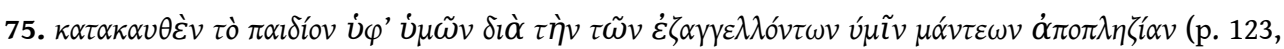
Scepticisme assez imprévu dans cette étrange histoire.

76. Friedersdorf, dans son éd. de Tite-Live (XXVII, 37, note à extorrem), dit que les androgynes étaient conduits dans des îles désertes et brûlés. Friedersdorf, qui n'indique aucune référence, ne peut guère en avoir d'autres que les deux passages ci-dessus, qui ne permettent nullement une conclusion aussi générale. Ce détail erroné a passé dans G. WIssowA, Relig. u. Kultus der Römer, $2^{\mathrm{e}}$ éd. p. 546. - L'empereur Maurice (mort en 602) fit tuer en Thrace un monstre que ses parents exhibaient pour de l'argent ; à la même époque, on s'inquiétait à Byzance à propos de naissances anormales (THÉOPHYLACTE, Hist. VI, I et II, signalé par M. Henry)

77. sUÉTONE, Calig. 5: quo defunctus est die, lapidata sunt templa, subuersae deum arae, Lares a quibusdam familiares in publicum abiecti, partus coniugum expositi. M. J. Hubaux a bien voulu me rendre attentive à ce passage. - Cf. LÉVY-BRUHL, Surnaturel et nature dans la ment. prim., p. 19: on abandonne les enfants nés aux jours néfastes.

78. LÉVY-BRUHL, Mentalité primitive, pp. 159, signalant l'éviction des nouveau-nés anormaux, générale chez les peuples qu'il étudie, relève des cas où l'enfant est abandonné, par exemple près d'une rivière, le soir, à l'endroit où les fauves viennent boire. Dans d'autres cas, l'enfant, dit-il, est tué. Cela est possible, mais souvent le missionnaire ou l'ethnographe qui fournit le 
renseignement abrège et dit qu'on tue alors que simplement on s'arrange pour laisser mourir, sans s'apercevoir que ces deux termes, psychologiquement parlant, ne sont nullement synonymes.

79. JUV. XV, 140. Terra clauditur infans et minor igne rogi. - PLINE VII, 7,2. Hominem prius quam genito dente cremari mos gentium non est. - A. DIETERICH. Mutter Erde, pp. 21 sqq.

80. «Il est remarquable, me dit M. Jeanmaire, que l'extermination des monstres par immersion soit propre à Rome et non attestée en Grèce ; à Athènes, la hache des Bouphonies est cependant jetée à la mer ». Cela est exact, mais il faut remarquer d'abord, que les Grecs parlent le moins possible et de l'aspect physique des monstres et du traitement qu'on leur fait subir; ensuite, que nous ignorons tout de ces "trous ", de ces lieux mystérieux où se faisaient les évictions. C'étaient peut-être des lits de torrent. 


\section{Chapitre III. Les remèdes aux Fléaux}

1 Un Fléau est causé par une impiété. C'est une punition collective qui frappe les innocents avec les coupables. La première chose que tentera le peuple éprouvé, c'est de savoir qui est le coupable, après quoi on fera tout pour rompre le lien de solidarité qui l'unit à son groupe. Cela fait, il faut arrêter la faute et la faire expier. Une fois ces satisfactions

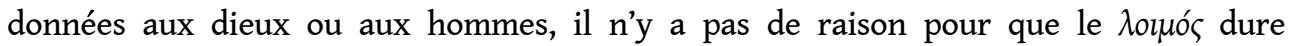
davantage ${ }^{1}$.

De nombreuses légendes sont construites selon ce premier schéma.

3 Dans $\mathbb{E}$ dipe-Roi, la malédiction résulte de la présence d'un coupable inconnu, c'est-à-dire

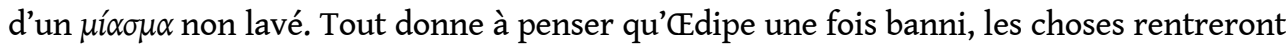
dans l'ordre. Alcméon meurtrier de sa mère épouse Arsinoé; la terre devient stérile (entendons probablement : et Arsinoé n'a pas d'enfants); l'oracle conseille à Alcméon de s'exiler². Parfois les dieux demandent que le coupable leur soit livré. Lycurgue roi des Edones tue son fils ; une stérilité s'ensuit : le dieu dit que la terre se remettra à donner des fruits si Lycurgue meurt. Les Edones exposent Lycurgue lié sur le Pangée; des chevaux le mettent en pièces. On reconnaît ici le recours à l'ordalie ${ }^{3}$. Même sentiment dans la légende d'Augé fille d'Aléos. Elle expose son enfant dans le téménos d'Athéna. Survient une stérilité. Aléos trouve l'enfant et le fait exposer sur une montagne où il est miraculeusement sauvét. Parfois, une légende a conservé un détail d'une étrange spiritualité : Pélops a commis un crime, toute la Grèce cesse de produire des fruits. Les oracles des dieux disent que le mal cessera si Eaque prie pour le pays ${ }^{5}$.

Mais, le plus souvent, les dieux exigent une victime et, dans leur choix, la notion de

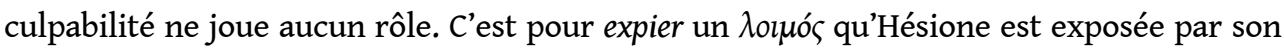
père Laomédon, que Ménécée est sacrifié par le sien ${ }^{6}$. Sous Busiris survient en Égypte une stérilité de neuf ans; Phrasios arrive de Chypre et dit qu'il faut sacrifier un étranger tous les ans; Busiris fait tuer d'abord Phrasios, puis tous les étrangers qui arrivent ${ }^{7}$. Minos assiège Athènes. Une famine et une stérilité éprouvent la ville. Les Athéniens égorgent les cinq filles de Hyacinthos sur le tombeau du Cyclope Geraistos. Cela ne sert à rien. L'oracle dit qu'il faut donner satisfaction à Minos, auquel on envoie alors, pour la première fois, les sept jeunes gens et les sept jeunes filles ${ }^{8}$. On a lu plus haut comment Ino fabrique un $\lambda$ toı́ó et une réponse d'oracle qui demande le sacrifice de son beau-fils Phrixos. 
On voit le rôle que jouaient dans ces expiations les jeunes gens et les jeunes filles vierges. Ce détail, nous allons le retrouver à travers tous les siècles, lié à la question des stérilités et des naissances anormales. Qu'on veuille bien se souvenir que, dans Edipe-Roi (18), ce sont des adolescents vierges qui escortent le grand-prêtre. Ce détail, qui se retrouve dans le Chant Séculaire d'Horace, n'est nullement un enjolivement littéraire. Il est, comme tout le reste de la description de Sophocle, d'une exactitude historique parfaite et il nous donne, sur un point de la vie religieuse, un renseignement corroboré par toutes nos autres sources.

Nous sommes donc en présence de légendes où, pour conjurer une stérilité, on sacrifie le coupable, et d'autres où l'on sacrifie une autre victime, généralement un être vierge. Les premières satisfont notre logique. Nul doute qu'elles ne soient les plus récentes. Faire de l'immolation une punition, une satisfaction consécutive à un jugement, cette pensée a dû venir tard, lorsque les idées morales étaient déjà arrivées à un haut degré de développement. Aussi faut-il retoucher sur ce point l'exposé de Diels, qui dit: «Les prodiges, d'après la conception antique, sont des marques de la colère divine qui doit être préexpiée (procurata) avant d'avoir pu éclater dans tout ce qu'elle a de destructeur. L'expiation consistait originairement dans la livraison du coupable; plus tard on la remplaça par des sacrifices aux puissances chthoniennes $»^{10}$. Tout donne à penser que, dans la pratique, on offrait aux dieux une victime capable de les apaiser et que l'idée de sacrifier le coupable relève d'exigences morales affinées et tardives. Hésychius a conservé une note qui dit que, pour purifier une ville, on offrait un homme et une femme ${ }^{11}$. On retrouve le même détail chez Tive-Live, et, dans le rituel sibyllin, l'offrande de deux animaux, l'un mâle, l'autre femelle, même si elle a une autre origine, a dû être comprise comme un substitut à l'immolation primitive d'un couple humain. Le sacrifice d'un homme et d'une femme s'explique comme moyen magique dans des cas de stérilité. Il ne figure du reste dans aucune des légendes relatives à l'apparition des Fléaux, ce qui montre combien ces légendes sont rationalisées et avec quel soin elles substituent des raisons tirées de la morale aux vieux motifs purement religieux. Le rituel est bien plus barbare que la fable et les écrivains n'arrivent pas à se reconnaître en lui. Voyez avec quelle gêne Tite-Live parle des quatre victimes humaines enterrées vivantes, en 216, dans le marché aux bestiaux (XXII, 57), minime romano $\mathrm{sacro}^{12}$. Euripide, trouvant la légende de Ménécée mis à mort, en fera un sacrifice volontaire en vue d'une victoire : seule façon pour lui de donner un sens et une valeur psychologique à une histoire affreuse dont la signification religieuse lui échappait.

7 Le Fléau du premier livre de l'lliade est arrêté par la restitution de Chryséis, après quoi on envoie à Chrysa une hécatombe pour Apollon en l'honneur de qui on chante le péan (315-473).

8 Le sacrifice des animaux, que nous allons retrouver dans toute l'histoire des purifications, s'est substitué à l'ancien sacrifice humain. Quant au péan, qui accompagne et célèbre ici la fin du Fléau, il a dû primitivement causer cette fin ${ }^{13}$. Les Grecs ont conservé quantité de légendes relatives à des sages et à des musiciens guérisseurs. On parlera plus loin de l'histoire d'Empédocle et on essaiera de débrouiller l'écheveau compliqué qui se mêle dans les traditions. Ce qui est sûr, c'est qu'à l'époque historique, en Grèce, le dieu le plus souvent invoqué pour guérir les Fléaux, c'est Apollon ${ }^{14}$. Le rituel tardif a conservé les 
chants à côté des immolations d'animaux. Il est à peu près certain qu'à une époque ancienne l'expiation comportait uniquement des sacrifices. Il n'est pas impossible que, dans certaines écoles, on se soit servi de la musique seule pour conjurer les maux. La pratique courante combine les deux méthodes, et de telle sorte que les grands dieux y apparaissent comme des nouveaux venus. Les cérémonies paraissent faites avant tout pour apaiser les puissances chthoniennes.

9 Toutefois, nous nous heurtons ici à une grosse difficulté. Presque toutes les cérémonies décrites par Tite-Live sont ordonnées pour expier des séries entières de prodiges, et il est souvent impossible de savoir ce qui se rapporte spécifiquement à l'ordre de phénomènes qui nous occupe. Tout ce qu'on peut dire, c'est que les cérémonies ont été en se compliquant de plus en plus.

10 En 436 éclate à Véies une peste (entendons : une maladie épidémique dont la nature nous est mal connue). Le peuple, sous la conduite des decemvirs, fait une obsecratio (Tite-Live, IV, 21,5). Après la peste de 399, un "été funeste à tous les êtres vivants ", un senatusconsulte renvoie aux livres sibyllins, lesquels ordonnent pour la première fois un lectisternium pour Apollon, Latone, Diane, Hercule, Mercure et Neptune (V, 13, 5).

11 En 392, la chaleur fait naître une peste et une famine (V, 31). En 363, nouvelle pestilentia : on fait un lectisternium et des jeux scéniques; des acteurs viennent d'Etrurie ; les jeux ont évidemment un rôle magique et servent à conjurer directement le fléau ${ }^{15}$. Après la peste de 348 (VII, 27), on en revient, d'après le conseil des livres sibyllins, au lectisternium. En 216, nous l'avons dit, on sacrifia des victimes humaines (XXII, 57,4). En 214, pour une série de prodiges parmi lesquels il y a un enfant qui parle dans le sein de sa mère, un bœuf qui parle et une femme devenue homme, on fait des sacrifices et des supplications à tous les dieux qui ont dans Rome un pulvinar (XXIV, 10). En 209, pour une série de prodiges du même genre, on sacrifie les grandes victimes, on ordonne des processions, des prières publiques, et on fait célébrer les Jeux d'Apollon, tels qu'ils avaient été récemment institués (XXVII, II, 4). En 207, pour des prodiges dont le plus effrayant est l'androgyne de Frusinone, on consulte les aruspices étrusques ; on fait faire des chœurs par vingt-sept jeunes filles. Elles chantent un chant composé par Livius Andronicus et conduisent à Junon-Reine deux statues de cyprès et deux génisses blanches (XXVII, 37).

12 Ces détails servent à illustrer le développement du rituel. Nous ne pouvons en tirer aucune conclusion particulière au sujet que nous étudions. Il nous faut maintenant signaler un document important, car il nous donne le cérémonial employé pour une purification qui eut lieu en 125, à Rome, après une naissance d'androgyne.

13 Le fait est raconté par Phlégon de Tralles ${ }^{16}$. Il ne nous dit malheureusement pas comment se fit l'éviction de l'enfant. Mais il rapporte que le Sénat fit consulter les livres sibyllins. A cette époque, les decemvirs avaient la garde à la fois des vieux oracles grecs et des prédictions que le devin Marcius avait remises en 212 au Sénat. Ils consultaient donc à la fois les Marciana et les Sibyllins. Phlégon a conservé le texte qu'ils lurent en 125 : deux longs oracles en hexamètres grecs acrostiches. Diels pense que le poème est d'un hellénisant qui sait mieux le rituel que la langue, et il suggère le nom de Fabius Pictor ; il suppose que Phlégon a pu trouver le texte des oracles chez Posidonius, lequel colligeait des histoires pieuses pour accabler les cyniques impies, en vertu de la même méthode qu'on voit exposée au premier livre du De divinatione de Cicéron ${ }^{17}$. 

de vingt-sept taureaux, sacrifice de vaches blanches par vingt-sept vierges, sacrifices offerts par les matrones qui font des libations à Déméter, torches pour Déméter. Si le cas se répète, on multipliera les libations offertes à Déméter par les matrones, on offrira un sacrifice identique à Perséphone, avec supplication par les vierges, et on fera une nouvelle offrande d'argent. à Pluton, qui lui sera conduit par une procession en habits de fête, une chèvre à Apollon à qui l'on adressera une prière la tête couronnée, une vache blanche à Junon-Reine. Les vierges feront un chant. On offrira à Junon des libations et des statues, et des béliers aux dieux chthoniens.

Ce rituel est formellement indiqué comme étant celui qui était pratiqué en Grèce ${ }^{18}$. Mais on s'expliquerait mal qu'il se fût implanté en Italie s'il n'avait pas trouvé des correspondances dans les coutumes et dans les croyances locales. On peut en dire autant des oracles relatifs aux Chants Séculaires, lesquels sont avant tout des cérémonies faites en vue d'obtenir la fécondité de la terre et des femmes. par Auguste en 17 avant J.-C. ${ }^{19}$. Il ordonne de sacrifier des brebis et des chèvres noires aux

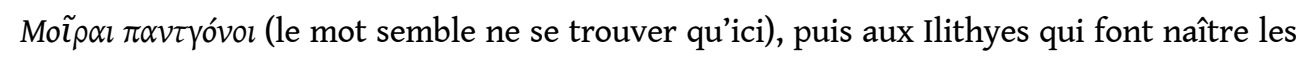
enfants, et une truie noire, pleine, à la Terre. Après ces rites qui ont un caractère à la fois chthonien et magique, viennent les sacrifices à Zeus, à Héra, à Phoebus, les chœurs d'enfants qui ont encore leur père et leur mère :

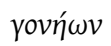

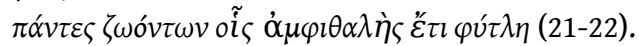

18

On rencontre ces enfants patrimi matrimi dans quantité d'expiations, notamment lors de naissances monstrueuses ${ }^{20}$. Ils figurent également dans nombre de cérémonies, sans qu'il soit possible de savoir exactement la raison profonde de leur présence. Faut-il l'expliquer simplement par l'idée de bonheur qu'ils évoquent, par la défaveur qui s'attache, déjà chez Homère, au nom de l'orphelin ? L'explication paraît bien courte et on n'arrive pas à en proposer une meilleure ${ }^{21}$. Il faudrait en trouver une qui correspondît au caractère de chacune des fêtes envisagées. On y arriverait peut-être en prenant comme dénominateur commun l'idée de fécondité. Ce qui est sûr, c'est qu'on comprend parfaitement la présence de ces enfants, symboles de la famille vigoureuse, féconde, bien portante, dans les cérémonies du mariage et dans les fêtes séculaires, où ils apparaissent comme des porte-bonheur chargés d'une signification magique ${ }^{22}$. On est tenté de la justifier en profondeur de la façon suivante : on stimule la fécondité de la Terre, d'une part, par la pratique de la continence, d'autre part, par des symboles qui rappellent la génération humaine. Ces deux procédés paraissent contradictoires et incompatibles; on les rencontre cependant fréquemment associés ${ }^{23}$. Des enfants vierges, nés d'un couple encore vivant, représentent peut-être un effort pour concilier deux ordres de superstitions qui semblent s'exclure. Il n'est pas impossible qu'à une époque ancienne ils aient été sacrifiés: l'Histoire Auguste raconte qu'Héliogabale $(8,1)$ fit sacrifier des victimes humaines, des jeunes gens nobles ayant encore leur père et leur mère. L'auteur ne comprend plus la signification du rite et croit que l'empereur les choisissait ainsi afin de faire souffrir les parents. Il est possible qu'Héliogabale ait agi par bravade pure, prenant exprès ses victimes parmi des personnes que l'on aurait cru préservées de l'arbitraire impérial. Il n'est pas impossible non plus qu'il ait voulu, soit renouveler quelque vieux 
rituel, soit parodier une cérémonie ancienne où l'on offrait aux forces de la nature quelque victime de choix.

19 La présence des enfants patrimi matrimi s'explique parfaitement partout où l'on veut assurer la pérennité de la race.

20 Ce qui donne à penser qu'ils sont bien les parèdres de la fécondité, c'est que, pour le recrutement de certains prêtres, on trouve deux conditions associées: l'absence d'infirmités physiques et l'existence de parents vivants. C'est le cas pour les Saliens, les Vestales, les assistants des Flamines et des Arvales. Les Vestales ne peuvent avoir aucun défaut corporel et, en cas de maladie, on ne les laisse pas dans l'atrium Vestae, on les soigne dans une maison privée ${ }^{24}$. L'excommunication des malades est psychologiquement si proche de l'éviction des anormaux qu'on est tenté d'expliquer les conditions de recrutement des Vestales par leur rôle dans de vieux rites de fécondité, par exemple les fordicidia apparentés aux Arrhétophories ${ }^{25}$. Et c'est probablement des raisons analogues qui expliquent, que, dans tant de religions, les infirmes ou les hommes de naissance irrégulière soient exclus de la prêtrise, survivances d'un temps où le clergé prêtait son ministère à des rites de féconditée ${ }^{26}$.

L'oracle ordonne ensuite de purifier tout le monde, hommes et femmes, mais surtout les femmes ${ }^{27}$. Ces mots seuls suffiraient à nous avertir que la vieille frayeur devant l'apparition d'une stérilité n'était pas éteinte. Dans le Chant Séculaire écrit par Horace en exécution de l'oracle sibyllin, on trouve, mêlées à des éléments littéraires et à des allusions politiques, des invocations qui sont exactement celles qu'auraient pu faire les

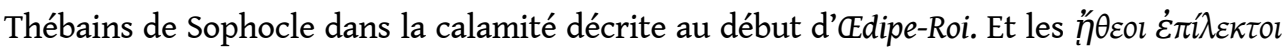
de Sophocle ne correspondent-ils pas curieusement aux uirgines lectas puerosque castos d'Horace ? Immédiatement après le Soleil, Ilithye est invoquée, comme Lucina et comme Genitalis, c'est-à-dire, probablement, celle qui protège l'accouchement et celle qui protège la grossesse (les Ilithyes dit l'oracle). Puis viennent les Parques, les Moĩp $\alpha_{l}$

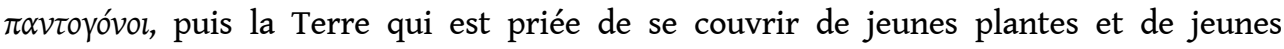
animaux ; les eaux et l'air sont invités à nourrir cette postérité. La fin du poème, adressée à Apollon et à Diane, est une ode morale où Horace suit son inspiration personnelle plutôt que les instructions de l'oracle. Mais nous savons par le procès-verbal des Jeux Séculaires que la fête eut bien le caractère strictement chthonien décrit par la Sibylle. Les citoyens reçurent des quindecemvirs les matières nécessaires à la purification; ils apportèrent les prémices de la terre, les fêtes durèrent trois jours et trois nuits. Les sacrifices eurent lieu la nuit: trois brebis et trois chèvres à chacune des Parques, des offrandes végétales aux Ilithyes, une truie pleine à la Terre. Zosime raconte que, dans la première année qui suivit l'expulsion des rois, pour arrêter une maladie contagieuse qui ravageait Rome, le consul Valerius Publicola sacrifia une vache et un taureau noirs à Pluton et à Proserpine, le taureau et la vache représentant l'homme et la femme des anciens sacrifices expiatoires. Le nombre deux, on l'a vu, ne joue plus aucun rôle clans le rituel des Fêtes Séculaires. Mais le rôle magique départi autrefois au couple humain, puis à un couple d'animaux, est joué ici par une femelle pleine. Il faut aussi remarquer l'importance du nombre trois et de ses multiples dans les cérémonies pour la naissance d'un anormal aussi bien que dans les rites séculaires (vide supra, p. 71). Or, ces nombres apparaissent fréquemment dans les cultes funéraires et chthoniens ${ }^{28}$.

Tout nous autorise donc à ranger les Fêtes Séculaires parmi les cérémonies faites pour conjurer la stérilité et pour appeler la fertilité sur un pays. On y retrouve le triple thème de la fécondité végétale, animale et humaine. Toutefois, Horace range les trois thèmes 
dans un ordre qui est le contraire de l'ordre ancien, où la terre figure toujours la première et les femmes en dernier lieu. C'est la seule modernisation qu'il imprime au vieux rituel. Les Fêtes séculaires sont étroitement apparentées aux cérémonies expiatoires pour la naissance d'un anormal, ce qui n'a rien d'étonnant si une naissance monstrueuse est, comme nous avons essayé de le montrer, un symptôme constant de stérilité mystérieuse.

Nous pouvons donc, dans les rites que nous avons analysés, distinguer les éléments suivants :

1. des sacrifices ou des symboles à caractère magique: le couple humain ou animal offert à la Terre comme principe de fécondité ; la truie pleine ; les enfants patrimi matrimi, image de la famille parfaite, bénie des dieux.

2. des sacrifices ou des symboles de caractère chthonien: les animaux noirs, les cérémonies nocturnes, le rôle joué par le nombre trois et ses multiples.

3. des chants qui, au début, ont eu une efficacité immédiate, encore sentie à Rome en 363, et qui, plus tard, ne servent plus qu'à orner une fête.

Les grands dieux tiennent dans ces rites une place très faible. Ils sont souvent mentionnés, mais on a généralement l'impression que c'est par simple prudence, comme fait Horace qui, dans la dernière strophe du Chant Séculaire, nomme rapidement Jupiter et «tous les dieux », comme s'il ne voulait pas mécontenter ceux dont il n'a pas encore parlé.

\section{NOTES}

1. HÉROD. VI, 139 ; APOLLODORE, Bibl. III, 15, 8.

2. APOLL., Bibl. III, 7, 5 .

3. APOLL. Bibl. III, $5,1$.

4. APOLL. Bibl. II, $7,4$.

5. APOLL. Bibl. III, 12, 6 .

6. APOLL. Bibl. II, 5, 9. - HYGIN, Fab. 67.

7. APOLL. Bibl. II, 5, 11.

8. APOLl. Bibl. III, $15,8$.

9. Les femmes se préparent aux Thesmophories par une continence de neuf jours (Ov. Mét. X, 434).

10. H. DIELS, Sibyllinische Blaetter, Berlin, 1890, p. 69.

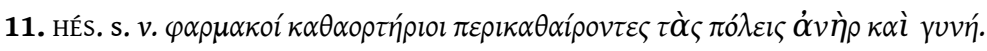

12. PLUTARQUe (Marc. III) dit qu'on expiait encore de son temps le meurtre accompli en exécution des oracles sibyllins.

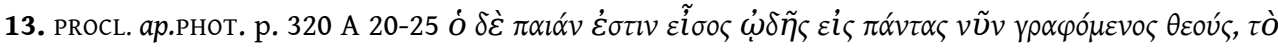

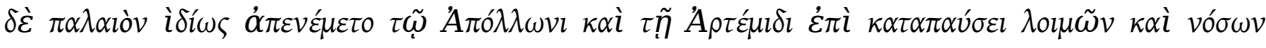
$\dot{\alpha} \delta$ ó́ $\varepsilon v$ os. - BOET. de Mus. I, 1 (p. 1064).

14. Cependant, il n'est appelé Loimios, à notre connaissance, qu'à Lindos (MACR. Sat., 1, 17), mais Alexicacos et Lytérios en quantité d'endroits. Cf. WELCKER, Kleine Schriften, III, pp. 33, sqq. Cet essai, 
sur les Seuchen von Apollo, reste bon à consulter, ne fût-ce qu'à cause de la netteté avec laquelle l'auteur distingue les maladies naturelles et les autres.

15. TITE-LIVE VII, 2, 3 : ludi scaenici... inter alia coelestis ira placamina instituti dicuntur.

16. WESTERMANN, Scriptores rerum mirabilium graeci, 1839, p. 133, 10 sqq. Le document est analysé dans la magistrale étude de DIELs, Sibyllinische Blaetter, Berlin 1890.

17. Sib. Blaetter, p. 106 et p. 21.

18. $\dot{\alpha} \chi \alpha i ̈ \sigma \tau i ́($ v. 16). Cf. DIELS, Sib. Blaetter, pp. 54 sqq. et WELKER, Prodig. bei den Römern, pp. 101 sqq.

19. zosime, Historia Noua, II, 1, 5 ; PHLÉGON DE TRALLES, de Longaeuis, IV. Diels commente le texte en appendice à ses Sibyllinische Blaetter.

20. Vide supra, pp. 58 ; TITE-LIVE, XXXVII, 3 ; TAC, Hist. IV, 53 ; MACR. Sat. I, 6, 14.

21. A. ФРКE (Arch. f. Relig. XXXI, 1934, pp. 42 sqq.), a réuni les textes, mais sans chercher à justifier par une raison générale la présence des enfants patrimi matrimi dans des cérémonies de natures différentes.

22. Plutarque dit qu'un enfant $\dot{\alpha} \mu \varphi \imath \theta \alpha \lambda \eta \dot{\zeta}$ apporte du pain dans une corbeille pendant la noce ( Prov. Alex. XVI, p. 1255). Certains documents figurés montrent les enfants pieds-nus ou un pied nu (ÆPKE, loc. cit., p. 53). Le détail nous ramène aux rites chthoniens. Auguste sacrifie également nupieds sur le relief de l'Ara Paris.

23. FRAZER, Rameau d'Or, pp. 62 sqq. et 127 sqq. de l'éd. abrégée, trad. fr., 1923. La continence de printemps, préalable aux semailles, est un rite bien connu. Marie Gevers écrit en 1938, parlant de la Campine anversoise : "Pour que le grain soit nombreux, il faut que celui qui l'a semé dorme avec sa femme dans le champ» (La ligne de vie). La continence prépare une union féconde qui, elle, a un caractère magique.

24. MARQUARDT, Culte romain, II, pp. 24 sqq.

25. Je dois ce rapprochement à M. Léon Halkin ; Cf. MARQUARDT, Culte romain I, p. 238.

26. Les prêtres catholiques ne peuvent être ni infirmes, ni bâtards (can. 984). On connaît les interdictions analogues relatives au clergé israélite.

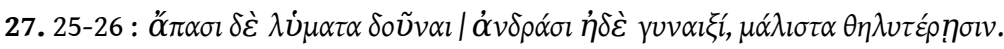

28. DIELS, Sib. Blaetter, pp. 40 sqq. 


\section{Chapitre IV. L'origine des Fléaux}

1 Il faut faire ici une distinction nette entre les choses qui sont dites dans les légendes et celles qui sont impliquées par les rites. C'est précisément parce que les secondes paraissent importantes et curieuses qu'on a préféré attendre le terme de cette étude avant de poser la question de l'origine des stérilités mystérieuses.

2 Les légendes les attribuent à la volonté d'un ou de plusieurs dieux irrités. Hésiode nomme Zeus, Callimaque Artémis; Sophocle invoque les mêmes divinités qu'Eschine invite à jeter la malédiction: Apollon, Artémis, Léto, Athéna. Le dieu auquel on prête le plus souvent le pouvoir de guérir la stérilité, c'est Apollon.

3 Les faits et les rites nous ramènent au culte de la Terre. C'est presque toujours un meurtre, le sang versé, un mort non vengé, qui déchaîne un Fléau.

4 Sa première manifestation, c'est l'infécondité du sol ; comme Gê est de plus nourricière des jeunes êtres, c'est elle encore qui paraît irritée si les animaux et les hommes n'ont pas de postérité. Un Fléau s'accompagne de naissances anormales : c'est la Terre qui est la mère des monstres ${ }^{1}$. Ces nouveau-nés maléfiques, on craint de les mettre en contact avec elle; on ne les enterre pas; on les jette dans des ravins où les animaux ont vite fait de les dévorer, ou bien on les expose sur l'eau. Dès que les signes avant-coureurs d'un Fléau ont commencé à se manifester - c'est-à-dire que des enfants anormaux sont nés -, on fait des cérémonies qui sont empruntées aux cultes chthoniens et aux rites funéraires. Dans un cas ancien, des victimes humaines sont enterrées vivantes. La Terre apparaît donc, non seulement comme l'exécutrice du Fléau, ce qui est impliqué dans la nature même de celui-ci, mais même comme sa cause.

5 Le sentiment populaire nous est sur ce point conservé par les tablettes de malédiction. Elles traduisent, nous l'avons dit, des rancunes personnelles trop limitées pour s'élever jusqu'à l'idée de stérilité générale. Mais les punitions rapides, immédiates qu'elles exigent, elles les demandent généralement à Déméter et à Coré, souvent aussi à la Terre². Celui qui glissait une tablette dans un tombeau confiait sa malédiction à la Terre et aux morts exactement comme Oreste leur confie sa vengeance dans les Choéphores. Et il n'est

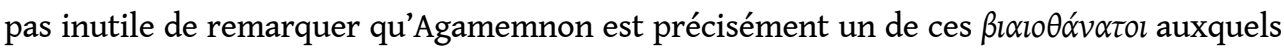
on s'en remettait, avec prédilection, pour l'exécution d'une vengeance.

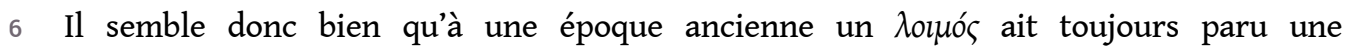
manifestation de la Terre irritée, de même que la fécondité est une preuve de sa 
bienveillance. Il semble que les deux idées soient connexes, l'une n'étant que l'envers de l'autre. Et, cependant, on les trouve dissociées. L'auteur du bel Hymne homérique à la Terre

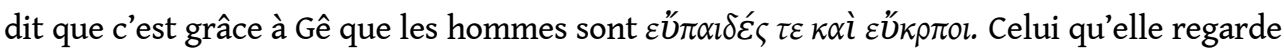
avec bienveillance est riche; il a de beaux enfants, filles et garçons. L'idée n'est pas exprimée ensuite sous la forme négative. On pourrait croire que l'auteur a simplement voulu montrer la Terre comme une puissance exclusivement bienfaisante et qu'il a préféré se taire sur ses forces redoutables. Mais d'autres textes donnent à penser que l'hymne exprime une opinion très précise qui est que la Terre est bonne et ne peut rien créer de mal ni de mauvais. Pline a écrit une page curieuse où il affirme que la Terre est incapable de s'irriter contre l'homme, qu'il est donc impie de la souhaiter, dans notre colère, pesante à nos ennemis. Cette opinion était absolument opposée au sentiment populaire qui dictait les malédictions inscrites sur les tablettes, les formules d'imprécation qui sont de règle dans les serments. Mais elle est bien conforme à la tendance, qui se trouve chez les poètes, à transformer la Terre en un être purement pacifique et débonnaire ${ }^{3}$. Elle engendre malgré elle, dit Pline, les êtres nuisibles, spontanément les êtres utiles. Les pestifera animantia sont tels par la faute du souffle vital. La Terre est bien obligée de recevoir les germes et de les nourrir. Dans les choses mauvaises, ce qui est coupable, c'est ce qui engendre ${ }^{4}$.

7 Cette page de Pline atteste une contamination entre deux ordres d'idées : on y trouve une pensée religieuse, celle de la bonté essentielle de la Terre, et un essai d'explication scientifique : c'est l'Air et l'Eau qui causent les désastres. Et ici, nous sommes obligés de revenir en arrière.

Dans les descriptions classiques de stérilités, le phénomène est toujours dépourvu de causes naturelles. Il n'est mis en liaison ni avec les vents, ni avec les saisons. Les dieux l'envoient; il reste rationnellement inexplicable. Le premier texte où une cause seconde intervient, c'est la prière d'Athéna dans les Euménides, qui demande pour l'Attique les brises et le soleil (904-906). Les Furies promettent que jamais le « souffle qui fait souffrir les arbres ne franchira la lisière du pays » (937-943).

On pourrait croire qu'engagées dans cette voie les recherches des anciens vont aboutir à des découvertes qui ruineront les vieilles superstitions. Il n'en est rien. Les savants travaillent de leur côté ; les pratiques religieuses subsistent ; les deux ordres d'idées ne se mêlent pas.

10 Tandis que l'on trouve, d'un bout à l'autre du monde classique et du commencement à la fin de l'antiquité, la croyance au caractère maléfique des enfants mal conformés, les philosophes et les médecins recherchaient les causes naturelles des malformations dont la foule s'effrayait. Démocrite donne, de la génération des monstres, une théorie fondée sur la confusion de deux semences. Aristote la réfute et en propose une autre, liée à la théorie hylémorphique : il y a monstre quand la matière n'est pas dominée par la forme ; le monstre est le signe d'un fléchissement; il résulte de l'erreur de l'être qui poursuit une fin étrangère à sa forme $e^{5}$. Hippocrate tient que l'enfant né boiteux ou aveugle a été malade pendant le huitième mois de la grossesse et que sa mère a souffert pendant cette période ${ }^{6}$.

11 Plutarque, dans le $\mathrm{V}^{\mathrm{e}}$ livre des Opinions des philosophes, rapprochant (ch. 8) quelques théories sur le point de savoir comment naissent les monstres, donne, après une explication d'Empédocle et une de Straton, celle de certains médecins : toutes trois font appel uniquement à des causes naturelles, l'état de la semence et celui de la matrice. 
Empédocle, Parménide, les stoïciens, les médecins avaient proposé des réponses à cette question : pourquoi y a-t-il des naissances multiples ${ }^{7}$ et pourquoi les enfants ressemblentils à leurs parents ou diffèrent-ils d'eux? A ne voir que les mots, on pourrait se croire ramené au risque indiqué par Hésiode lorsqu'il dit que l'impie doit craindre de voir naître

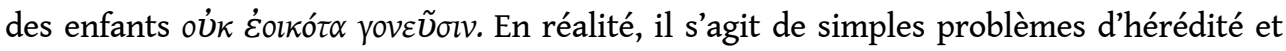
d'atavisme. Les recherches rationnelles relatives aux monstres sont attestées par des textes presque aussi anciens que ceux qui révèlent la crainte qu'inspiraient les nouveaunés maléfiques. Ces recherches ont duré toute l'antiquité, parallèlement aux vieilles superstitions, sans les modifier. Tout se passe comme si la tératologie scientifique d'une part, la peur des monstres d'autre part, existaient dans deux mondes différents, sans communication de l'un avec l'autre.

L'astrologie apporta des croyances inconciliables avec l'ancienne idée qu'on se faisait des stérilités mystérieuses. C'est l'état du ciel qui décide de la réussite d'une récolte, de la fécondité d'un mariage et de la bonne constitution des enfants. Qu'un enfant soit ou non exposé, cela tient à des conjonctions d'astres, mais non à des raisons tirées soit de l'état du nouveau-né, soit de la condition de ses parents; et c'est un astre encore qui fait que l'enfant exposé sera recueilli, ou ramené chez lui, ou déchiré par des chiens ${ }^{8}$.

Résumons : à l'origine, les Fléaux apparaissent comme une preuve de la colère de la Terre, dont la bienveillance se manifeste par la fécondité du sol, des femelles et des femmes. Mais, dès nos premiers textes littéraires, cette idée est déjà obscurcie; les grands dieux envoient les Fléaux et sont invoqués pour les arrêter. Apollon est celui qu'on semble avoir appelé le plus souvent. On a recours à son oracle pour connaitre le coupable et les moyens de purification; on a recours à lui-même pour éloigner le mal. Dans le chapitre suivant, nous verrons ce qu'a pu être le culte d'Apollon Hyperboréen considéré comme guérisseur. Ce qui apparaît dès maintenant, c'est qu'en matière de Fléau comme en matière de meurtre, le rôle primitivement accordé à la Terre a été peu à peu usurpé par Apollon. Et ce qui mérite peut-être d'être relevé, c'est que, si la Terre a été dépossédée, c'est en partie parce que, assez tôt, on a cessé de se la représenter comme une force redoutable et qu'on n'a plus voulu voir en elle qu'une puissance bienfaisante.

Lorsqu'on commence à envisager les Fléaux comme des phénomènes naturels, on en arrive bientôt à tenir compte du rôle des Vents et des Eaux, lesquels, chez les poètes, n'interviennent jamais, excepté une fois, dans les Euménides. Le chapitre suivant montrera peut-être que l'importance donnée aux Vents n'est pas sans lien avec le rôle croissant joué par Apollon dans l'explication des Fléaux.

Les croyances qui rattachent la stérilité à la colère de la Terre et des dieux, et les idées orientales qui la font dépendre de la figure du ciel, n'ont eu aucune influence les unes sur les autres. 


\section{NOTES}

1. Dans la Théogonie, les monstres naissent de Gê et d'Ouranos, lequel les cache à l'intérieur de la Terre. Il faut entendre qu'ils en sortent un jour. Lorsque Cronos mutile son père, il coupe les bourses et les jette derrière lui ; les gouttes de sang tombent sur Gê et il en natt les Erinyes, les Géants et les nymphes des frênes. Cronos jette alors le membre divin loin de la terre, dans la mer,

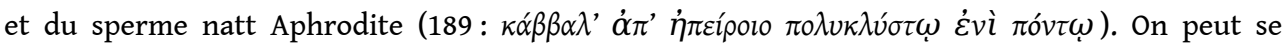
demander si cette légende n'en recouvre pas une plus ancienne où la Terre seule est mère des monstres. On connait toutes les légendes de monstres naissant dans les grottes (par exemple Théogonie 297-301, 333-335). Il est probable que, dans l'imagination populaire, les monstres ont commencé par naître des grottes elles-mêmes, matrices chthoniennes. Plus tard, elles ne sont plus que le lieu de la naissance.

2. AUDOLLENT, Defixionum tabellae, p. LXII.

3. Pour voir cette tendance à l'œuvre, il suffit de lire l'histoire poétique de l'oracle de Delphes. L'auteur de l'Hymne homérique à Apollon n'établit aucun lien entre le Dragon-femelle malfaisant (300 sqq.) et la Terre, source de vie (341). Eschyle fait de Gê une force purement bienfaisante et pacifique (Eum., 1 sqq) et, dans la pièce, les Erinyes ne sont pas ses filles, mais les filles de la Nuit.

4. PLINE, II, 63. Sequitur terra cui uni rerum naturae partium eximia propter merita cognomen indidimus maternae uenerationis... Cuius numen ultimum iam nullis precamur irati graue : tanquam nesciamus hanc esse solam, quae nunquam irascatur homini. Aquae subeunt in imbres, rigescunt in grandines, tumescunt in fluctus, praecipitantur in torrentes: aer densatur nubibus, furit procellis. At haec benigna, mitis, indulgens, ususque mortalium semper ancilla, quae coacta generat ! quae sponte fundit! ... Pestifera enim animantia, uitali spiritu habente culpam, necesse est illi seminata excipere et genita sustinere; sed in malis generantium noxa est.

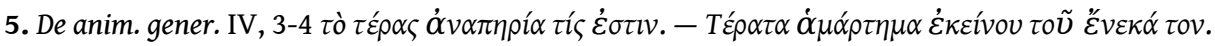

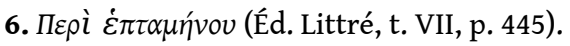

7. De plac. phil., V, 10-12.

8. F cUMONT, L'Égypte des astrologues, p. 184 ; Geopon. I, 8 ; I, 12 ; XVIII, 8. - FIRM. MATERNUS, VII, 2, traite de expositis et non nutritis. - JASTROW, Bab.-Assyr. Birth-Omens (Relig. Vers. u. Vorarb. XIV (1914), pp. 50 sq.) essaie vainement de ramener à une influence orientale les croyances grecques et latines relatives aux naissances anormales. Sur l'hétérogénéité foncière du fatalisme astral dans les religions antiques, cfr. F. CUMONT, Rev. hist. et litt. rel. III (1912) pp. 513-43. 


\section{Chapitre V. Les Fléaux en Sicile au temps d'Empédocle}

1 Il faut dire un mot d'une curieuse histoire qui figure chez les biographes d'Empédocle et dont les éléments ne sont pas faciles à distinguer.

2 Timée raconte que les vents étésiens avaient soufflé avec tant de violence que les fruits gâtaient. Empédocle fit écorcher des ânes et tendre les peaux sur les collines et les sommets, afin d'arrêter le vent. Celui-ci ayant cessé, on appela Empédocle Kôlusanemas ${ }^{1}$. Cette version, plusieurs fois répétée, implique un arrêt mécanique des vents, soit par des outres où ils s'engouffrent (souvenir de l'épisode d'Eole dans l'Odyssée), soit par une sorte de barrage de peaux. C'est en tout cas ainsi qu'ont compris les auteurs qui ont ensuite rationalisé cet épisode.

Plutarque (de Curios. I, p. 515. C), trouvant probablement ces peaux d'ânes absurdes, dit qu'Empédocle a procédé en faisant boucher une fissure de rocher par où soufflait le Notus

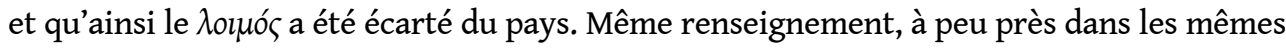
termes, dans Adv. Col. (32, 4, p. 1126, B) : Empédocle fait construire un mur pour

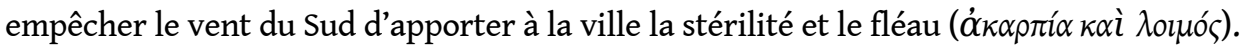

Clément d'Alexandrie raconte qu'Empédocle a arrêté (il ne dit pas comment) un vent qui faisait souffrir les habitants et qui rendait les femmes stériles. Il est le premier à situer l'histoire à Agrigente ${ }^{2}$.

5 Ces trois témoignages rationalisent le moyen employé par Empédocle : un mur paraît plus admissible qu'un barrage de peaux. Ils contiennent deux invraisemblances : d'abord, le Notus, vent du Midi, est celui qui apporte la fécondité ${ }^{3}$; ensuite, le site d'Agrigente rend impossible toute protection contre un vent venu de la mer. Timée, qui parle de vents étésiens, c'est-à-dire du Nord-Ouest, ne nomme pas Agrigente. Cela montre que cette histoire existait avant d'être localisée dans l'espace et peut-être aussi avant d'être

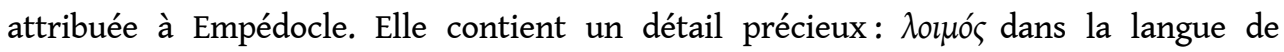
Plutarque peut signifier une maladie épidémique quelconque ; mais ce qui prouve qu'il

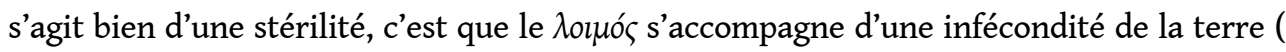
$\dot{\alpha} \kappa \alpha \rho \pi i ́ \alpha)$ et des femmes ( $\dot{\alpha} \gamma o v i \alpha)$.

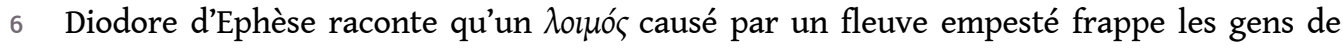
Sélinonte, provoquant des fausses couches. Empédocle, à ses frais, fait mélanger deux 


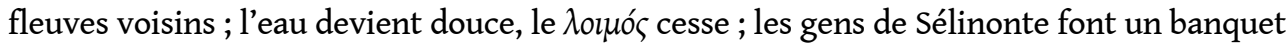
sur la rive du fleuve; Empédocle apparaît à la manière d'un dieu; les gens se lèvent, l'adorent et lui adressent des prières. C'est alors que, voulant encourager ce sentiment, il se jette dans le feu ${ }^{4}$.

Essayons d'isoler, dans ces histoires, les éléments dont l'origine est discernable.

8 Empédocle lui-même avait promis à ses disciples de leur donner la science des remèdes et le pouvoir d'arrêter les vents qui gâtent les fruits de la terre :

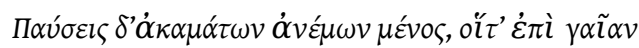

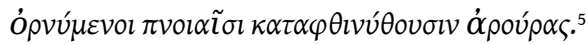

Le titre de Kôlusanemas pourrait n'avoir pas d'autre origine qu'un souvenir de ces vers.

10 Diodore d'Ephèse dit qu'Empédocle assainit la région de Sélinonte en rendant douces les eaux salées d'un marais ${ }^{6}$. Il semble qu'il y ait ici une contamination de deux renseignements différents : des travaux exécutés dans les marais que l'on draina en y faisait passer l'Hypsas et le Sélinos, travaux auxquels Empédocle est peut-être complètement étranger; et, d'autre part, les recherches d'Empédocle sur la présence, dans l'eau de mer, d'eau douce en quantité suffisante pour nourrir les poissons, recherches qui furent reprises ensuite par Démocrite, Aristote et Théophraste ${ }^{7}$. La réputation d'Empédocle comme savant d'une part, comme thaumaturge d'autre part, a dû lui faire attribuer tous les travaux que, de son temps et dans son pays, on considérait comme prodigieux.

11 Restent maintenant quelques détails que nous pouvons expliquer et qui vont éclairer ce qu'on peut appeler la méthode d'Empédocle.

12 Dans les deux faits il y a un élément commun : le mal se manifeste par de la stérilité. Les vents, dit Clément, rendent les femmes stériles ; la mauvaise odeur de l'eau, dit Diodore, cause des fausses couches. Ce détail doit être ancien, car il est étranger aux vers d'Empédocle qui ont influencé la légende. Timée et Plutarque l'ont écarté, probablement comme absurde. Timée dit que les vents font gâter les fruits, Plutarque (de Curios.) dit

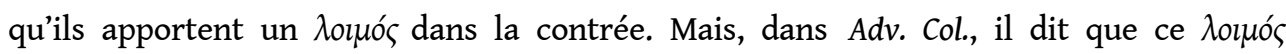
s'accompagnait d'une $\alpha_{\kappa} \alpha \rho \pi i \alpha$, d'une stérilité végétale. On se souvient des vers du $\Pi \varepsilon \rho i$ $\varphi v ́ \sigma \varepsilon \omega \varsigma$ d'Empédocle à propos des vents qui gâtent les produits de la terre :

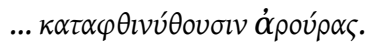

On comprend donc très bien que les auteurs qui rationalisent à demi aient gardé le détail des fruits gâtés, et supprimé celui des femmes qui ont des couches malheureuses : le vent peut avoir un effet sur la maturité des fruits ; il paraît moins capable d'en avoir un sur la

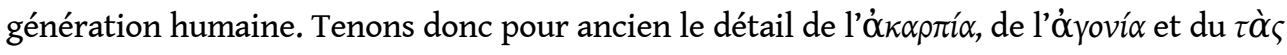

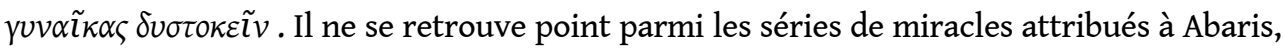
à Pythagore, à Empédocle lui-même dans la légende tardive, telle qu'elle est conservée par Porphyre et Jamblique.

14 Timée a conservé un autre renseignement précieux: Empédocle combat le Fléau en faisant écorcher des ânes. Encore une fois, nous touchons certainement ici un fonds archaïque. Dans le passage de l'Odyssée où il raconte son voyage chez Eole intendant des Vents, Ulysse dit que le dieu les lui remit dans des outres en peau de bœuf. Empédocle se souvient certainement d'Eole, intendant des vents, lorsqu'il promet à son disciple que lui aussi pourra les gouverner à son grés. Et, inversement, Eustathe, dans son commentaire au passage de l'Odyssée (p. 1643) mentionne Empédocle parmi les hommes qui ont eu le 
pouvoir, non d'arrêter, mais de régler les vents. Un seul détail échappe au parallélisme : les ânes écorchés de l'histoire sicilienne.

Or, nous savons qu'à Tarente on offrait des ânes aux Vents'. D'autre part, un passage de Columelle montre que le sacrifice de l'âne servait à la fois à écarter les vents mauvais et tous les fléaux, et à amener la fécondité. Jupiter Porte-Fléau sévit par de lourdes averses ; des calamités surviennent; pour y échapper, les paysans tentent toutes sortes d'expériences et ils parviennent enfin à apaiser les vents furieux, à écarter le mauvais temps, par des sacrifices toscans. Suivent alors quatre méthodes : le sang et les entrailles d'un jeune chien écartent la rouille qui grille l'herbe ; - le Tyrrhénien Tagès plante à la limite de son champ la tête écorchée d'un ânon ; - Tarchon met des couleuvres autour de sa maison pour la préserver de la foudre ; - Mélampe a appris de Chiron à mettre des chauves-souris en croix ${ }^{10}$. La tête d'âne paraît figurer dans cette liste comme moyen apotropaïque, d'abord à cause du contexte, ensuite parce qu'on la plante à la limite du champ. Mais nous ignorons ce qu'elle devait écarter. Et, d'autre part, on dit ailleurs qu'un crâne d'âne, de jument ou d'ânesse appelle la fécondité, lorsqu'on le met au milieu du champ ${ }^{11}$. Nous trouvons donc, parmi les superstitions relatives à l'âne, les deux détails qui sont également conjoints dans les anecdotes de la vie d'Empédocle: les vents et la fécondité. Les superstitions, lorsqu'elles sont localisées, sont référées à l'Italie du Sud-Est. Il semble bien que l'on ait attribué à Empédocle l'usage, en Sicile, d'une méthode contre la stérilité. Sous l'influence du passage d'Homère relatif à Eole intendant des vents et du passage d'Empédocle lui-même promettant à ses disciples la maîtrise des vents, des historiens qui avaient de la mémoire ont passé des ânes sacrifiés, moyen magique, aux outres en peau d'âne, moyen mécanique, puis au mur dans la montagne. Et le travail de rationalisation s'est poursuivi, soutenu par l'idée qu'on se faisait, d'après ses propres œuvres, d'un Empédocle hostile au sacrifice des animaux ${ }^{12}$.

Qu'est-ce que c'était que la méthode d'Empédocle, telle que nous l'entrevoyons dans les anecdotes de sa biographie?

Il attribuait la stérilité à des causes secondes naturelles, l'air, l'eau. Nous trouvons les mêmes idées dans le traité hippocratique Des airs, des eaux et des lieux, où la fécondité est mise en rapport avec le climat (ch. V) et où il est dit notamment que, "près des marais, les femmes conçoivent difficilement et leurs accouchements sont pénibles; les nouveaunés sont gros et boursouflés ; pendant la nourriture ils maigrissent et deviennent chétifs » (VII). Un moderne reconnaîtra là une description des effets dé la malaria. Il n'est pas impossible que cette théorie se soit répandue même parmi ceux qui voyaient dans la stérilité un phénomène d'ordre religieux, grâce à la croyance qui refuse à la terre toute action néfaste. $\mathrm{Si}$, comme le dira Pline, la terre est toujours et invariablement bienfaisante, alors que les autres éléments nous témoignent parfois de l'hostilité, c'est dans l'air et dans les eaux qu'il faut chercher la cause des calamités.

Les traditions présentent Empédocle comme agissant tantôt par des moyens naturels, en assainissant un marais, tantôt par des moyens magiques, en sacrifiant des ânes aux Vents, ou en suspendant leurs dépouilles dans les champs.

19 Empédocle croyait-il à l'efficacité des deux méthodes? ou bien croyait-il à la première seule tout en pratiquant la seconde afin de frapper l'imagination des gens? Nous l'ignorons. Mais le détail des ânes sacrifiés nous permet d'aller un peu plus loin dans une autre direction. 
20

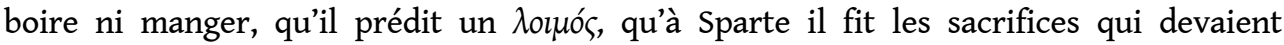
empêcher le mal et qu'à la suite de cela il n'y eut plus jamais de $\lambda$ or ós $_{\text {à Sparte }}{ }^{16}$. De plus, Abaris avait une flèche d'or qui lui montrait le chemin et qui lui faisait franchir les obstacles. Cette flèche qu'il donna ensuite à Pythagore, était celle dont Apollon s'était servi pour tuer les Cyclopes et venger Esculape. Menacé par Zeus, il avait caché la flèche chez les Hyperboréens ; lorsque le dieu eut terminé son année de servage et d'expiation chez Admète, la flèche lui revint "à travers les airs, avec la féconde Déméter ${ }^{17}$ Dans l'état actuel de nos connaissances, il nous est impossible de tirer au clair cette étrange histoire.

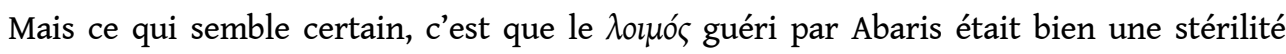
contre laquelle il requérait l'aide de Déméter, en imitant son jeûne, et d'Apollon Hyperboréos. La flèche d'or d'Apollon est liée à l'histoire d'Admète, dans la maison de qui Apollon apporte une exceptionnelle opulence. Une légende racontait qu'Ilithye était venue de chez les Hyperboréens à Délos pour secourir Léto ${ }^{18}$. Entendons qu'on honorait une Ilithye Hyperboréa que l'on mettait en rapport avec le culte d'Apollon. Les histoires de la flèche d'or, d'Abaris l'Hyperboréen, semblent donc bien recouvrir de vieux récits de fécondité ramenée. Or, Porphyre et Jamblique, dans leurs Vies de Pythagore, fondées sur

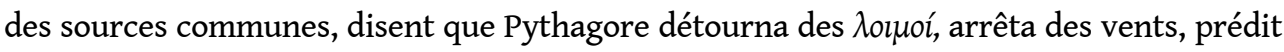
des tremblements de terre et fit d'autres miracles, en compagnie d'Empédocle, d'Epiménide et d'Abaris ${ }^{19}$. Il serait bien inutile de chercher à faire la part de chacun des thaumaturges. Mais ce qui ressort clairement de ces histoires, c'est que le culte d'Apollon Hyperboréos florissait, $\mathrm{au} \mathrm{VI}^{\mathrm{e}}$ et au $\mathrm{v}^{\mathrm{e}}$ siècle, en Grande-Grèce et en Sicile, et que l'on invoquait ce dieu dans des cas de stérilité, comme étant celui qui rend la richesse à la terre. Les ânes écorchés de la Vie d'Empédocle ont probablement été offerts comme $\kappa \omega \lambda v \tau \eta_{p} \iota_{\alpha}$ à Apollon Hyperboréen. Les vieilles superstitions qui attribuent un pouvoir fécondant aux têtes d'ânesses doivent être en rapport avec les idées d'opulence, de naissance heureuse, qui caractérisent les divinités hyperboréennes.

Toutefois, il faut faire une distinction très nette parmi les traditions relatives à Pythagore et à Empédocle considérés comme thaumaturges. Pythagore agit par des méthodes purement religieuses : c'est probablement à lui qu'on faisait honneur d'avoir développé le 
culte d'Apollon Hyperboréen. Empédocle semble faire des recherches sur les causes secondes, après quoi il agit sur elles tantôt par des remèdes naturels, tantôt par un appel aux forces divines. Nous ne saurons jamais pourquoi on a consigné les méthodes par lesquelles il essayait de guérir la stérilité. En faisant assainir un marais (et c'était là remonter très exactement à la cause, la malaria), a-t-il scandalisé les esprits religieux par son rationalisme? Ceux qui ont associé son nom aux offrandes d'ânes pour Apollon Hyperboréos, étaient-ce des savants choqués par les concessions qu'il faisait à la religion populaire? Nous sommes condamnés, avec cet étrange et complexe esprit, à terminer par une question toutes les études qui le concernent.

\section{NOTES}

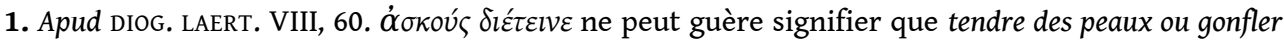
des outres. Pour les autres récits qui ne font que copier celui-ci, cf. DIELS, Vorsokr., Emped. A, 2.

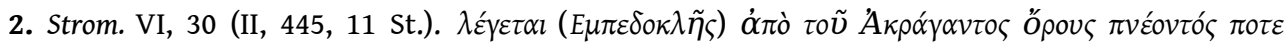

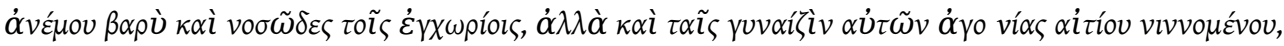

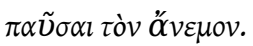

3. H. orph. 82,5 sqq.

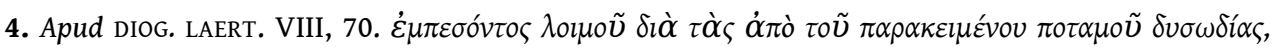

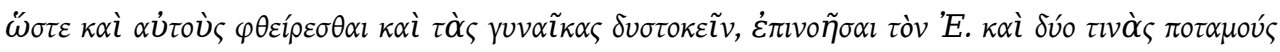

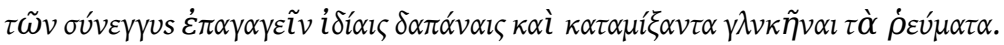

5. DIELS, Vorsokr., Emped. fr. III, 3-4. Cf. la pénétrante étude que J. BIDEZ (La Biographie d'Empédocle, pp. 43 sqq.) a consacrée aux contaminations entre l'œuvre et la légende.

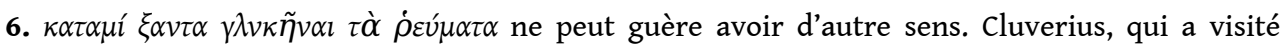
Sélinonte et les environs au début $\mathrm{du} \mathrm{XvII}^{\mathrm{e}} \mathrm{s}$., y a encore vu des eaux salées et stagnantes et il fait remarquer que Diodore se trompe en parlant d'un fleuve empesté alors qu'il s'agit d'un marais. Cette anecdote, comme celle des vents, a été colportée par des gens qui ne connaissaient plus les lieux. Cf. CLUVERIUS, Sicilia antiqua, Leyde, 1619, p. 227, et HEAD, Historia Numorum, p. 147 sqq.

7. ELIEN, Hist. Nat., IX, 64 ; DIELS, Vorsokr., Emped. A., 66.

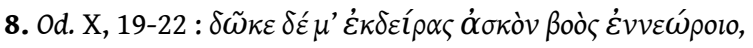

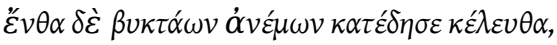

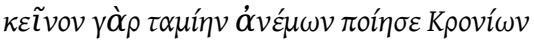

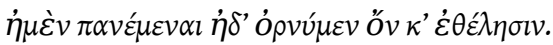

$\Pi \varepsilon \rho \grave{i} \varphi v ́ \sigma \varepsilon \omega \varsigma$, fr. III (Diels), 5 :

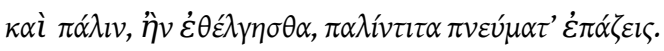

9. Le renseignement est conservé par deux sources qui malheureusement sont altérées l'une et

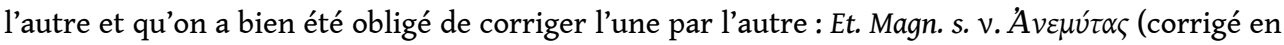

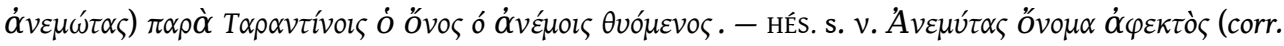

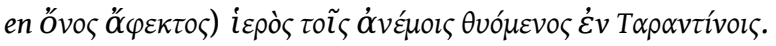

10. CoL., de Re rustica, $\mathrm{X}, 331$ sqq.

11. PALLADIUS, de Re Rust., I, 35, 6. Equae caluaria sed non uirginis intra hortum ponenda est, uel etiam

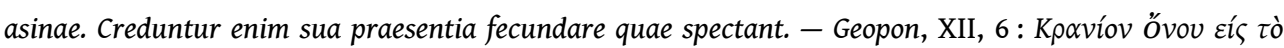

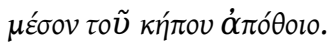


12. BIDEZ, Biogr. d'Emp. pp. 43, 122, 139 ; DIELS, Vorsokr., Emp. fr. 136, 117, 137.

13. Le fait est attesté par C. I. G. I, p. 807, 14.

14. JAMBL., Pyth., 92, 135 et 140 ; PORPH., Pyth., 27 et 28 ; APOLL. Hist. Mir. 6 ; ElIEN, Var. Hist. II, 26 ; Diog. Laert. VIII, 11.

15. P. Corssen attribue cet embellissement de la légende à Héraclide Pontique, Rhein. Mus. 67 (1912), pp. 37 sqq.

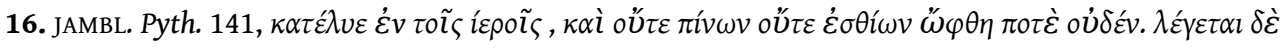

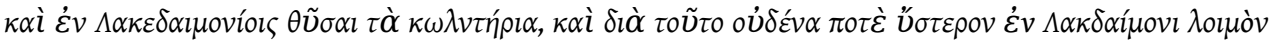

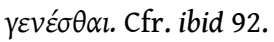

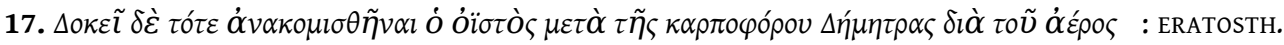
Catast. rel. XXIX (ed. Robert, 1878). Robert supprime $\Delta \eta \mu \eta \dot{\tau} \rho \rho$ qui, dit-il, a dû être ajouté par un

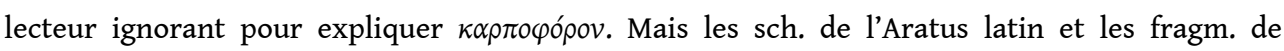
Catastérismes du Vat. gr. 1087 donnent également le détail. Hygin (Astr. II, 15, sagittam uento perlatam cum frugibus) l'a certainement lu aussi dans la source qu'il suit. On trouvera cités et classés par A. ROEHM, Rhein. Mus. LXVII (1912), pp. 417 sqq, les cinq textes sur lesquels repose l'histoire de la flèche d'or d'Apollon devenue une constellation. Robert rapproche l'allusion à Déméter et à ses fruits des offrandes de prémices qu'Hérodote réfère déjà aux Hyperboréens (IV, 33) et dont parle Callimaque (H. Ap. Dél. 278 et 283). Que les épis soient des emblèmes de fécondité, cela ne fait pas de doute. Mais l'histoire de la flèche plantée en terre recouvre probablement aussi un très vieux rite de fécondité (DIETERICH, Mutter Erde, p. 16, n. 1) et doit s'expliquer comme une représentation magique de la blessure fécondante faite par le ciel à la

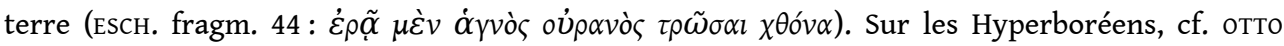
SCHROEDER, Arch. f. Rel. VIII (1905) pp.69 sqq. ; sur les sacrifices d'ânes, COOK, Journ. of hell, st. XIV (1894) pp. 81 sqq.

18. PAUS. I, $18,5$.

19. PORPH. Pyth., 28-29 ; JAMBL., Pyth., 135-136. 


\section{Conclusion}

1 Dans son étude sur la Théogonie d'Hésiode, M. Mazon, commentant l'épisode de la mutilation d'Ouranos, dit : « La force mystérieuse qui fait naître la vie, si rien ne vient la régler et la contenir, ne crée que confusion et mort : elle détruit aussitôt ce qu'elle vient de mettre au jour ... Mais Ciel est mutilé par son fils et un terme est enfin mis à son odieuse et stérile fécondité. Aphrodite va régner sur le monde. La vie ne se perpétuera plus désormais indéfiniment, au hasard: le pouvoir d'enfanter appartiendra aux créatures elles-mêmes. Deux êtres, en s'unissant, pourront faire œuvre de vie, - deux êtres de même espèce, car l'amour ne se conçoit qu'à l'intérieur de l'espèce. La fixité des espèces, voilà le premier point solide auquel s'est attachée la pensée des premiers humains lorsque, parcourant d'un regard anxieux l'immensité de la création, elle y cherchait un principe d'ordre. Que, dans des millions d'êtres de même espèce, les mêmes organes se retrouvent toujours à la même place, pour remplir les mêmes fonctions ... n'y a-t-il pas là un sujet d'émerveillement capable de devenir le point de départ de toute une philosophie?»

2 Une étude minutieuse des croyances relatives à la stérilité et aux naissances monstrueuses montre combien cette synthèse est exacte.

3 Les Grecs ont redouté une extinction de l'espèce humaine. Beaucoup d'entre eux s'imaginaient, comme Hésiode, le monde peuplé successivement de races qui, une à une, avaient disparu. Tout se passe comme s'ils craignaient de voir décliner de leur vivant celle à laquelle ils appartenaient.

4 Plus nette encore est leur terreur devant une déviation de l'espèce. Il ne s'agit pas seulement ici du type humain; leur inquiétude est la même devant une singularité de structure dans un être vivant, végétal ou animal. Une mule qui met bas paraît un présage aussi mauvais à Hérodote qu'à Paul Orose.

5 Les Babyloniens et les Assyriens, mis en présence d'un être monstrueux, le traitent comme ils feraient de n'importe quelle pièce du matériel divinatoire. Le présage qu'ils en tirent est souvent défavorable, mais non pas toujours. Les Grecs et les Latins considèrent tout être mal formé comme maléfique, même dans des cas où, interprétée suivant notre logique, l'étrangeté aurait pu apparaître comme un signe heureux. Il n'y a à cette règle que des exceptions apparentes. Si le devin Lampon tire, de la vue d'un bélier difforme, un heureux présage pour Périclès, si les aruspices déclarent à César que le monde lui 
appartiendra parce que son cheval a des pieds presque humains, cela signifie simplement qu'un pauvre prêtre ne s'expose pas à mécontenter des grands seigneurs. En d'autres circonstances, ces malformations auraient reçu une interprétation fâcheuse ${ }^{1}$.

6 Les prêtres babyloniens, non seulement énumèrent complaisamment toutes les hypothèses possibles en fait de difformités, mais, entraînés par une sorte d'humour féroce, ils continuent leurs séries à l'infini, parlent, après les jumeaux, les tridymes et les tétradymes, d'enfants qui naissent par six, huit, dix à la fois, ou qui ont cinq, six, dix têtes. Chacun de ces cas a été, sinon constaté du moins prévu, et il a reçu d'avance son interprétation particulière. Les Grecs parlent le moins possible des vices concrets à quoi on reconnaît qu'un être qui naît est un $\tau \tilde{\varepsilon} \rho \alpha \varsigma$. Ils ne nous donnent sur ce point aucun détail. Il faut attendre les auteurs latins pour savoir enfin ce que c'est qu'un monstre. Tout se passe comme si les Grecs avaient eu si peur des déviations de l'espèce qu'ils eussent craint de les évoquer en les décrivant.

$7 \quad$ Les calamités annoncées par les naissances monstrueuses concernent tout le pays où elles apparaissent. Hésiode pense que la race de fer s'éteindra quand les hommes naîtront avec les tempes blanches. L'antiquité tout entière semble avoir anxieusement cherché, sur le corps des nouveau-nés. les signes à quoi on pourrait reconnaître que la race humaine n'était plus semblable à elle-même et qu'elle allait disparaître.

Cette angoisse devant l'altération de la race, deux peuples l'ont éprouvée pendant des générations. Elle se marque dans leurs croyances et dans leurs rites. Aucun poète, à notre connaissance, ne l'a exprimée, excepté Hésiode. Hésiode a décrit la paix que donne au monde la naissance d'Aphrodite. Mais cette paix peut être précaire. Quatre races ont apparu et se sont évanouies Deux d'entre elles se sont rendues odieuses aux dieux qui les ont anéanties. Que deviendra la cinquième? Malheur au jour où elle attirera sur elle la colère divine, où elle verra naître d'elle des enfants qui ne ressemblent pas à leurs parents, - malheur au jour où les nouveau-nés auront des cheveux blancs !

\section{NOTES}

1. MORRISJASTROW, Babylonian-Assyrian Birth Omens, dans Relig. Vers. u. Vorarb. XIV (1914), p. 5. - P LUT., Périclès, 6 ; Alex., 57 ; sUÉT., J. César, 61. - Il est cependant possible que la réponse des aruspices à César doive s'expliquer, non par la simple servilité, mais par la tradition étrusque, qui paraît avoir été différente de la tradition latine sur ce point. Le peu qu'on sait des doctrines étrusques relatives aux prodiges semble indiquer qu'elles prévoient des cas où le prodige est favorable, ce qui est exclu par les doctrines strictement romaines. Il en résulte qu'il existe une divination par les prodiges en Étrurie, comme en Babylonie et en Assyrie, alors que la chose est inconnue à Rome. Du reste la naissance d'un anormal, en Étrurie, comme à Rome, était toujours fâcheuse. Cf. C. O. THULIN, die Etruskische Disciplin, III : die Ritualbuecher, Goeteborg, 1909, pp. 76 sqq. Mais les faits ne sont pas toujours faciles à interpréter. Thulin dit, en renvoyant à Macrobe, Sat. III, 7, 2, que la traduction par Tarquilius Priscus du livre étrusque des prodiges était encore en usage sous l'Empire ; elle portait que les béliers à toison rousse ou jaune étaient signe de bonheur pour l'empereur. L'attribution à l'empereur du présage favorable rend toute l'histoire suspecte : 
il était trop aisé de fabriquer des textes de ce genre pour permettre à un personnage haut placé d'échapper au caractère universellement maléfique des prodiges. Cependant, si la tradition d'un Ostentarium Tuscum s'est conservée, c'est qu'il y avait eu une divination étrusque par les prodiges. On ne peut rien affirmer de plus. 


\section{Appendice}

\section{LE FLÉAU DANS LA LÉGENDE THÉBAINE.}

1 Tous les commentateurs, sans exception, sont d'accord pour voir dans le thème du Fléau au début d'Edipe-Roi une invention de Sophocle. Les uns, nous l'avons dit, y trouvent une imitation du début de l'Iliade, les autres une allusion à la peste d'Athènes; dans les deux cas, le Fléau thébain a été introduit dans la légende par un dramaturge habile qui, donnant à un drame un début d'une exceptionnelle intensité, arrive néanmoins à faire croître ensuite l'intérêt et l'émotion.

On a démontré plus haut que Sophocle ne s'est inspiré, ni d'Homère, ni de ses souvenirs personnels. Ou bien il a inventé de toutes pièces le thème de la stérilité thébaine, ou bien il l'a trouvé dans la vieille légende de la famille de Laïos. Cette dernière hypothèse, qui nous paraît bonne, expliquerait bien des choses.

D'abord, le caractère hautement archaïque de la description, qui se rattache aux plus vieilles traditions populaires. Si Sophocle avait inventé l'épisode, il lui aurait probablement donné un caractère plus littéraire, moins strictement religieux. Le Fléau du début de l'lliade est une fantaisie de poète qui révèle aussitôt ses disparates à qui se place au point de vue des croyances.

4 De plus, le Fléau est censé punir un meurtre non-expié, vieux de douze à quinze ans. Cela est évidemment absurde. Mais ce genre d'illogismes trahit presque toujours une contamination ou un déplacement de thème. Tout s'explique si Sophocle a simplement reculé un épisode qui, primitivement, se plaçait après la mort de Laïos.

5 A partir du premier épisode, il n'est plus question du Fléau. On objectera que l'attention est prise par autre chose. C'est exact, mais Sophocle sait tisser sa toile et faire reparaitre un fil dont on a momentanément perdu la trace. Une rupture grossière, comme celle-ci, trahit généralement une survivance. Par exemple, dans la même pièce, le poète mentionne l'épisode des pieds percés (1030) puis l'abandonne parce qu'elle ne cadre pas avec la version qu'il crée, où (Edipe nouveau-né est remis par ses parents à un berger et par celui-ci à un autre (1038). L'incohérence laisse affleurer une version ancienne. 
Voilà les arguments négatifs. Cherchons, dans les textes, les traces positives d'une tradition ancienne d'après laquelle il y aurait eu une stérilité à Thèbes au début du règne d'CEdipe.

Homère raconte rapidement l'histoire suivante :

"Je vis la mère d'Edipe, la belle Epicaste, qui fit une grande chose par ignorance, ayant épousé son propre fils. Edipe, ayant tué son père, épousa Epicaste. Alors, les dieux révélèrent tout aux hommes. Edipe, dans la belle Thèbes, cruellement éprouvé, gouvernait les Cadméens en vertu des volontés funestes des dieux. Epicaste alla chez Hadès, le Portier inflexible, ayant, dans sa douleur, pendu un lacet en haut de la maison. Elle laissa à Edipe toutes les souffrances qu'accomplissent les Erinyes d'une mère $»^{1}$. à la mort de Jocaste ${ }^{2}$, car d'autres malheurs, postérieurs à cette mort et causés par elle, sont indiqués aux vers 279-280. Il est impossible de voir ici une allusion à la cécité d'Ædipe ou à la malédiction des enfants. Homère ignore l'aveuglement d'œdipe, et son union avec sa mère est stérile. Robert pense qu'il s'agit de la guerre pour les troupeaux d'ÆEdipe, dont Hésiode parle au début des Travaux ${ }^{3}$. Je doute qu'on puisse trouver dans la littérature épique de la Grèce une allusion à une guerre, - et à une guerre qui a dû être

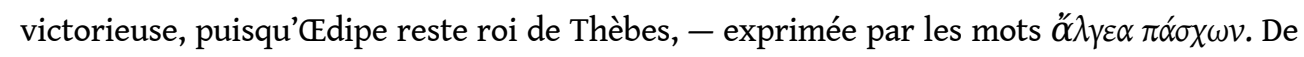
plus, Robert met le passage d'Hésiode en rapport avec les Jeux pour ÆEdipe dont Homère parle à propos des Jeux pour Patrocle, lorsqu'il rappelle que Mécisteus a été le premier aux joutes funéraires pour đEdipe tombé à la guerre ${ }^{4}$. Si Robert s'imagine CEdipe mourant dans la "guerre pour les troupeaux ", celle-ci ne peut être la même chose que les $\alpha$ ' $\lambda_{y \varepsilon \alpha}$ mentionnés par Homère. En effet, ๔edipe survit aux «maux », voit ensuite mourir sa mère et souffre des châtiments envoyés par les Erinyes maternelles. Les «maux» se placent, non à la fin de la vie d'ÆEdipe, mais peu après son mariage avec sa mère. Ils doivent faire allusion à une douleur passive et non à la conduite d'une guerre. Ils ont un caractère mystérieux puisqu'on les attribue à un dessein des dieux irrités. Comment n'être pas tenté de compléter le très elliptique récit d'Homère en admettant que, dans la légende qu'il suit, les dieux irrités par le parricide et l'inceste envoient en châtiment à Thèbes une stérilité analogue à celle qui est décrite par Sophocle? Le Fléau tombe sur la ville et frappe également đEdipe ( $\left.\alpha \lambda_{\gamma \varepsilon \alpha} \pi \alpha \alpha \sigma \chi \omega v\right)$ dont l'union avec sa mère reste stérile. Il interroge un oracle qui lui découvre la vérité. Epicaste se tue en le maudissant. Il continue à régner, poursuivi par les Erinyes de sa mère.

13 Sophocle aurait donc trouvé le thème du Fléau dans la légende ancienne. Mais, là, le Fléau servait à amener rapidement une révélation complète. Sophocle suppose que le dieu interrogé répond à une question de façon à en provoquer une autre : «C'est le meurtrier de Laïos qu'il faut tuer ou exiler : mais qui est le meurtrier de Laïos?» Et ainsi l'intérêt rebondit. 

poète a eu l'idée de faire naître des enfants de l'union incestueuse. Dans la légende ancienne, cette union maudite est stérile. Mais il s'est passé ici ce qui s'est passé ailleurs : en voulant enrichir le contenu psychologique d'une histoire, les poètes en faussent le caractère et ne s'aperçoivent pas que, religieusement parlant, elle a cessé d'être intelligible.

Apollodore a conservé, de la légende d'Admète, une version qui est certainement la plus ancienne : Alceste se sacrifie au lendemain de son mariage; Admète étant le dernier de sa race, la femme doit donner sa vie pour sauver son mari ${ }^{5}$. Euripide a voulu que le sacrifice d'Alceste eût un poids et un mérite plus grands : il la montre épouse et mère. La psychologie dramatique y gagne, mais la logique y perd, car Admète, ayant des fils, pourrait disparaitre. Le flottement se marque dans le caractère même d'Admète, lequel, d'abord, trouve naturel qu'on se sacrifie pour lui (et ce serait le cas s'il était le dernier mâle de sa race), puis se repent d'avoir accepté le dévouement de sa femme.

Sophocle a procédé de même si, comme je le crois, il a trouvé dans la légende ancienne le thème du Fléau. La source épique qu'il a probablement suivie devait être plus explicite que la brève allusion d'Homère. Le Fléau qui servait d'occasion à la révélation divine frappait Thèbes et ses rois immédiatement après le crime et le mariage maudit. Une stérilité qui atteint un pays douze ou quinze ans après la faute qu'elle est censée châtier est une pure absurdité. Seulement, Sophocle compte bien que ses auditeurs, emportés par le mouvement de la pièce, n'y penseront pas; et le délai qu'il accorde à la justice divine lui permet de mettre, entre ÆEdipe et Jocaste, un attachement renforcé par la naissance de quatre enfants, par la pratique conjointe du pouvoir, par une longue habitude de vie en commun. Le sort qui les arrache l'un à l'autre est bien plus cruel que celui qui sépare les nouveaux époux d'Homère. Comme Euripide dans Alceste, Sophocle montre ici qu'il tient plus à la richesse psychologique qu'à la logique matérielle des événements.

Mais, cette logique, d'autres poètes et des mythographes ont tenté de la sauver. Pour concilier la légende archaïque du mariage maudit, stérile, avec la légende des enfants d'ÆEdipe, qui sera celle des tragiques, on a dédoublé le personnage féminin. ÆEdipe épouse d'abord sa mère et n'a pas d'enfants, puis une autre femme qui, elle, est féconde. Robert estime que le dédoublement a dû être tardif. Or, il est attesté dès l'œEdipodie. En effet, une des rares choses que nous sachions relativement à ce poème perdu, c'est le détail transmis par Pausanias qui dit (IX, 5, 11) que la mère des enfants était, dans l'EEdipodie, Euryganeia. Voici ce passage, dont Robert a donné une interprétation difficile à admettre :

«Pendant que Laïos était roi et marié à Jocaste, un oracle lui arriva de Delphes disant que de son fils lui viendrait la mort si Jocaste lui en donnait un. A la suite de quoi il exposa Edipe, lequel devait, ayant grandi, tuer son père, épouser sa mère. Je ne pense pas qu'il eut d'elle des enfants, étant donné le témoignage d'Homère qui dit dans l'Odyssée: «... les dieux révélèrent aussitôt le crime aux hommes. " Comment auraient-ils pu le révéler aussitôt, si quatre enfants étaient nés de Jocaste et d'Édipe? C'est d'Euryganeia, fille d'Hyperphas, qu'ils naquirent. Ainsi parle celui qui fit le poème qu'on appelle l'Ædipodie, et Onasias à Platées a peint Euryganeia les yeux baissés devant la querelle de ses enfants. "

Pour Robert, ceci signifie simplement que la mère-épouse s'appelait Jocaste chez les tragiques, Epicaste chez Homère, Euryganeia dans l'ÆEdipodie, et que les mythographes ont fait des personnages différents avec chacun des noms qui, primitivement, désignaient une seule et même personne. Il est impossible de prêter une telle confusion à Pausanias. Il sait et dit très clairement que Jocaste et Epicaste sont une seule personne, mais qu'Euryganeia 
en est une autre ; qu'Epicaste, chez Homère, doit être supposée stérile et qu'Euryganeia, dans l'ÆEdipodie, apparaissait dans un rôle nouveau, comme génitrice des enfants d'Ædipe. Cela prouve que, lorsque l'ÆEdipodie fut composée, la légende des enfants était déjà constituée, mais que, d'autre part, l'histoire de la stérilité résultant de la faute était encore vivante. Cette stérilité frappait, peut-être, Thèbes tout entière, mais, assurément, le couple incestueux en premier lieu.

On s'est beaucoup demandé quels rapports il y avait primitivement entre la légende des frères ennemis et le mariage incestueux. La haine des frères résulte-t-elle de l'impiété dont ils sont le fruit, ou bien la guerre des Sept, légende autonome, a-t-elle été attirée après coup dans le cycle d'ÆEdipe ? Si ce qui précède est exact, la seconde hypothèse est seule possible. EEdipe et Epicaste ne peuvent avoir d'enfants. Lorsque l'épisode de la rivalité des frères est entré dans l'histoire d'ÆEdipe, il a bien fallu donner à celui-ci une postérité et on a été obligé de forger l'anneau manquant, Euryganeia, épousée après l'apaisement du Fléau et capable d'enfanter.

Or, des récits, provenant de versions étrangères à la tradition tragique, montrent bien qu'Euryganeia y joue uniquement ce rôle de génitrice que Jocaste ne pouvait jouer. Un long scho-lion des Phéniciennes (au vers 1760) expose la fable suivie par Pisandre. D’après lui, la Sphinx avait été envoyée d'Éthiopie par Héra, irritée contre Laïos, lequel avait introduit en Grèce l'amour pour les jeunes garçons. Tirésias conseille à Laïos de recourir à Apollon et à Héra, mais Laïos méprise ces conseils. Il est tué par CEdipe qui épouse sa mère. La reconnaissance a lieu, semble-t-il, tôt après le mariage. "Pisandre ajoute qu'après la mort de Jocaste đEdipe, qui s'est aveuglé, épouse Eurygané, une jeune fille, de laquelle naquirent les quatre enfants ». Ce texte a été longuement commenté par Robert, qui le juge plein d'invraisemblance ${ }^{6}$. Il devient parfaitement clair si l'on veut bien, en le lisant, se rappeler ceci: l'auteur du résumé raconte uniquement les épisodes où la narration de Pisandre s'écarte des différentes versions tragiques : la Sphinx est envoyée contre Laïos ; Jocaste reconnaît en đdipe le meurtrier de Laïos parce que, allant avec lui au Cithéron pour y faire des sacrifices, ils passent à l'endroit du meurtre qu'CEdipe lui raconte en montrant à l'appui de son récit le baudrier de l'inconnu qu'il a tué. Certains épisodes ne sont pas mentionnés ou le sont à peine : naissance et exposition d'œedipe, victoire sur la Sphinx. Ce devaient être ceux où Pisandre suivait une version connue. Il en était de même pour la fin de l'histoire: Jocaste se tue comme Epicaste dans l'Odyssée. Eurygané est simplement mentionnée comme mère des enfants. Apollodore, après avoir raconté l'histoire d'ÆEdipe conformément à la version sophocléenne, ajoute : « Il y a aussi des auteurs qui disent que les enfants sont nés d'Euryganeia fille d'Hyperphas $»^{7}$. Pausanias, un scholiaste d'Euripide, Apollodore, connaissent des poèmes où đEdipe a deux femmes l'une après l'autre. Robert trouve cette invention insoutenable. Les poètes n'y regardent pas de si près lorsqu'il s'agit de souder deux légendes; Euryganeia n'est là que pour réunir la légende d'ÆEdipe à celle d'Etéocle et Polynice. Mois, si elle est là, c'est que Jocaste-Épicaste devait rester stérile. Un détail de cette version prouve sa haute antiquité : Jocaste-Epicaste, en se sacrifiant, satisfait les dieux. Or, elle est parfaitement innocente de tout ce qui est arrivé. Nous avons vu qu'à une époque ancienne, on immole aux dieux une victime qui n'est pas nécessairement le coupable. Chez Homère, Æđdipe ne s'inflige aucun châtiment pour son double crime. Le début d'ÆEdipe-Roi et l'oracle qui réclame le coupable trahissent les préoccupations d'une époque récente, où la notion de responsabilité va s'affinant. Rien de semblable dans les versions anciennes ni dans celle que suit encore Pisandre. 
Il est bien difficile de tirer un parti quelconque de la légende signalée par un scholiaste d'Euripide (Phén. 52). "Voici, dit-il, comment Phérécyde raconte ce qui concerne les enfants d'œEdipe et les femmes qu'il épousa. Créon lui donne la royauté et la femme de Laïos, sa mère Jocaste, de laquelle il a Phrastor et Laonytos, qui meurent tués par les Minyens et Erginos. Lorsqu'une année eut passé, CEdipe épouse Euryganeia, fille de Périphantos, de laquelle naissent Antigone, Ismène... Etéocle, Polynice. Après la mort d'Euryganeia, Edipe épouse Astymédousa, fille de Sthénélos.» On retrouve cette Astymédousa dans un scholion de l'Iliade (IV, 376), qui dit qu'Edipe l'épousa après avoir répudié Jocaste. La jeune femme calomnia ses beaux-fils ; leur père s'emporta contre eux et les condamna par sa malédiction à prendre le pouvoir dans le sang, après quoi il le leur donna ${ }^{8}$. On a greffé sur la légende d'€Edipe le thème de la méchante belle-mère afin de faire de la malédiction d'€́dipe une réplique de la malédiction de Thésée. Astymédousa, contrairement à Euryganeia, doit appartenir à des récits tardifs. La femme de Polybe, père nourricier d'ÆEdipe, s'appelle parfois Médousa (Sch. $E d . R .775$ ).

Les tragiques, qui concentrent la légende et qui veulent montrer dans toute leur ampleur les conséquences de la malédiction des dieux, se débarrassent d'Euryganeia et font de Jocaste la femme deux fois mère, malheureuse dans son premier fils, malheureuse encore dans sa seconde union. Et Sophocle, qui doit avoir trouvé quelque part le vieux thème du Fléau, ne s'aperçoit pas qu'il introduit dans sa construction une double absurdité : une stérilité qui frappe brusquement un crime déjà vieux et presque oublié ; une stérilité qui épargne le couple humain chargé de ce crime. Ses auditeurs n'ont jamais dû y penser ; ses lecteurs ne s'en avisent qu'à la réflexion.

Un autre texte semble bien prouver encore que le thème du Fléau appartient à l'ancienne légende thébaine.

Hygin (fable LXVII) raconte l'histoire d'ÆEdipe en suivant la version sophocléenne jusqu'au moment où il dit : «Interim (après la naissance des quatre enfants) incidit Thebis sterilitas frugum et penuria ob Edipodis scelera, interrogatusque Tiresias quid ita Thebae uexarentur, respondit, si quis ex draconteo genere superesset et pro patria interiisset, pestilentia liberaturum. Tum Menoeceus Jocastae pater, se de muris praecipitauit. Dum haec Thebis geruntur, Corintho Polybus decedit... »

«Une stérilité de la terre et une famine tombent sur Thèbes. » De deux choses l'une : ou bien Hygin suit Sophocle et il voit dans le Fléau - comme les scholiastes grecs du reste, une stérilité et non une maladie, ou bien il ne suit pas Sophocle et, dans ce cas, la source qu'il suit contient l'épisode du Fléau.

29 Ce qui donne à penser que Hygin ne suit pas Sophocle, c'est qu'à cet endroit précis sa narration dévie et donne un détail inattendu. Ce n'est pas Delphes que l'on consulte, mais Tirésias; les dieux ne réclament pas le coupable, mais une victime née du Dragon. Ménécée se jette du haut des murailles.

30 Robert considère tout ce passage comme intrus et provenant d'un résumé des Phéniciennes d'Euripide. Il estime que le bon texte a dû être conservé par le fragmentum Niebuhrianum qui, pour ce passage, dit simplement: incidit Thebis sterilitas et pestilentia ob EEdipodis scelera. Interim Eriboea, Polybii regis uxor... Thebas venit ${ }^{9}$.

31 Il est assurément possible que quelques lignes qui ont trait à une pièce d'Euripide se soient glissées dans un récit étranger. Cela est cependant peu probable. En effet, l'épisode du jeune Ménécée se sacrifiant au moment du siège de Thèbes figure dans la fable LXVIII. 
La fable LXVII dit que c'est son grand-père qui s'est offert en holocauste au moment de la stérilité. Le dernier éditeur Rose, suivant en cela Robert, considère comme interpolés les mots Jocastae pater, simplement parce qu'ils estiment impossible le sacrifice de ce vieillard. S'il y a une interpolation, elle est antérieure à la dernière rédaction de la compilation, car Menoeceus Jocastae pater figure au ch. CCXLII dans la liste de ceux qui se sont tués eux-mêmes.

Je croirais volontiers ancienne l'histoire de Ménécée immolé pour arrêter le Fléau. Il s'agissait probablement du petit-fils : le sacrifice d'une jeune fille ou d'un jeune homme vierge pendant des stérilités est un thème bien connu. Euripide l'a transposé sur le plan guerrier : son Ménécée se donne la mort pour assurer la victoire des Thébains.

Que vient faire dans cette histoire le grand-père? Cela est bien difficile à savoir. Les sacrifices de jeunes gens sont fréquents, mais non les sacrifices de vieillards. Y avait-il une légende où il se substituait à son petit-fils comme Alceste à Admète? Les dieux avaient-ils exigé un Ménécée sans dire lequel ? Le grand-père avait-il joué sur l'identité de nom? Nous serions alors en présence d'un de ces cas où les hommes trompent les dieux à la faveur d'une homonymie. Cela n'est pas impossible. Ce qui est certain, c'est qu'il est contraire à toute méthode de considérer un détail comme inauthentique, alors qu'il revient deux fois dans un texte. Il est d'autant plus précieux qu'il est plus difficile à expliquer.

Il est donc probable que le thème du Fléau appartient à l'ancienne légende thébaine. Au

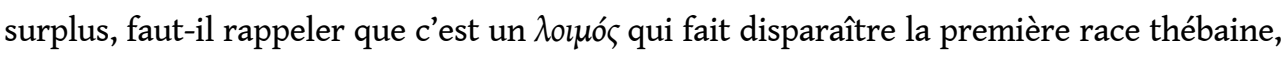

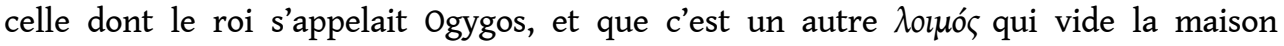
d'Amphion ${ }^{10}$ ? Il y a peu de traditions où les Fléaux jouent un rôle aussi grand que celles qui sont relatives à la patrie d'ÆEdipe.

CEdipe lui-même, qu'est-il ? L'histoire des pieds percés n'appartient pas à la légende ancienne qui donne deux autres versions : tantôt l'enfant est exposé sur l'eau, tantôt sur le Cithéron ${ }^{11}$. La blessure aux pieds semble bien avoir surtout servi, antérieurement à Sophocle, à la reconnaissance (c'est pourquoi Sophocle la mentionne, puis la tient nonavenue, puisqu'il représente l'enfant remis par un berger à un autre) et aussi à expliquer le nom. Mais n'est-il pas étrange qu'ÆEdipe n'ait pas de nom en dehors de son sobriquet ? Pâris, autre enfant exposé, s'appelait Alexandre dans la maison de Priam; Cyrus a un autre nom chez le bouvier qui l'a élevé.

La légende d'ÆEdipe remonterait-elle à une histoire plus ancienne d'un nouveau-né maléfique exposé à cause de son infirmité et déjouant sans le savoir les précautions prises contre lui et contre les malheurs dont il est le dépositaire? Son grand père s'appelle Labdakos, le Boiteux ${ }^{12}$. CEdipe serait-il un de ces Pieds-Enflés que nous avons cru retrouver dans une loi d'Éphèse, et que l'on condamnait à mort avec d'autant plus d'horreur que, signes de stérilité, leur anomalie était le symptôme même de la mort par inanition? Ce n'est certainement pas impossible. On objectera qu'on ne trouve rien d'analogue dans la légende grecque. Assurément, mais, si nous ne lisions pas Philoctète, nous affirmerions que les Grecs n'ont jamais traité poétiquement le thème de la souffrance physique, ni celui de l'excommunication des malades. 


\section{LES JUMEAUX MALÉFIQUES.} Cela est extrêmement difficile parce que les textes sont peu nombreux et se contredisent les uns les autres. A l'époque où le plus ancien a été écrit, il n'y avait probablement déjà plus un sentiment unique à l'égard des jumeaux, des tridymes, des tétradymes. Denys d'Halicarnasse (III, 22) dit que, depuis le haut fait des Horaces, les tridymes sont nourris chez leurs parents, aux frais de l'État, jusqu'à la fin de leur jeunesse. Cependant Julius Obsequens relate pour l'année 163 avant J.-C. une naissance triple qui semble bien être présentée comme un prodige de mauvais augure ${ }^{13}$. Pline dit (VII, 3), comme une chose qui va de soi, que la quadruple naissance qu'on vit à Ostie à la fin du règne d'Auguste annonçait une famine, laquelle se produisit en effet. Au contraire, l'auteur des Mirabilia attribués à Aristote voit (LXXX) dans les naissances multiples un signe de fécondité générale. Et Phlégon de Tralles raconte (Mirab. XXIX pp. 140-141) que, sous Trajan, une femme mit au monde, en une seule fois, trois garçons et deux filles : l'empereur ordonna de les faire élever sur sa cassette particulière. Il n'est pas impossible que le nombre des enfants ait joué un rôle dans l'idée que l'on se faisait de leur caractère favorable et défavorable. On peut avoir considéré les tridymes comme bien faisants, les tétradymes comme maléfiques ${ }^{14}$. retrouve aisément la trace d'une ordalie primitive ; les dieux, en les sauvant tous les deux, prouvent qu'ils tiennent la mère innocente et qu'ils veulent que l'enfant vive. Danaé est ainsi exposée avec Persée, Augé avec Téléphos. Mais il arrive aussi que des enfants soient exposés sans la mère, et, dans ce cas, ce sont souvent des jumeaux : Nélée et Pélée, Zéthus et Amphion, Romulus et Rémus ${ }^{16}$. A-t-on le droit de tirer une conclusion quelconque d'exemples aussi peu nombreux? En tous cas, il semble bien qu'il faille distinguer nettement les deux cas, celui où l'ordalie porte sur la mère et l'enfant, celui où elle ne porte que sur ce qui est né. Dans ce dernier cas, que peut-elle prouver? Peut-être, à une époque très ancienne, croyait-on encore, comme c'est le cas dans certains peuples sauvages, qu'un seul des jumeaux est l'enfant du mari ; l'autre résulte d'un adultère de la mère. On pourrait alors demander aux dieux de faire la distinction et de laisser vivre seulement l'enfant légitime. Cela n'est pas impossible, car les légendes de ce genre conservent le souvenir des persécutions infligées à la mère. Il se peut aussi que les jumeaux aient été primitivement considérés comme maléfiques et exposés comme tels. Aucun texte ne permet d'aller plus loin qu'une simple hypothèse.

Ce qui est sûr, c'est que, chez un grand nombre de peuples, la naissance de jumeaux est un signe mis en rapport avec l'apparition de la pluie, aussi bien lorsqu'elle est un symptôme fâcheux que lorsqu'elle est supposée porter bonheur ${ }^{17}$. Il est regrettable que toutes nos légendes classiques soient trop rationalisées pour nous offrir encore des traces perceptibles de ces vieilles croyances. 


\section{LA LÉGENDE DE PHILOCTÈTE ET L'EXCOMMUNICATION DES MALADES.} l'origine divine est évidente. Nous avons là, dans la littérature grecque, un cas peut-être unique de malheureux excommunié. Au terme d'une étude où l'on a évité tout rapprochement entre les croyances grecques et latines d'une part, les religions des peuples non-civilisés d'autre part, sera-t-il permis de rappeler les pages pénétrantes où Lévy-Bruhl étudie l'éviction des malheureux? connaît plus, c'est un membre retranché ; les sentiments qu'il inspire, le traitement qu'on lui inflige rappellent les excommuniés du moyen âge." "Quand un homme risque de périr accidentellement, c'est à cause du courroux des puissances invisibles qui se révèle aussi nettement que si l'homme était déjà mort. L'aider à s'échapper serait se rendre complice de sa faute et attirer sur soi le même malheur. » Chez les Cafres, les femmes qui accouchent ne peuvent pas crier, sous peine de voir fuir tout le monde et de rester sans secours, abandonnées de tous. Aux îles Fidji, les naufragés sont regardés comme des victimes de la colère des dieux. Partout se justifie la formule res est sacra miser, à condition "que l'on donne au mot sacra son sens plein, non pas digne de respect et d'égard, mais mis dans un état qui interdit qu'on s'en approche et qu'on y touche». Et Lévy-Bruhl montre parfaitement que l'excommunication des malades et des moribonds n'a rien de commun avec la crainte d'une contagion naturelle ${ }^{18}$.

44 Le public d'Homère sentait-il en Philoctète un maudit qu'il était tout naturel d'écarter, dans l'intérêt même de la communauté ? Cela est probable, puisque le poète ne donne aucune justification de l'acte des Grecs:

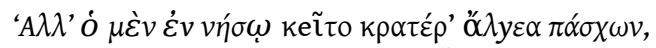

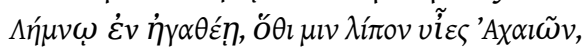

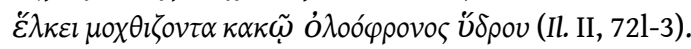

Quel est l'auteur qui, le premier, a jugé ce motif insuffisant, c'est à dire aux yeux de qui l'excommunication des malheureux est apparue comme une chose inhumaine, parce qu'il ne partageait plus les croyances obscures sur quoi elle repose? Il est probable que la transformation de la légende est antérieure à Sophocle. Mais tout donne à penser que c'est lui qui a imaginé la raison qui figure en ordre principal dans sa tragédie : que les cris de Philoctète empêchent les sacrifices et gênent la vie religieuse de l'armée. En effet, cette raison est mentionnée au début du prologue, là où les auteurs signalent volontiers leurs innovations personnelles, afin d'éviter que l'esprit des auditeurs puisse s'engager sur une fausse piste, celle de la mythopée tracée par leurs devanciers. Avant Sophocle, il doit y avoir eu un commencement de rationalisation. Dans sa tragédie, il est question à plusieurs reprises de l'ennui qu'apporte dans un bateau un homme atteint d'une blessure purulente. Ce motif n'est nullement en contradiction avec celui des gémissements qui empêchent les sacrifices, mais il est singulièrement plus faible et Sophocle parait bien l'avoir gardé pour étayer la raison principale ${ }^{19}$.

Au surplus, que l'on relise les vers où est donnée la justification nouvelle :

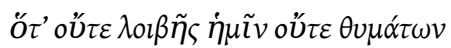

$\pi \alpha \rho \tilde{\eta} v \dot{\varepsilon} \kappa \hat{\lambda} \lambda o \iota \varsigma \pi \rho \circ \sigma \theta l \gamma \varepsilon \tilde{\varepsilon} v, \dot{\alpha} \lambda \lambda^{\prime} \dot{\alpha} \gamma \rho i \alpha \iota \varsigma$ 


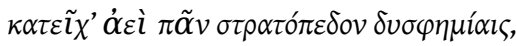

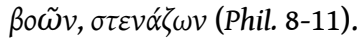
Néoptolème prenne Troie avec l'aide de Philoctète, ils doivent accepter du même coup que ce dernier, jusqu'à sa guérison, gêne les sacrifices : Philoctète lui-même signale avec amertume l'illogisme de ceux qui, après l'avoir abandonné, viennent le rechercher, alors qu'il est resté le même (1031). Les auditeurs devaient admettre que la révélation apportée par Hélénus annulait les considérations tirées de la vie religieuse de tous les jours. Il reste que Philoctète, sur le bateau, sera un hôte pénible et qu'il faudra, pour le supporter, de la patience et de la générosité. Or, ce n'est pas pour sa patience que Néoptolème est loué lorsqu'il se décide à emmener le malade, mais pour son courage ${ }^{20}$. Qu'est-ce que cela signifie ? Simplement que nous avons ici une rémanence de la mythopée primitive : si le malheureux est maléfique, il faut du courage pour ne pas l'abandonner, pour accepter son contact, pour s'exposer à recevoir les contre-coups de la colère des dieux. "Quand un homme tombait dans une crevasse et que nous l'aidions à sortir de l'eau, nous étions reçus par les siens comme si nous avions fait quelque chose d'héroïque $»^{21}$, raconte un voyageur après un séjour chez les Esquimaux.

\section{STÉRILITÉ ET NAISSANCES ANORMALES DANS LE FOLK-LORE DES AUTRES PEUPLES.}

On retrouve à Rome toutes les superstitions que Lévy-Bruhl croit appartenir en propre à la mentalité primitive. Dans les récits de missionnaires et de voyageurs dont il s'est servi pour décrire celle-ci, on voit en effet que l'on considère comme monstrueux les enfants nés les pieds en avant, les enfants qui percent les incisives supérieures les premières, que l'on tue des chèvres qui montent sur le toit d'une maison. L'enfant monstrueux est exposé, plus souvent qu'il n'est tué. Lorsqu'il est épargné, il est isolé, excommunié, et sa femme le sera aussi : «Il ne peut toucher aux graines préparées pour être plantées, sinon la récolte serait perdue. De même il ne peut manger des bananes d'une plantation en plein rapport, sinon tous les fruits pourriraient. Bref, il a le mauvais ceil ». Combien on regrette de trouver ici cette conclusion probablement prématurée! Rien ne nous dit que la nocivité du monstre était universelle : elle concerne peut-être uniquement la fertilité du sol, comme cela semble avoir été le cas en Grèce à une époque ancienne. 

les peuples civilisés, il reste une différence : les premiers ne se préoccupent nullement de donner un camouflage rationaliste à leurs superstitions, à quoi du reste les Grecs s'efforcent beaucoup plus que les Latins. Cela fait que les «primitifs » ne confondent pas enfants monstrueux et enfants débiles. "L'enfant que l'on étouffe ou que l'on expose aux bêtes fauves parce qu'il s'est présenté les pieds les premiers ou parce qu'il a percé ses incisives du haut avant celles du bas pouvait être parfaitement constitué d'ailleurs, sain et fort. Il pouvait même promettre de devenir un membre vigoureux et robuste du groupe social, cela ne le sauvait pas d'une mort immédiate, tandis que d'autres enfants, plus chétifs, mais exempts d'anomalies, étaient épargnés et continuaient à vivre tant bien que mal. » Les philosophes anciens ont pris tant de soin d'effacer cette distinction qu'ils y sont à peu près parvenus. Les écrits des peuples qui ont rougi de leurs superstitions sont ceux qui livrent le plus malaisément leur contenu religieux.

51 Comme les Grecs et les Romains, les « primitifs » établissent un lien entre la fécondité des femmes et celle de la terre. Chez bien des peuples, le fait seul que la culture est faite par les femmes a déjà le sens d'une participation magique. D'autres mettent la fausse-couche en rapport avec la fécondité du sol. L'accident doit être expié. S'il ne l'est pas, le mari et la femme sont sévèrement punis : «Une fausse-couche secrète, qui permet à la femme et à son mari d'éviter les tabous expiatoires, met tout le groupe social en danger de mort. La pluie ne peut plus tomber. Les moissons seront brûlées; le bétail périra de soif. Le tribu sera réduite au désespoir.» Ils établissent également un lien entre certaines fautes et l'apparition de la stérilité : «Chez les Battas de Sumatra, dans le cas d'un inceste, toute la moisson serait perdue, si la faute commise n'était aussitôt expiée $»^{22}$.

Qui se serait attendu à trouver dans l'œuvre du très savant Sophocle des thèmes apparentés à ces vieilles et grossières superstitions?

\section{LABDAKOS ET LABDA}

Labdakos est un personnage sans légende inséré entre Poly-dore et Laïos dans la liste des rois cadméens. Robert pense que le nom de Labdakos, le boiteux, doit avoir été inventé d'après celui de son petit-fils Oidipous, le Pied-Enflée ${ }^{23}$. Cela est assurément possible, mais on se demande alors pourquoi ceux qui ont fabriqué le nom n'ont pas aussi inventé un bout de légende pour le justifier. Et, en tous cas, on ne peut pas quitter Labdakos sans avoir rapproché son nom et son histoire du nom et de l'histoire de Labda.

Labda est une Bacchiade que personne ne veut épouser parce qu'elle est boiteuse. Elle finit cependant par se marier avec Eétion; des oracles annoncent que leur enfant fera beaucoup de mal à Corinthe. Dès qu'il est né, dix envoyés du peuple viennent pour le prendre et l'exposer. Mais l'enfant sourit et, désarmés, ils le rendent à sa mère. Celle-ci, craignant pour lui, le cache dans un coffre ( $\kappa v \psi \varepsilon \dot{\lambda} \eta)$ et le sauve ainsi.

55

L'histoire est suspecte parce qu'elle pourrait avoir été inventée pour rendre raison du nom de Cypsélos. Mais, alors, comment expliquer l'étrange parallélisme de cette histoire avec celle d'ÆEdipe?

Labdakos et Labda, deux boiteux, sont, lui le grand-père, elle la mère d'un nouveau-né dénoncé comme maléfique avant sa naissance. Dans les deux cas, l'enfant survit. L'histoire du sauvetage de Cypsélos n'est en rien influencée par celle du sauvetage d'ÆEdipe, ni réciproquement. Aucun des quatre personnages n'a de nom. Ils portent 
uniquement des sobriquets tirés, pour les parents, de leur infirmité, pour les enfants, d'un épisode de leur sauvetage. Une caisse de bois était l'instrument ordinaire des ordalies par l'eau : il est probable que, dans une forme plus ancienne de la légende, le fils de Labda était exposé comme Ædipe et miraculeusement sauvé. Enfin, l'infirmité attribuée ici à la mère, là au grand-père, ne joue aucun rôle dans l'histoire. Les oracles qui mettent les Corinthiens en garde contre le fils d'Eétion ne disent pas que sa mère lui ait transmis aucun caractère maléfique ${ }^{24}$. Il n'y a donc pas de lien logique entre la difformité de l'ascendant et la malédiction qui pèse sur l'enfant.

Tenons compte de ces remarques pour proposer - avec toutes les réserves d'usage l'explication suivante.

đEdipe et Cypsélos auraient été primitivement des nouveau-nés difformes condamnés à mort. C'est pourquoi on ne leur a pas donné de nom. Ils ont été exposés et ont eu la chance de survivre pour une destinée sombre mais glorieuse.

Mais la légende antique ne peut guère admettre que ses héros soient physiquement déficients. Ce trait s'efface peu à peu des légendes relatives à đEdipe, à Cypsélos. On explique les menaces qui ont pesé sur leur naissance par des oracles antérieurs à elle. Mais, comme on garde le souvenir d'une infirmité maléfique, on attribue celle-ci à un ascendant : le grand-père, la mère. Ces derniers n'ont pas de nom: ils sont de simples personnifications de la difformité qui est probablement à la source de toute l'histoire.

Hérodote (IV, 161) raconte l'avènement de Battos en termes si elliptiques qu'il est impossible d'en rien conclure. Lorsque le fils boiteux d'Arcésilas, Battos, se trouva hériter du royaume, les Cyrénéens envoyèrent à Delphes pour demander ce qu'il fallait faire. Il est certain que c'était l'infirmité qui faisait hésiter les sujets de Battos ${ }^{25}$. Mais était-ce à cause de ses conséquences fonctionnelles ou de ses conséquences religieuses? Craignaient-ils d'avoir un roi impotent ou d'avoir un roi maléfique ? Chez aucun auteur, le remaniement rationaliste n'est plus constant ni plus profond que chez Hérodote et rien n'affleure ici de ces vieilles superstitions dont nous avons partout cherché la trace.

\section{NOTES}

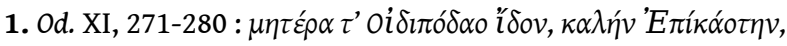

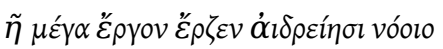

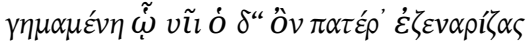

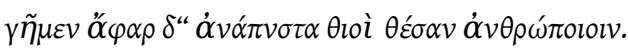

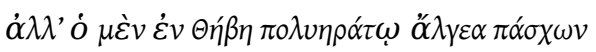

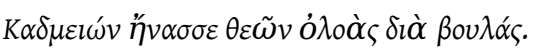

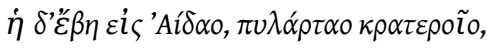

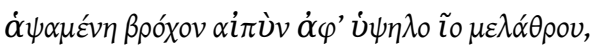




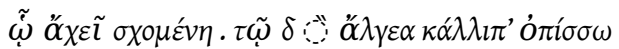

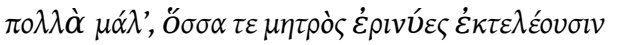

2. On trouvera les principales interprétations proposées chez HOEFER, ๔Edipus, dans Roscher, p. 701. Leur défaut à toutes est de s'appuyer sur la légende telle qu'elle apparaît dans son développement ultérieur. 'A $\lambda y \varepsilon \alpha \pi \alpha ́ \sigma \chi \omega v$ est une formule homérique ; il ne faudrait peut-être pas essayer de trop en tirer si le vers suivant n'insistait sur les malheurs d'€Edipe.

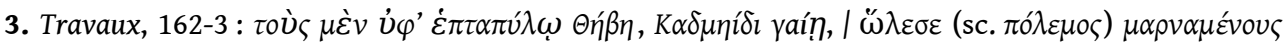

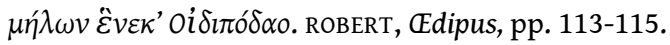

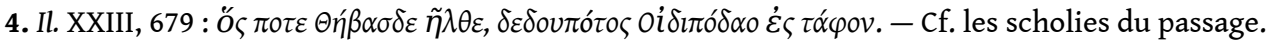

5. Bibl. I, 9. 15.

6. Ædipus, pp. 150 sqq.

7. Bibl., III, $5,7$.

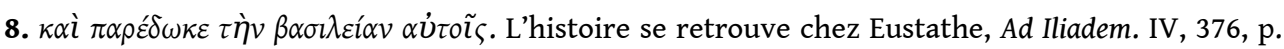
369,40 , à l'exception du dernier détail qui aura été supprimé à cause de son absurdité. WECKLEIN, die Kykl. Thebais (Sitz. Bayr. Ak. Wiss. zu München, 1901, p. 681), pense que, dans cette tradition, le nom de Jocaste doit recouvrir celui d'Eurygenia : cela n'expliquerait pas les disparates du récit. La version attribuée à Phérécyde doit être, dit-il, celle de l'œdipodie, mais rapportée très inexactement.

9. Edipus, pp. 317 sqq.

10. Paus. IX, 5,1 et 9.

11. ROBERT, CEdipus, pp. 62-76.

12. Cf. Appendice V.

13. Prod. lib. 14 : Terracinae pueri trigemini nati, corrigé par Oudendorp en pueri tres gemina natura, par Wopkens en pueri trimani. Il est inutile d'insister sur l'erreur de méthode qu'il y a à corriger un texte parce qu'il offre une difficulté.

14. Dans le concret, il devait y avoir très peu d'enfants nés d'un accouchement multiple et qui survivaient à la naissance. On compte aujourd'hui environ une naissance de jumeaux pour cent naissance simples; une naissance de tridymes sur dix mille, une naissance de tétradymes sur un million, une naissance quintuple sur cent millions. Ces chiffres se suivent comme les puissances successives de cent.

15. vonNegelein, Arch. f. Rel. V, (1902), p. 271 ; - C. SPIESS, ibid., XV (1912), p. 162.

16. Romulus et Rémus ne sont pas des jumeaux dans l'ancienne légende latine. Mais le fait qu'on a contaminé leur histoire avec celle de deux jumeaux exposés permet de les citer ici. W. Soltau ( Arch. f. Rel. XII (1909) pp. 101 sqq.) pense que cet épisode pourrait venir de la Tyro de Sophocle, c'est-à-dire de la légende de Nélée et Pélée. Cela est bien peu vraisemblable.

17. LÉVY-BRUHL, Mentalité primitive, pp. 160 sqq. ; Le Surnaturel et la Nature dans la Mentalité primitive, pp. 27 sqq. ; FRAZER, Rameau d'Or, éd. abr. trad. fr., pp. 62 sqq.

18. Mentalité primitive, pp. 315 à 350.

19. A. SEVERYNS, Le cycle épique dans l'école d'Aristarque, pp. 299 sqq., estime qu'il a existé une version de la légende où Philoctète restait à Lemnos de son plein gré. Il le démontre en

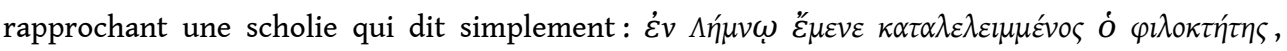
d'une autre qui dit que Philoctète fut laissé à Lemnos par les Grecs afin qu'il pût être soigné par les prêtres d'Héphaistos habiles à guérir, les morsures des serpents (ad Iliadem, II, 722). Rien n'indique à vrai dire que cette raison, alléguée par les Grecs, fut acceptée par Philoctète. Il est évidemment impossible de faire des conjectures sur ce qui pouvait rester des vieilles superstitions dans une légende ainsi rationalisée.

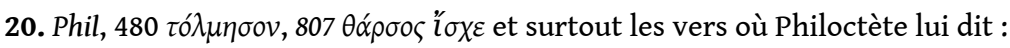

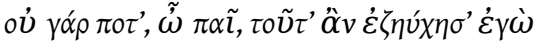

$\tau \lambda \tilde{\eta} \nu \alpha i \sigma^{\prime} \dot{\varepsilon}^{\prime} \lambda \varepsilon v v \tilde{\omega} \tilde{\omega} \delta \varepsilon \tau \dot{\alpha} \mu \grave{\alpha} \pi \dot{\eta} \mu \alpha \tau \alpha$ 


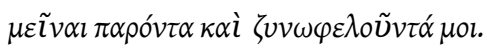

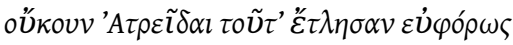

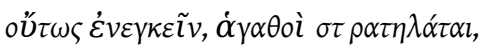

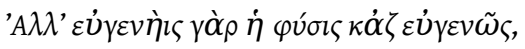

$\tilde{\omega} \tau \dot{\varepsilon} \kappa v o v, \dot{\eta}$ or, $\pi \dot{\alpha} v \tau \alpha \tau \alpha \tilde{v} \tau^{\prime} \dot{\varepsilon} v \varepsilon \dot{\mathcal{U}} \chi \varepsilon \rho \varepsilon \tilde{\varepsilon}$

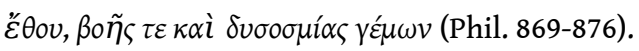

Néoptolème est loué pour sa générosité, mais les Atrides sont blâmés d'avoir été lâches, eux qui se disent de bons généraux. Les commentateurs ne paraissent pas s'être étonnés d'un reproche cependant assez bizarre : des chefs d'armée critiqués parce qu'ils n'ont pas eu les qualités d'un bon infirmier. Tout s'explique si, dans une version antérieure, quelqu'un a reproché aux Atrides d'avoir excommunié un des meilleurs soldats de l'armée par complaisance envers des superstitions. Cet esprit fort pourrait bien avoir été Philoctète lui-même. Mais il est assez inutile de chercher à connaître la teneur psychologique de poèmes perdus, alors que celle des ouvrages conservés est déjà si difficile à saisir avec quelque précision.

21. Cité par LÉVY-BRUHL, Mentalité primitive, p. 319.

22. LÉVY-BRUHL, Mentalité primitive, pp. 160 à 170 et p. 300 ; Fonctions mentales, p. 403 ; Le Surnaturel et la Nature dans la Mentalité primitive, pp. 233-260 et 397 sqq. ; FRAZER, Rameau d'Or, t. III, de la trad. franç., p. 258.

23. ๔dipus, p. 59 et la note, II, p. 26.

24. Tout ceci d'après HÉROD., V, 92. Dans la version traitée par NIC. DE DAMAS (VII, 58, F. H. G., III, p. 391), Éétion conduit l'enfant à Olympie pour être le suppliant du dieu.

25. Macan, dans ce passage de son commentaire, ne peut admettre que l'infirmité soit la vraie raison de leur hésitation: « $\chi \omega \lambda$ ós looks like the translation into physics of the political situation » et il rappelle l'oracle rappelé à propos d'Agésilas (supra, p. 48). J'espère avoir démontré qu'on a craint en Grèce la malédiction attachée à l'infirmité congénitale longtemps avant d'avoir formé l'idée

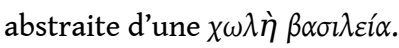

